\title{
Stimulation of different foot structures and functions : effects on physical performance in older adults
}

Citation for published version (APA):

Hartmann, A. (2009). Stimulation of different foot structures and functions : effects on physical performance in older adults. [Doctoral Thesis, Maastricht University]. Maastricht University. https://doi.org/10.26481/dis.20091106ah

Document status and date:

Published: 01/01/2009

DOI:

10.26481/dis.20091106ah

Document Version:

Publisher's PDF, also known as Version of record

\section{Please check the document version of this publication:}

- A submitted manuscript is the version of the article upon submission and before peer-review. There can be important differences between the submitted version and the official published version of record.

People interested in the research are advised to contact the author for the final version of the publication, or visit the DOI to the publisher's website.

- The final author version and the galley proof are versions of the publication after peer review.

- The final published version features the final layout of the paper including the volume, issue and page numbers.

Link to publication

\footnotetext{
General rights rights.

- You may freely distribute the URL identifying the publication in the public portal. please follow below link for the End User Agreement:

www.umlib.nl/taverne-license

Take down policy

If you believe that this document breaches copyright please contact us at:

repository@maastrichtuniversity.nl

providing details and we will investigate your claim.
}

Copyright and moral rights for the publications made accessible in the public portal are retained by the authors and/or other copyright owners and it is a condition of accessing publications that users recognise and abide by the legal requirements associated with these

- Users may download and print one copy of any publication from the public portal for the purpose of private study or research.

- You may not further distribute the material or use it for any profit-making activity or commercial gain

If the publication is distributed under the terms of Article $25 \mathrm{fa}$ of the Dutch Copyright Act, indicated by the "Taverne" license above, 


\section{STIMULATION OF DIFFERENT FOOT STRUCTURES AND FUNCTIONS}

Effects on physical performance in older adults 
ISBN: 978-3-033-02031-3

\section{Cover art:}

,Foot prints' by Family Roten

\section{Printed by:}

Digitalis Print $\mathrm{GmbH}$, www.digitalis.ch

(C) 2009, Antonia Hartmann

All rights reserved. No part of this thesis may be reproduced, stored in a retrieval system, or transmitted, in any form or by any means, electronic, mechanical, photocopying, recording, or otherwise, without written permission from the author or from the publisher holding the copyright of the published article. 


\title{
STIMULATION OF DIFFERENT FOOT STRUCTURES AND FUNCTIONS
}

\section{Effects on physical performance in older adults}

\section{DISSERTATION}

\author{
to obtain the degree of Doctor at \\ the Maastricht University, \\ on the authority of the Rector Magnificus, \\ Prof.dr. G.P.M.F. Mols \\ in accordance with the decision of the Board of Deans, \\ to be defended in public \\ on Friday $6^{\text {th }}$ of November 2009 at 12.00 o'clock
}

by

Antonia Hartmann 


\section{Supervisors}

Prof.dr. R.A. de Bie

Prof.dr. K. Murer (Swiss Federal Institute of Technology Zurich, Switzerland)

\section{Co-supervisor}

Dr. E.D. de Bruin (Swiss Federal Institute of Technology Zurich, Switzerland)

\section{Assessment Committee}

Prof.dr. H. Kuipers (Chairman)

Dr. H.J.M. Hendrik

Dr. Kenneth Meijer

Prof.dr. H. van Mameren

Prof.dr. G.H.I.M. Walenkamp

Stiftung Diakoniewerk Neumünster - Schweizerische Pflegerinnenschule and PROXOMED ${ }^{\circledR}$ are gratefully acknowledged for funding and supporting the studies in this thesis. 


\title{
STIMULATION OF DIFFERENT FOOT STRUCTURES AND FUNCTIONS
}

\section{Effects on physical performance in older adults}

\author{
PROEFSCHRIFT
}

ter verkrijging van de graad van doctor

aan de Universiteit Maastricht,

op gezag van de Rector Magnificus,

Prof.dr. G.P.M.F. Mols

volgens het besluit van het College van Decanen,

in het openbaar te verdedigen

op vrijdag 6 november 2009 om 12.00 uur

door

Antonia Hartmann 


\section{Promotores}

Prof.dr. R.A. de Bie

Prof.dr. K. Murer (ETHZ)

\section{Copromotor}

Dr. E.D. de Bruin (ETHZ)

\section{Beoordelingscommissie}

Prof.dr. H. Kuipers (voorzitter)

Dr. H.J.M. Hendrik

Kenneth Meijer PhD

Prof.dr. H. van Mameren

Prof.dr. G.H.I.M. Walenkamp

Stiftung Diakoniewerk Neumünster - Schweizerische Pflegerinnenschule and PROXOMED ${ }^{\circledR}$ are gratefully acknowledged for funding and supporting the studies in this thesis. 
Die Leistungsfähigkeit des Menschen nimmt nur deshalb so erheblich ab, weil er sich hat einreden lassen, dass sie abnehmen muss. 



\section{Contents}

Chapter 1 General introduction

Chapter 2 Reproducibility of an isokinetic strength-testing protocol of the knee and ankle in older adults

Chapter 3 Concurrent validity of a trunk tri-axial accelerometer system for gait analysis in older adults

Chapter 4 Reproducibility of spatio-temporal gait parameters under different conditions in older adults using a trunk tri-axial accelerometer system

Chapter 5 The effect of a training program combined with augmented afferent feedback from the feet using shoe insoles on gait performance and muscle power in older adults: a randomised controlled trial

Chapter 6 The effect of a foot gymnastic exercise program on gait performance in older adults: a randomised controlled trial

Chapter 7 Effectiveness of a training program to reduce falls and fallrelated injuries during a 12-month follow-up period in older adults

Chapter $8 \quad$ General discussion

Chapter 9 References

Chapter 10 Summary

Samenvatting

Co-authors and affiliations

Acknowledgements

Publications

Curriculum Vitae 

Chapter 1

General introduction 


\section{An aging society}

Increased aging of society is common in many countries. In Switzerland, the proportion of people aged 65 years and over increased from $11.5 \%$ to $16.2 \%$ between 1970 and 2006, and is expected to rise to $28 \%$ by 2050 [1]. In addition, between 1970 and 2006, life expectancy at birth increased from 70 to 79 years for men and from 76 to 84 years for women and is expected to rise further in the next years. Life expectancy includes all years of expected life, regardless whether these years are enjoyed in good health or with significant disability. However, the primary public health goal is to increase the number of years of good health and, therefore, to maintain independence and quality of life as long as possible. Healthy aging is characterized by the avoidance of disease and disability, the maintenance of high physical and cognitive function, and sustained engagement in social and productive activities [2].

An abundance of epidemiological data reveal clearly that regular physical exercise decreases the risk of age-related chronic diseases, mitigates the physiological changes of aging in a sedentary society, and assists in maintaining independence and preventing disability [3]. However, most Swiss older adults are physically inactive or relatively sedentary, and the extent of inactivity increases with advanced age. In 2002, 40\% of adults aged between 55 to 64 years were inactive; the percentage of inactivity increases to $50 \%$ to $70 \%$ for adults aged between 65 to 74 years and for adults aged over 75 [1]. Since a large proportion of the population is inactive or relatively sedentary, an increase of physical exercise is one of the most important intervention strategies that would enhance population health [3].

\section{Older adults and falls}

A fall is defined as 'an unexpected event in which the participants come to rest on the ground, floor, or lower level' [4]. A fall can endanger mobility, physical performance and health in older adults and, consequently their independence and quality of life [5]. Falls are one of the major problems of older adults and care services for the aged. Between $30 \%$ to more than $50 \%$ of the population aged 65 years and over fall each year. Of those who fall, $50 \%$ do so repeatedly [6-9]. Common fall-related consequences include injuries, decreased mobility or physical performance, loss of independence, increased health care utilization and mortality [5-8]. Up to $10 \%$ of falls result in serious injuries such as hip fractures, subdural hematoma, serious soft tissue injuries and head injuries, with hip fractures being associated 
with the highest morbidity and mortality [6-10]. 90\% of hip fractures result from a fall [8]. In addition to injury, falls can also have psychological and social consequences. Fear of falling and avoidance of activities due to fear of falling are well-recognized negative consequences of falls [6]. Therefore, a health promotion priority area in the aging population is the prevention of falls and fall-related injuries.

\section{Fall risk factors}

Maintaining balance, physical performance and mobility depend on the interaction of neural, sensory and musculoskeletal systems [11]. Functioning of each of these systems declines with age, independent from geriatric pathologies [12], with consequences for physical performance and risk of falling [13].

Fall risk factors are generally considered to be either intrinsic (i.e. those pertaining to the physical and cognitive status of the individual) or extrinsic (i.e. environmental hazards or factors affecting the interface between the individual and the environment, such as footwear, assistive devices or spectacles) [5]. Most falls occur as a result of an interaction between intrinsic and extrinsic factors. Furthermore, multiple risk factors increase the risk of falls [5]. A summary of the relative strength of the evidence for the intrinsic risk factors associated with normal physiological aging, deconditioning from inactivity, and superimposed acute and chronic disease is shown in table 1. The strongest risk factor domains are discussed in more detail in the following paragraphs.

\section{Balance and gait}

Good balance is essential for mobility, physical performance and avoiding falls. Age-related decline of vision, vestibular and somatosensory senses, muscle weakness, reduction in range of motion (ROM) and impairment of cognition contribute to balance and mobility impairments and risk of falling $[3,11,14-16]$. These changes result in slower central nervous system processing and integration of information to correct balance or sustain upright mobility, and a compromised ability to perform multiple tasks simultaneously [3]. For balance control, the sensory and motor systems operate as an integrated system that requires constant challenge to remain optimally tuned. Inactivity and disease contribute to the deterioration of balance and mobility in older adults [16]. 


\section{Table 1}

Relative strength of evidence of intrinsic fall risk factors [3,5].

\begin{tabular}{|c|c|c|}
\hline Domain & Risk factor & Association \\
\hline \multirow[t]{8}{*}{ Psychosocial / demographic } & Advanced age & *** \\
\hline & History of falls & 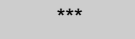 \\
\hline & Walking aid use & *** \\
\hline & Physical performance limitations & 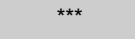 \\
\hline & Fear of falling & *** \\
\hline & Female gender & ** \\
\hline & Living alone & ** \\
\hline & Inactivity & ** \\
\hline \multirow[t]{5}{*}{ Mobility and balance } & Impaired gait and mobility & $\star \star \star *$ \\
\hline & Impaired ability in standing up and transferring & $* * *$ \\
\hline & Impaired leaning and reaching ability & ** \\
\hline & Slow voluntary stepping & ** \\
\hline & Inadequate responses to perturbation & * \\
\hline \multirow[t]{5}{*}{ Gait patterns } & Reduced walking speed & $* * *$ \\
\hline & Reduced cadence & *** \\
\hline & Reduced step length & $* \star *$ \\
\hline & Increased stance duration & $* * *$ \\
\hline & Increased gait variability & $* \star *$ \\
\hline \multirow[t]{17}{*}{ Sensorimotor } & Vision & \\
\hline & Poor visual contrast sensitivity & $* \star *$ \\
\hline & Decreased depth perception & $* * *$ \\
\hline & Poor visual acuity & *** \\
\hline & Visual field loss & ** \\
\hline & Increased visual field dependence & * \\
\hline & Sensation & \\
\hline & Reduced peripheral sensation & \\
\hline & Reduced vestibular function & ** \\
\hline & Poor hearing & * \\
\hline & Strength & \\
\hline & Reduced muscle strength & $* * *$ \\
\hline & Reduced muscle power & *** \\
\hline & Reduced muscular endurance & * \\
\hline & Reaction time & \\
\hline & Simple reaction time & 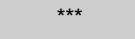 \\
\hline & Choice reaction time & *** \\
\hline \multirow[t]{10}{*}{ Medical conditions } & Impaired cognition & $* \star *$ \\
\hline & Stroke & $* * *$ \\
\hline & Parkinson's disease & 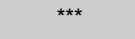 \\
\hline & Foot problems & *** \\
\hline & Depression & ** \\
\hline & Arthritis & ** \\
\hline & Abnormal neurological signs & ** \\
\hline & Dizziness & * \\
\hline & Orthostatic hypotension & * \\
\hline & Vestibular disorders & - \\
\hline \multirow[t]{4}{*}{ Medications } & Use of multiple medications & *** \\
\hline & Psychoactive medications & *** \\
\hline & Benzodiazepines, Antidepressants, Antipsychotics & *** \\
\hline & Analgesics and Anti-inflammatory & - \\
\hline
\end{tabular}

*** Strong evidence (consistently found in good quality studies); ${ }^{* *}$ moderate evidence (usually but not always found); ${ }^{*}$ weak evidence (occasionally but not usually found); and - little or no evidence (not found in published studies despite research to examine the issue). 
Compared to younger adults, older adults often exhibit a more conservative gait pattern that is characterized by reduced speed, step length and cadence and increased gait variability $[17,18]$. These gait changes are more pronounced when walking on an irregular surface than on level ground [19] and under dual-task conditions [20,21]. Further, reduced gait function may be directly related to impaired physical activity, and has been identified as a fall risk factor $[17,18,22]$. The foregoing underscores the need for dual-tasking gait assessment protocols that are applied in challenging walking conditions.

\section{Muscle strength and power}

There are two main factors that lead to muscle weakness in old age. Muscle atrophy resulting in reduced muscle strength is one of the frequently described age-related changes. Aging atrophy seems to be due to a reduction in the number and size of muscle fibers, mainly fast twitch (type II), and to a loss of motor units [3,23]. Consequently, the usual heterogeneity of fiber types disappears in favour of type I fibers [3,24]. The second important age-related change in skeletal muscle is a reduction in contractile speed, since the type I fibers contribute proportionally more to force generation $[23,25]$. Other factors such as excitation-contraction coupling processes and rates of crossbridge cycling, noncontractile properties related to muscle and tendon compliance can also be important contributors to altered contractile speed. However, changes in central neural control of muscle and decrease in anabolic function may be negligible [3].

Muscle power is a function of both strength and speed, and therefore, a product of muscle mass and fiber type. In general, the loss of power is $25 \%$ larger than the loss of isometric strength [23,26-28] and may be more directly related to impaired physical function, loss of independence and quality of life in the elderly [26,27]. In particular, the ability to generate power around the ankle and knee joint is strongly related to physical performance $[27,29,30]$. A limitation of current research literature is the lack of credible isokinetic assessment protocols for use in older adults.

Because aging is associated with substantial structural and functional neuromuscular alterations, it is reasonable to expect that endurance capacity, muscle fatigue and motor control capabilities will also be affected [3]. Slowness of movement, reductions in motor skill, impaired coordination, and poor balance combined with strength and power loss may significantly affect an individual's success in physical performance [3]. 


\section{Foot problems}

Because the feet are the point of direct contact between the body and the surface, they play an important role in the control of balance during standing and walking. Structures and functions of the feet and ankles change with age. Several studies demonstrated that older people have more pronated feet [31,32], reduced ankle [31,33] and 1st metatarsophalangeal joint [31] flexibility, toe plantarflexor weakness [31,34,35] and reduced plantar tactile sensation $[31,36]$. It has been shown that there is a general decrease in ankle joint ROM of $20 \%$ to $30 \%[31,33,37,38]$ and a loss of toe plantarflexor strength of $27 \%$ to $32 \%[34,35]$ with age. Further, age-related loss of plantar tactile sensation, ankle ROM and toe plantarflexor strength appears to correlate with impaired balance [11,34,39], physical performance $[11,34]$ and risk of falling [14].

Several studies have shown that the risk of falling increases dramatically when the number of risk factors increases. The percentage of older people falling increased from $10 \%$ to $30 \%$ for those with no or one risk factor and to $70 \%$ to $80 \%$ for those with four or more risk factors $[6,40]$. Physical exercise not only enhances population health, but may also modify some of the aforementioned strongest risk factor domains and thus lead to fewer falls in older adults $[3,5,41,42]$.

\section{Training strategies}

Training in older age is successful for various reasons [5]:

1. training may slowdown the biological aging process;

2. training can modify risk factors for disability related to certain diseases;

3. training can alter the expression or consequences of diseases that are already present;

4. training can indirectly influence other modifiers of disability, such as psychosocial functioning;

5. training directly strengthens muscles and improves balance so that falls are prevented;

6. training strengthens bones, thereby preventing fractures.

Literature on fall prevention describes various training strategies that target an increase in physical performance in order to reduce falls and fall-related injuries in older adults. However, the optimal exercises to preserve balance and mobility and reduce the risk of falls are not yet known $[3,16]$. The most promising strategies are discussed in the following paragraphs. 
Several reviews have summarized literature supporting the benefits and limitations of strength or resistance exercise in older adults $[3,25,43,44]$. Despite wide variations in task, training regimens, and assessment techniques, the overall message is that remarkable improvements in muscle strength and power are achievable. Older adults basically respond to strength exercise in the same way as young adults, showing large gains in isometric and dynamic strength, power and force control. However, moderate- to heavy-intensity resistance exercises ( $>60 \%$ of the 1 Repetition Maximum) are required to maximize gains in muscle function relating to maintenance of the function of type II fibers $[3,25,43,44]$.

There is evidence that aerobic exercises (e.g. balance, gait or Tai Chi exercises) may improve balance control and gait performance. However, older adults should challenge their balance and mobility through a wide variety of activities under different environmental conditions and the training program must be combined with exercises specific to the task to show improvement $[3,16]$.

It is well established that stretching can effectively increase joint ROM in older people $[3,45-$ 47]. However, the results of several studies are inconsistent as to whether stretching of the lower limbs has a beneficial effect on mobility and gait performance [46-48].

Current recommendations for conventional training in older adults include strength and power training for maintenance of muscle mass and specific muscle-group performance, balance, mobility and stretching exercises, as well as moderately vigorous cardiorespiratory activities (e.g. brisk walking). It has been shown that a conventional training program contributes to maintenance of independence and quality of life and has the strongest evidence base for preventing falls $[3,5]$. However, exercise needs to be progressive, with a maintenance program undertaken in the long term, as the benefits of exercise are lost when exercise is discontinued [5].

Age-related changes in musculoskeletal and sensory characteristics of the feet are important risk factors [14] but have not, however, been the focus of exercise studies to date. Afferent feedback from the feet can theoretically be influenced by therapeutic shoes or insoles [49]. There is emerging evidence that insoles with raised projections [50], vibrating [51] or magnetic [52] pads, lead to enhanced plantar tactile and proprioceptive feedback from the feet and ankles, increased a-motoneuron activities in the muscles and, therefore, may improve the strength of toe plantarflexor muscles, balance and physical performance. In addition, physical exercise involving toe muscles like dancing [53] or grasping [54] may improve toe muscle function. Kobayashi et al. [54] showed that grasping exercises to 
strengthen toe muscles result in improving standing balance in older people. It is unclear, however, whether effects of conventional training with older adults, e.g. training large muscle groups of the lower extremities to improve gait function, can be enhanced by additionally adding shoe insoles or by including grasping and stretching exercises as a complement to conventional training.

\section{Objectives of this thesis}

The main objectives of this thesis are to evaluate the effects of stimulation of different foot structures and functions, combined with conventional training, on physical performance and fear of falling, and whether training reduces the rates of falls and fall-related injuries during a 12-month follow-up period in independent living, older adults. For such intervention studies, valid and reliable assessment procedures for muscle power and gait performance are needed. Hence, the three objectives of this thesis are:

1. to determine the validity and reliability of newly developed testing procedures for muscle power and gait in independent living, older adults;

2. to evaluate the effects of stimulation of different foot structures and functions combined with conventional training on physical performance and fear of falling in independent living, older adults;

3. to determine the effectiveness of the conventional training program to reduce falls and fall-related injuries during a 12 month follow-up period in independent living, older adults.

Findings will contribute to a better understanding of whether age-related changes in musculoskeletal and sensory characteristics of the foot may be modified by therapeutic intervention strategies, and whether such additional strategies result in enhanced training effects. Hence, this thesis may provide a further piece to the puzzle in the research area of fall prevention. 


\section{Outline of this thesis}

The objectives of this thesis are presented in the different chapters. The first objective - the validity and reliability of newly developed strength- and gait-testing protocols in independent living, older adults - is addressed in Chapters 2 to 4. The second objective - estimation of training with additional elements in the training programme - is covered in Chapters 5 and 6. Chapter 7 focuses on the reduction of falls and fall-related injuries, which is the third objective of this thesis. Chapter 8 concludes this thesis with a general discussion and an outlook on future research.

Chapter 2: $\quad$ the reliability of a newly developed isokinetic strength-testing protocol around the knee and ankle joint in independent living, older adults;

Chapters 3 and 4: determination of the validity and the reliability of the gait analysis using a trunk tri-axial accelerometer system;

Chapter 5: the effect of a conventional training program combined with augmented afferent feedback from the feet using shoe insoles on gait performance and muscle power in older adults;

Chapter 6: $\quad$ the effect of a foot gymnastic exercise program on gait performance in older adults;

Chapter 7: $\quad$ effectiveness of the conventional training program to reduce falls and fall-related injuries during a 12-month follow-up period in older adults;

Chapter 8: $\quad$ a general discussion with respect to the main findings and limitations of the presented studies, as well as implications for practice and future research are provided. And lastly, to complete this thesis, some general conclusions with personal comments have been included. 




\section{Chapter 2}

Reproducibility of an isokinetic strengthtesting protocol of the knee and ankle in older adults

Antonia Hartmann, Ruud Knols, Kurt Murer, Eling D. de Bruin.

Gerontology 2009;55:259-26 


\section{Abstract}

Background: Muscle power assessed by isokinetic dynamometers has the potential for playing an important role in investigating functional status in older subjects. Researchers and clinicians are interested in the reliability of isokinetic test protocols for the confidential assessment of status, as this affects the interpretation of the results of an intervention program.

Objective: The current study investigated the inter- and intrarater reliability of an isokinetic strength-testing protocol of the knee and ankle preceded by a familiarization session.

Methods: Twenty-four independent living, older subjects (6 males, 18 females, mean age $71.2 \pm 5.5$ years) were assessed 3 times in two test sessions. The main outcomes were the intraclass correlation coefficient, standard error of measurements (SEM) and ratio of limits of agreement (RLOA) for isokinetic knee and ankle contractions, as measured with the Biodex System 3.

Results: The intraclass correlation coefficients of the isokinetic variables varied from 0.81 to 0.99 representing 'good' to 'very good' reliability. Most SEM and RLOA indexes represented acceptable agreement which varied from $6 \%$ to $13 \%$ and $18 \%$ to $37 \%$, respectively. No acceptable agreement was found for ankle plantar flexion with SEMs that varied from $14 \%$ to $17 \%$ and RLOAs from $39 \%$ to $48 \%$.

Conclusions: The results of this study demonstrate that the Biodex System 3 is a reliable device when used for elderly living independently. The ability of the device to determine a real change in isokinetic ankle and knee contractions is better on a group level than on an individual level. The Biodex System 3 can be employed with confidence in studies to determine the effect of exercise intervention programs on physical activity. 


\section{Introduction}

The loss of muscle strength and muscle power that leads to a decline in functional status and an increased risk of falls is a common consequence of aging. Several basic tasks of daily life (climbing stairs, walking, chair rise, etc.) are, above all, related to the ability to generate power around the ankle and knee joint [27,29,30], and more precisely to the ability to generate power at low velocities [55]. Some studies showed that muscle power decreases at a much greater rate $[26-28,56]$ - and may be more directly related to impaired physical performance in the elderly $[26,27]$ - than isometric strength, making it a potentially major etiological factor in age-related functional decline. Moreover, Skelton et al. [30] showed, in a cross-sectional study, significant differences in leg power in fallers and nonfallers and no differences in leg strength. For such studies precise, sensitive power testing methods are needed to investigate muscle function in older subjects. One such measurement device is the isokinetic dynamometer. However, data on isokinetic measurements in aged populations are, at present, scarce.

Little is known about the reliable use of isokinetic tests for the lower limbs in older adults. Studies have focused on the intrarater reliability of knee strength tests [57-61], only one report described ankle strength tests [57], and one study investigated the interrater reliability on ankle strength [62]. These few studies on isokinetic tests in older adults reveal variable intraclass correlation coefficients (ICCs). The ICCs for highest peak torque, average peak torque, power and work found by Symons et al. [58,61] ranged from 0.84 to 0.93 . Capranica et al. [60] reported values that ranged from 0.29 to 0.80 . The results of absolute reliabilities, as expressed by the coefficient of variation $(\mathrm{CV})$ and the ratio of limits of agreement (RLOA), reveal suboptimal values. CVs ranged from $7 \%$ to $21 \%$ as reported by Symons et al. [58,61]. Ordway et al. [57] and Symons et al. [58,61] described RLOAs that ranged from $21 \%$ to $43 \%$ and $21 \%$ to $57 \%$, respectively.

It can be hypothesized that the isokinetic test protocols used are, at present, maladapted to the motor performance abilities of the elderly. Connelly et al. [43] showed that for older people effects of learning the (isokinetic) motor task should be accounted for in test protocols. From this viewpoint, it seems clear that the use of a single-session test protocol, as often used for younger subjects, should not be recommended for aged persons [12] and the learning process of the elderly should be considered in test protocols for elderly. 
Researchers and clinicians are interested in the relative and absolute reliability of a measurement instrument, as this effects the interpretation of results of an intervention program. Furthermore, an important feature of clinical measurements is that they are performed in individuals and not only in groups. Therefore, clinicians are concerned about the reliability of individual measurement results [63]. It has been suggested that the CV or the standard error of measurement (SEM), depending on whether heteroscedasticity is present or not, can be used to indicate the limit for the smallest change that indicates a real improvement for groups of subjects, whereas for a single person the RLOA or the limits of agreements (LOA) indicate a real change $[64,65]$. If the changes are less than the SEM or CV and RLOA or LOA, this reflects measurement noise and is most likely meaningless.

Therefore, the aim of this study was to determine intra- and interrater reliability of a newly developed isokinetic strength testing protocol around the knee and ankle joint in an older adult population.

\section{Methods}

\section{Subjects}

Twenty-four independent living, older subjects participated in the study. Community-dwelling subjects were recruited from the elderly residence Diakoniewerk Neumunster-Zurich $(n=3)$ and from the local community at Zollikerberg, Zurich $(n=21)$. The inclusion criteria were a minimum age of 65 years. Exclusion criteria were cardiovascular diseases (a myocardial infarction in the previous 6 months, untreated ischemic heart disease and hypertension), neuromuscular and musculoskeletal limitations in the lower back and extremities (e.g. knee and foot osteoarthritis) which might impair the ability to maximally contract the muscles of the leg. There were no selection criteria for habitual physical activity. All elderly participating in the study provided informed consent. The local ethics committee approved the study.

\section{Instruments}

A Biodex System 3 isokinetic dynamometer with a sampling rate of $100 \mathrm{~Hz}$ (Biodex Medical Systems, Shirley, N.Y., USA) was used for all isokinetic strength testing. The mechanical reliability of this dynamometer has been shown to be excellent [66]. For all testing trials, the Biodex System 3 Advantage software (version 3.2.) calculated the highest peak torque, the average peak torque and average power for each movement and speed combination. The Biodex was calibrated in accordance with the manufacturer's specifications before the start of each test session. 


\section{Design of the Total Assessment Protocol}

To minimize the learning effect, the total assessment protocol started with a familiarization session for isokinetic muscle testing, followed by the two test sessions (figure 1). The two test sessions were performed at approximately the same time of day, and were separated by 5 to10 days, under the assumption that the isokinetic strength of the subjects does not change over this time. Each subject was assessed three times (t1, t2, t3) in the two test sessions, twice in the first (t1, t2) and once in the second test session (t3). The interrater reliability was established in the first test session (t1, t2) with 1-hour rest between the assessments by two different raters. The intrarater reliability was calculated from one of two measurements of the first test session (randomly selected by flipping a coin: $\mathrm{t} 1$ or t2) and from the single measurement in the second test session ( $\mathrm{t} 3$ ), where assessment was performed by one rater only.

Familiarization session

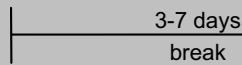

$\mathrm{R} 1$ or $\mathrm{R} 2$
Test session 1

$\mid$\begin{tabular}{c|}
$1 \mathrm{~h}$ \\
break
\end{tabular}

$\mathrm{t} 1 \mathrm{t} 2$

R1 R2
Test session 2

5-10 days

break

$\mathrm{R} 1$ or $\mathrm{R} 2$

\section{Figure 1}

Time table of the total assessment protocol - one familiarization session, three tests (t1, t2, t3) and two raters (R1, R2).

For reasons of time, isokinetic strength testing was performed on the dominant lower leg only. In general, leg dominance is defined as the leg used to manipulate an object [67] and, therefore, leg dominance was determined in this study according to leg preference while kicking a ball. We maintained the order of isokinetic strength testing for all participants as follows: concentric knee contractions at $60 \%$ were performed first, followed by concentric knee contractions at $120 \% \mathrm{~s}$, and finally concentric ankle contractions at $60 \% \mathrm{~s}$. These velocities were chosen because most daily activities are, above all, related to the ability to generate power at low velocities [55]. The positioning was recorded in the familiarization session to ensure consistency of participant setup for the two test sessions.

Each participant was seated in the Biodex chair in an upright position with the back of the seat tilted at an angle of $85^{\circ}$. Stabilization was provided by two shoulder straps that crossed the participant's chest, a waist strap, and a thigh strap. The lateral femoral epicondyle was aligned with the axis of rotation of the dynamometer. The length of the attachment was adjusted to ensure that the ankle pad rested comfortably above the lateral and medial malleoli. Range of motion (ROM) was determined individually by each subject. Prior to the 
knee joint measurements, the dynamometer performs gravity compensation at an approximate angle of $30^{\circ}$, while the effect of gravity on the torques is measured with the subject completely relaxed.

On the testing days, the subjects completed a standardized 5-min period of warm-up. All subjects performed 6 to 8 passive repetitions followed by 3 submaximal contractions at each speed. All tests started with knee flexion followed by knee extension. The subjects performed 4 continuous maximal voluntary flexion-extension contractions at each speed with 1 min of rest between the 2 speeds. The first knee flexion and the last knee extension were not recorded. This procedure was chosen to ensure that the test conditions of all recorded contractions would be equal. The subjects were instructed to push and pull 'as fast and hard as possible' through the full available ROM at every trial. All raters gave standardized instructions and verbal encouragement.

The subjects rested on the same dominant side while the Biodex was configured for the ankle protocol. The subjects were positioned semi-reclined for ankle testing with the knee in $30^{\circ}$ of flexion and with the back of the seat tilted at an angle of $40^{\circ}$ (figure 2). A pad was fixed under the thigh for stabilization. The flexed-knee protocol allows full ROM at the ankle and prevents the hip and knee muscles from contributing. Stabilization was provided by a waist strap and a thigh strap. The subject's foot was positioned so that the axis of rotation of the ankle was aligned with the axis of rotation of the dynamometer. The foot was secured to the footplate with two straps, one strap just distal to the ankle and the second over the metatarsal bones. The test procedure of the ankle was identical to the procedure of the knee, however, without gravity compensation. The subjects performed 4 maximal voluntary contractions after the warm-up procedure starting with dorsiflexion, whereas the first dorsiflexion and the last plantar flexion were not recorded.

Figure 2

Subject performing an isokinetic ankle test with the knee in $30^{\circ}$ of flexion and with the back of the seat tilted at an angle of $40^{\circ}$.

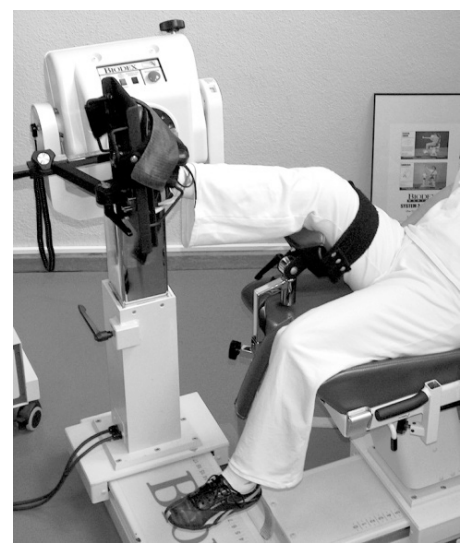




\section{Statistical analyses}

The highest peak torque, the average peak torque and the average power were recorded for analysis for each movement and speed combination. Means and standard deviations (SDs) were calculated for each test by the raters (at $\mathrm{t} 1, \mathrm{t} 2, \mathrm{t} 3$ ). Bland-Altman plots were generated to provide a visual representation of heteroscedasticity, systematic bias, random error and LOA by plotting the individual subject differences between the two tests against the individual mean of the two tests [65]. The normal distribution of the data was tested by KolmogorovSmirnov test [68]. Statistically significant differences between the two raters and the two test sessions (same rater) were calculated by means of a paired $t$-test. Results were considered significant at $p<0.05$. The levels of inter- and intrarater reliability were expressed as ICC, SEM, associated $95 \%$ confidence intervals (Cls) of ICC and SEM, systematic bias, random error, LOA and RLOA [69]. The smallest detectable difference (SDD), which also indicates the limits for the real change for a single person, is equivalent to the LOA statistic [65]. For this reason, we do not use the expression SDD. Two-way random effects models $\left(\mathrm{ICC}_{2,1}\right.$ and $\left.\mathrm{ICC}_{2,3}\right)$ and two-way mixed models $\left(\mathrm{ICC}_{3,1}\right.$ and $\left.\mathrm{ICC}_{3,3}\right)$ were used for relative inter- and intrarater reliabilities, respectively. Single measure reliabilities $\left(I C C_{2,1}\right.$ and $\left.I C C_{3,1}\right)$ were used for highest peak torque, whereas averagemeasure reliabilities $\left(\mathrm{ICC}_{2,3}\right.$ and $\left.I \mathrm{ICC}_{3,3}\right)$ were used for average peak torque and average power [69]. The SEM was calculated as the square root of the mean square of error (residual mean square) between the measurements from the ANOVA results: SEM $=\sqrt{ }($ residual mean square) $[65,69]$. The $95 \%$ Cls of SEM were detected as $95 \% \mathrm{Cl}= \pm 1.96 \times$ SEM [65]. LOA were detected as LOA $=$ (average difference between the two tests) $\pm 1.96 \times$ SD $[68,69]$. The systematic bias represents the average difference between the two tests, and random error represents the difference between the LOA and the systematic bias. All statistical analyses were performed using the SPSS 15.0 and Microsoft Excel.

\section{Results}

\section{Subjects}

All subjects completed the study and no subject reported any discomfort throughout the total assessment. A summary description of the demographic variables of the subjects is presented in table 1. The activity levels of the subjects ranged from sedentary to regular exercisers. None of the subjects was familiar with isokinetic dynamometry. 
Table 1

Subjects' demographics.

\begin{tabular}{lccc}
\hline Gender & $\begin{array}{c}\text { Subjects } \\
\text { N }\end{array}$ & $\begin{array}{c}\text { Age (years) } \\
(\text { Mean } \pm \text { SD) }\end{array}$ & $\begin{array}{c}\text { Body mass index } \\
\text { (Mean } \pm \text { SD) }\end{array}$ \\
\hline Women & 18 & $69.9 \pm 5.0$ & $25.0 \pm 4.4$ \\
Men & 6 & $75.0 \pm 5.6$ & $25.2 \pm 3.1$ \\
Total & 24 & $71.2 \pm 5.5$ & $25.0 \pm 4.0$ \\
\hline
\end{tabular}

\section{Reliability}

All power measurements with regard to intrarater reliability are illustrated in figure 3 by way of examples Bland-Altman plots. There were similar findings for plots of highest peak torque, average peak torque and with regard to interrater reliability (results not shown). All data were normally distributed and showed no heteroscedasticity.

Intrarater reliability

Table 2 presents means, SDs and $p$-values with regard to intrarater reliability. There were no statistically significant differences between the values of day 1 and day 2 , except for highest peak torque $(p=0.001)$, average peak torque $(p=0.019)$ and average power $(p=0.026)$ for knee flexion measurements at $120 \%$ s. The relative and absolute intrarater reliabilities are shown in table 3 . ICCs varied from 0.85 to 0.98 , SEMs from $8.0 \%$ to $14.9 \%$, systematic biases from -0.1 to $3.2 \mathrm{Nm}$ for peak torques and from -0.2 to $3.7 \mathrm{~W}$ for power, random errors from 2.3 to $19.7 \mathrm{Nm}$ for peak torques and from 1.6 to $21.3 \mathrm{~W}$ for power and RLOAs from $22.1 \%$ to $41.4 \%$. All average peak torque and average power measures had an ICC greater than 0.90 , representing 'very good' reliability. The ICCs for highest peak torque ranged from 0.85 to 0.96 .

\section{Interrater reliability}

Table 4 presents means, SDs, and $p$-values from the first test session (t1, t2). Significantly higher values in the second test were recorded for the average power in knee extension measurements at $60 \%$ s $(p=0.035)$ and for all values on ankle plantar flexion at $60 \% \mathrm{~s}(p$ values ranged from 0.005 to 0.042 ). The relative and absolute interrater reliabilities are shown in table 5 . ICCs varied from 0.81 to 0.99 , SEMs from $6.3 \%$ to $17.2 \%$, systematic biases from -0.8 to $5.3 \mathrm{Nm}$ for peak torques and from 0.1 to $4.7 \mathrm{~W}$ for power, random errors from 1.7 to $19.8 \mathrm{Nm}$ for peak torques and from 1.4 to $21.4 \mathrm{~W}$ for power and RLOAs from $17.6 \%$ to $47.7 \%$. The relative and absolute reliability for ankle plantar flexion tended to be less well $(0.81$ to 0.88$)$ than those of the other measurements $(0.89$ to 0.99$)$. 

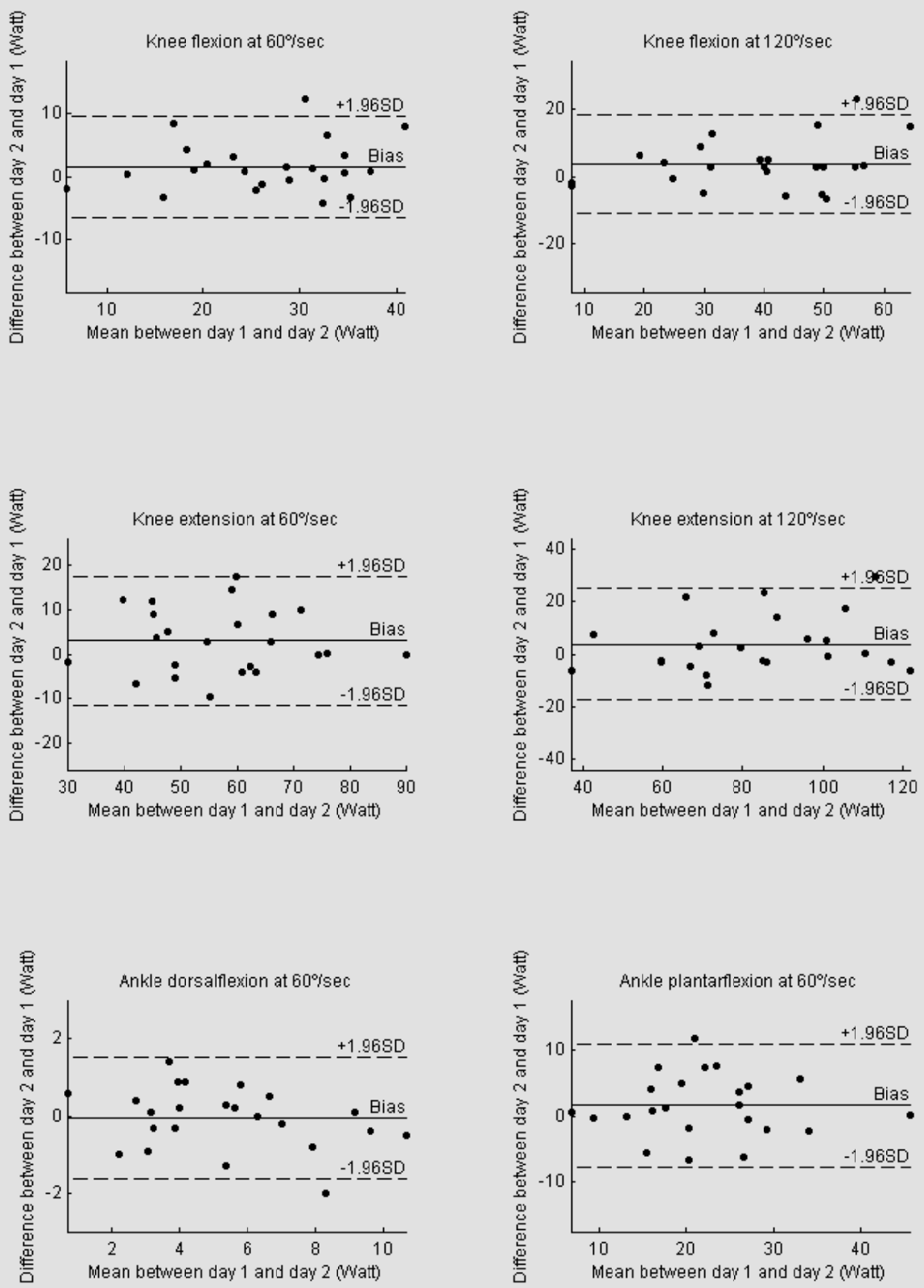

\section{Figure 3}

The individual subject differences between day 2 and day 1 are plotted against each individual's mean for the two tests for the average power with regard to intrarater reliability. Solid line systematic bias; dashed lines limits of agreement. 


\section{Table 2}

Means and $p$-values with regard to intrarater reliability.

\begin{tabular}{|c|c|c|c|c|}
\hline & & $\begin{array}{c}\text { Day } 1 \\
(\text { Mean } \pm \text { SD) }\end{array}$ & $\begin{array}{c}\text { Day } 2 \\
(\text { Mean } \pm S D)\end{array}$ & $p$ \\
\hline \multicolumn{5}{|c|}{ Knee flexion at $60 \% \mathrm{~s}$} \\
\hline Highest $^{\mathrm{a}}$ & Peak Torque (Nm) & $40.4 \pm 12.5$ & $42.3 \pm 14.6$ & 0.217 \\
\hline \multirow[t]{2}{*}{ Average $^{b}$} & Peak Torque (Nm) & $38.0 \pm 11.9$ & $40.4 \pm 14.0$ & 0.116 \\
\hline & Power (W) & $25.6 \pm 8.7$ & $27.2 \pm 9.4$ & 0.075 \\
\hline \multicolumn{5}{|c|}{ Knee flexion at $120 \% \mathrm{~s}$} \\
\hline Highest $^{a}$ & Peak Torque (Nm) & $33.7 \pm 11.0$ & $36.6 \pm 12.7$ & 0.010 \\
\hline \multirow[t]{2}{*}{ Average $^{b}$} & Peak Torque (Nm) & $32.1 \pm 10.7$ & $35.0 \pm 12.6$ & 0.019 \\
\hline & Power (W) & $36.8 \pm 14.6$ & $40.4 \pm 16.8$ & 0.026 \\
\hline \multicolumn{5}{|c|}{ Knee extension at $60 \% \mathrm{~s}$} \\
\hline Highest $^{\mathrm{a}}$ & Peak Torque (Nm) & $88.9 \pm 22.0$ & $89.7 \pm 22.4$ & 0.690 \\
\hline \multirow[t]{2}{*}{ Average $^{b}$} & Peak Torque (Nm) & $84.7 \pm 22.6$ & $85.6 \pm 22.3$ & 0.657 \\
\hline & Power (W) & $55.5 \pm 14.3$ & $58.5 \pm 14.1$ & 0.067 \\
\hline \multicolumn{5}{|c|}{ Knee extension at $120 \% \mathrm{~s}$} \\
\hline Highest $^{a}$ & Peak Torque (Nm) & $72.7 \pm 18.0$ & $75.9 \pm 20.5$ & 0.124 \\
\hline \multirow[t]{2}{*}{ Average $^{b}$} & Peak Torque (Nm) & $68.7 \pm 17.9$ & $71.8 \pm 19.4$ & 0.092 \\
\hline & Power (W) & $81.0 \pm 22.7$ & $84.7 \pm 24.8$ & 0.116 \\
\hline \multicolumn{5}{|c|}{ Ankle dorsiflexion at $60 \% \mathrm{~s}$} \\
\hline Highest $^{a}$ & Peak Torque (Nm) & $10.4 \pm 4.7$ & $10.2 \pm 4.2$ & 0.462 \\
\hline \multirow[t]{2}{*}{ Average $^{b}$} & Peak Torque (Nm) & $9.5 \pm 4.3$ & $9.5 \pm 4.0$ & 0.804 \\
\hline & Power (W) & $5.3 \pm 2.7$ & $5.3 \pm 2.5$ & 0.736 \\
\hline \multicolumn{5}{|c|}{ Ankle plantarflexion at $60 \% \mathrm{~s}$} \\
\hline Highest $^{a}$ & Peak Torque (Nm) & $41.0 \pm 15.8$ & $42.6 \pm 15.5$ & 0.371 \\
\hline \multirow[t]{2}{*}{ Average $^{b}$} & Peak Torque (Nm) & $37.7 \pm 14.7$ & $40.5 \pm 15.2$ & 0.122 \\
\hline & Power (W) & $21.5 \pm 8.9$ & $23.1 \pm 8.9$ & 0.129 \\
\hline
\end{tabular}

${ }^{a}$ Highest value of 3 repetitions

${ }^{\mathrm{b}}$ Average of 3 repetitions 


\section{Table 3}

Intrarater reliability of isokinetic knee and ankle measurements.

\begin{tabular}{|c|c|c|c|c|c|c|c|c|c|c|c|}
\hline & & $I C C^{a}$ & $\begin{array}{l}95 \% \mathrm{Cl} \\
\text { for ICC }\end{array}$ & SEM & $\begin{array}{l}\text { SEM } \\
(\%)\end{array}$ & $\begin{array}{l}95 \% \mathrm{Cl} \\
\text { for SEM }\end{array}$ & bias & error & LOALB & LOAUB & $\begin{array}{c}\text { RLOA } \\
(\%)\end{array}$ \\
\hline \multicolumn{12}{|c|}{ Knee flexion at $60 \% \mathrm{~s}$} \\
\hline Highest $^{\mathrm{b}}$ & Peak Torque (Nm) & 0.85 & $0.68-0.93$ & 5.3 & 12.8 & \pm 10.4 & 2.0 & 14.6 & -12.7 & 16.6 & 35.4 \\
\hline \multirow[t]{2}{*}{ Average $^{c}$} & Peak Torque (Nm) & 0.92 & $0.80-0.97$ & 5.0 & 12.7 & \pm 9.7 & 2.4 & 13.8 & -11.4 & 16.2 & 35.2 \\
\hline & Power (W) & 0.94 & $0.85-0.97$ & 2.9 & 11.1 & \pm 5.8 & 1.6 & 8.1 & -6.5 & 9.7 & 30.8 \\
\hline \multicolumn{12}{|c|}{ Knee flexion at $120 \% \mathrm{~s}$} \\
\hline Highest $^{\mathrm{b}}$ & Peak Torque (Nm) & 0.89 & $0.69-0.96$ & 3.6 & 10.1 & \pm 7.0 & 3.0 & 9.8 & -6.9 & 12.8 & 28.0 \\
\hline \multirow[t]{2}{*}{ Average $^{c}$} & Peak Torque (Nm) & 0.93 & $0.81-0.97$ & 3.9 & 11.5 & \pm 7.6 & 2.9 & 10.7 & -7.8 & 13.6 & 31.9 \\
\hline & Power (W) & 0.93 & $0.82-0.97$ & 5.2 & 13.5 & \pm 10.2 & 3.7 & 14.4 & -10.8 & 18.1 & 37.3 \\
\hline \multicolumn{12}{|c|}{ Knee extension at $60 \% \mathrm{~s}$} \\
\hline Highest $^{\mathrm{b}}$ & Peak Torque (Nm) & 0.90 & $0.78-0.96$ & 7.1 & 8.0 & \pm 13.9 & 0.8 & 19.7 & -18.9 & 20.6 & 22.1 \\
\hline \multirow[t]{2}{*}{ Average $^{c}$} & Peak Torque (Nm) & 0.93 & $0.89-0.98$ & 6.8 & 8.0 & \pm 13.4 & 0.9 & 19.0 & -18.1 & 19.9 & 22.3 \\
\hline & Power (W) & 0.92 & $0.81-0.97$ & 5.2 & 9.1 & \pm 10.1 & 2.9 & 14.3 & -11.4 & 17.2 & 25.1 \\
\hline \multicolumn{12}{|c|}{ Knee extension at $120 \% \mathrm{~s}$} \\
\hline Highest $^{\mathrm{b}}$ & Peak Torque (Nm) & 0.87 & $0.72-0.94$ & 6.7 & 9.0 & \pm 13.1 & 3.2 & 18.5 & -15.4 & 21.7 & 24.9 \\
\hline \multirow[t]{2}{*}{ Average $^{c}$} & Peak Torque (Nm) & 0.94 & $0.86-0.98$ & 6.0 & 8.6 & \pm 11.8 & 3.1 & 16.7 & -13.5 & 19.8 & 23.7 \\
\hline & Power (W) & 0.94 & $0.86-0.98$ & 7.7 & 9.3 & \pm 15.1 & 3.7 & 21.3 & -17.6 & 25.0 & 25.7 \\
\hline \multicolumn{12}{|c|}{ Ankle dorsiflexion at $60 \% \mathrm{~s}$} \\
\hline Highest $^{\mathrm{b}}$ & Peak Torque (Nm) & 0.96 & $0.91-0.98$ & 0.9 & 8.4 & \pm 1.7 & -0.2 & 2.4 & -2.6 & 2.2 & 23.4 \\
\hline \multirow[t]{2}{*}{ Average $^{c}$} & Peak Torque (Nm) & 0.98 & $0.96-0.99$ & 0.8 & 8.7 & \pm 1.6 & -0.1 & 2.3 & -2.3 & 2.2 & 24.0 \\
\hline & Power (W) & 0.98 & $0.95-0.99$ & 0.6 & 10.6 & \pm 1.1 & -0.1 & 1.6 & -1.6 & 1.5 & 29.3 \\
\hline \multicolumn{12}{|c|}{ Ankle plantarflexion at $60 \% \mathrm{~s}$} \\
\hline Highest $^{\mathrm{b}}$ & Peak Torque (Nm) & 0.86 & $0.71-0.94$ & 5.8 & 14.0 & \pm 11.4 & 1.6 & 16.2 & -14.6 & 17.7 & 38.7 \\
\hline \multirow[t]{2}{*}{ Average $^{c}$} & Peak Torque $(\mathrm{Nm})$ & 0.92 & $0.80-0.96$ & 5.7 & 14.6 & \pm 11.2 & 2.7 & 15.9 & -13.1 & 18.6 & 40.6 \\
\hline & Power (W) & 0.92 & $0.81-0.97$ & 3.3 & 14.9 & \pm 6.5 & 1.5 & 9.2 & -7.7 & 10.8 & 41.4 \\
\hline
\end{tabular}

Abbreviations: ICC, intraclass correlation coefficient; $95 \% \mathrm{Cl}$, 95\% confidence interval; SEM, standard error of measurements; bias, systematic bias; error, random error; LOALB, lower boundary of limits of agreement; LOAUB, upper boundary of limits of agreement; ROLA, ratio limits of agreement.

${ }^{\mathrm{a}} \mathrm{ICC}_{3,1}$ for highest peak torque; $\mathrm{ICC}_{3,3}$ for average peak torque and average power

${ }^{\mathrm{b}}$ Highest value of 3 repetitions

${ }^{\text {c }}$ Average of 3 repetitions 


\section{Table 4}

Means and $p$-values with regard to interrater reliability.

\begin{tabular}{|c|c|c|c|c|}
\hline & & $\begin{array}{c}\text { Test } 1 \\
(\text { Mean } \pm \text { SD) }\end{array}$ & $\begin{array}{c}\text { Test } 2 \\
(\text { Mean } \pm \mathrm{SD})\end{array}$ & $p$ \\
\hline \multicolumn{5}{|c|}{ Knee flexion at $60 \% \mathrm{~s}$} \\
\hline Highest $^{\mathrm{b}}$ & Peak Torque (Nm) & $43.2 \pm 12.8$ & $42.5 \pm 13.0$ & 0.472 \\
\hline \multirow[t]{2}{*}{ Average $^{c}$} & Peak Torque (Nm) & $40.1 \pm 12.0$ & $40.4 \pm 12.6$ & 0.828 \\
\hline & Power (W) & $27.0 \pm 8.4$ & $27.5 \pm 38.8$ & 0.727 \\
\hline \multicolumn{5}{|c|}{ Knee flexion at $120 \% \mathrm{~s}$} \\
\hline Highest $^{\mathrm{b}}$ & Peak Torque (Nm) & $34.8 \pm 11.0$ & $36.4 \pm 12.4$ & 0.073 \\
\hline \multirow[t]{2}{*}{ Average $^{c}$} & Peak Torque (Nm) & $33.5 \pm 11.1$ & $34.6 \pm 12.2$ & 0.175 \\
\hline & Power (W) & $38.0 \pm 14.9$ & $40.4 \pm 16.1$ & 0.050 \\
\hline \multicolumn{5}{|c|}{ Knee extension at $60 \% \mathrm{~s}$} \\
\hline Highest $^{\mathrm{b}}$ & Peak Torque (Nm) & $91.7 \pm 22.8$ & $93.3 \pm 22.5$ & 0.356 \\
\hline \multirow[t]{2}{*}{ Average $^{c}$} & Peak Torque (Nm) & $87.4 \pm 23.2$ & $89.5 \pm 22.1$ & 0.271 \\
\hline & Power (W) & $57.2 \pm 14.7$ & $60.2 \pm 14.2$ & 0.035 \\
\hline \multicolumn{5}{|c|}{ Knee extension at $120 \%$ s } \\
\hline Highest $^{\mathrm{b}}$ & Peak Torque (Nm) & $74.8 \pm 19.9$ & $75.9 \pm 21.4$ & 0.585 \\
\hline \multirow[t]{2}{*}{ Average $^{c}$} & Peak Torque (Nm) & $71.0 \pm 19.4$ & $73.5 \pm 19.3$ & 0.149 \\
\hline & Power (W) & $83.2 \pm 25.1$ & $87.9 \pm 24.0$ & 0.050 \\
\hline \multicolumn{5}{|c|}{ Ankle dorsiflexion at $60 \% \mathrm{~s}$} \\
\hline Highest $^{\mathrm{b}}$ & Peak Torque (Nm) & $10.1 \pm 4.4$ & $10.2 \pm 4.3$ & 0.341 \\
\hline \multirow[t]{2}{*}{ Average $^{c}$} & Peak Torque (Nm) & $9.4 \pm 4.2$ & $9.6 \pm 4.0$ & 0.328 \\
\hline & Power (W) & $5.2 \pm 2.6$ & $5.3 \pm 2.5$ & 0.456 \\
\hline \multicolumn{5}{|c|}{ Ankle plantarflexion at $60 \% \mathrm{~s}$} \\
\hline Highest $^{b}$ & Peak Torque (Nm) & $42.0 \pm 16.3$ & $47.2 \pm 18.0$ & 0.016 \\
\hline \multirow[t]{2}{*}{ Average $^{c}$} & Peak Torque (Nm) & $39.1 \pm 15.2$ & $43.7 \pm 16.9$ & 0.042 \\
\hline & Power (W) & $22.1 \pm 9.0$ & $25.8 \pm 10.4$ & 0.005 \\
\hline
\end{tabular}

${ }^{a}$ Highest value of 3 repetitions

${ }^{\mathrm{b}}$ Average of 3 repetitions 


\section{Table 5}

Interrater reliability of isokinetic knee and ankle measurements.

\begin{tabular}{|c|c|c|c|c|c|c|c|c|c|c|c|}
\hline & & $I C C^{a}$ & $\begin{array}{l}95 \% \mathrm{Cl} \\
\text { for ICC }\end{array}$ & SEM & $\begin{array}{l}\text { SEM } \\
(\%) \\
\end{array}$ & $\begin{array}{c}95 \% \mathrm{Cl} \\
\text { for SEM }\end{array}$ & bias & error & LOALB & LOAUB & $\begin{array}{c}\text { RLOA } \\
(\%)\end{array}$ \\
\hline \multicolumn{12}{|c|}{ Knee flexion at $60 \% \mathrm{~s}$} \\
\hline Highest $^{\mathrm{b}}$ & Peak Torque $(\mathrm{Nm})$ & 0.92 & $0.83-0.97$ & 3.6 & 8.5 & \pm 7.1 & -0.8 & 10.1 & -10.8 & 9.3 & 23.5 \\
\hline \multirow[t]{2}{*}{ Average $^{c}$} & Peak Torque (Nm) & 0.96 & $0.90-0.98$ & 3.6 & 9.0 & \pm 7.1 & 0.2 & 10.0 & -9.8 & 10.3 & 24.9 \\
\hline & Power (W) & 0.95 & $0.89-0.98$ & 2.7 & 9.8 & \pm 5.2 & 0.3 & 7.4 & -7.1 & 7.7 & 27.3 \\
\hline \multicolumn{12}{|c|}{ Knee flexion at $120 \% \mathrm{~s}$} \\
\hline Highest $^{\mathrm{b}}$ & Peak Torque (Nm) & 0.93 & $0.84-0.97$ & 2.9 & 8.1 & \pm 5.7 & 1.6 & 8.0 & -6.4 & 9.6 & 22.5 \\
\hline \multirow[t]{2}{*}{ Average $^{c}$} & Peak Torque (Nm) & 0.97 & 0.93-0.99 & 2.7 & 7.9 & \pm 5.3 & 1.1 & 7.4 & -6.3 & 8.5 & 21.8 \\
\hline & Power (W) & 0.96 & $0.90-0.98$ & 4.0 & 10.1 & \pm 7.8 & 2.4 & 11.0 & -8.6 & 13.4 & 28.1 \\
\hline \multicolumn{12}{|c|}{ Knee extension at $60 \% \mathrm{~s}$} \\
\hline Highest $^{b}$ & Peak Torque $(\mathrm{Nm})$ & 0.93 & $0.85-0.97$ & 5.9 & 6.3 & \pm 11.5 & 1.6 & 16.3 & -14.6 & 17.9 & 17.6 \\
\hline \multirow[t]{2}{*}{ Average $^{c}$} & Peak Torque (Nm) & 0.96 & $0.91-0.98$ & 6.2 & 7.0 & \pm 12.1 & 2.1 & 17.1 & -15.0 & 19.1 & 19.3 \\
\hline & Power (W) & 0.94 & $0.85-0.98$ & 4.5 & 7.6 & \pm 8.8 & 3.0 & 12.4 & -9.4 & 15.4 & 21.2 \\
\hline \multicolumn{12}{|c|}{ Knee extension at $120 \% \mathrm{~s}$} \\
\hline Highest $^{\mathrm{b}}$ & Peak Torque (Nm) & 0.89 & $0.75-0.95$ & 7.1 & 9.4 & \pm 13.9 & 1.2 & 19.6 & -18.5 & 20.8 & 26.0 \\
\hline \multirow[t]{2}{*}{ Average $^{c}$} & Peak Torque (Nm) & 0.95 & $0.89-0.98$ & 5.6 & 7.7 & \pm 10.9 & 2.5 & 15.5 & -13.0 & 17.9 & 21.4 \\
\hline & Power (W) & 0.94 & $0.85-0.98$ & 7.7 & 9.0 & \pm 15.1 & 4.7 & 21.4 & -16.6 & 26.0 & 24.9 \\
\hline \multicolumn{12}{|c|}{ Ankle dorsiflexion at $60 \% \mathrm{~s}$} \\
\hline Highest $^{\mathrm{b}}$ & Peak Torque (Nm) & 0.98 & $0.95-0.99$ & 0.7 & 6.6 & \pm 1.3 & 0.2 & 1.9 & -1.7 & 2.0 & 18.2 \\
\hline \multirow[t]{2}{*}{ Average $^{c}$} & Peak Torque $(\mathrm{Nm})$ & 0.99 & $0.97-1.00$ & 0.6 & 6.5 & \pm 1.2 & 0.2 & 1.7 & -1.5 & 1.9 & 18.1 \\
\hline & Power (W) & 0.98 & $0.96-0.99$ & 0.5 & 9.2 & \pm 1.0 & 0.1 & 1.4 & -1.2 & 1.5 & 25.6 \\
\hline \multicolumn{12}{|c|}{ Ankle plantarflexion at $60 \% \mathrm{~s}$} \\
\hline Highest $^{\mathrm{b}}$ & Peak Torque (Nm) & 0.81 & $0.55-0.92$ & 6.8 & 15.3 & \pm 13.4 & 5.3 & 18.9 & -13.7 & 24.2 & 42.5 \\
\hline \multirow[t]{2}{*}{ Average $^{c}$} & Peak Torque $(\mathrm{Nm})$ & 0.88 & $0.70-0.95$ & 7.1 & 17.2 & \pm 14.0 & 4.5 & 19.8 & -15.2 & 24.3 & 47.7 \\
\hline & Power (W) & 0.88 & $0.61-0.95$ & 4.0 & 16.8 & \pm 7.9 & 3.7 & 11.2 & -7.5 & 14.9 & 46.6 \\
\hline
\end{tabular}

Abbreviations: ICC, intraclass correlation coefficient; $95 \% \mathrm{Cl}$, 95\% confidence interval; SEM, standard error of measurements; bias, systematic bias; error, random error; LOALB, lower boundary of limits of agreement; LOAUB, upper boundary of limits of agreement; ROLA, ratio limits of agreement.

${ }^{\mathrm{a}} \mathrm{ICC}_{3,1}$ for highest peak torque; $\mathrm{ICC}_{3,3}$ for average peak torque and average power

${ }^{\mathrm{b}}$ Highest value of 3 repetitions

${ }^{\text {c }}$ Average of 3 repetitions 


\section{Discussion}

This study was performed to establish the relative and absolute reliabilities of an isokinetic strength-testing protocol around the knee and ankle joint preceded by a familiarization session in an elderly population. The present study showed 'very good' relative reliabilities for knee extension and flexion at $60 \%$ s and $120 \%$ s and for ankle dorsiflexion at $60 \% \mathrm{~s}$ and 'good' reliability for ankle plantar flexion at $60 \%$ s. The results of absolute reliabilities were partly satisfactory. The SEMs were moderate for ankle plantar flexion and low for all other contractions, and the LOAs were moderate to high.

Only few studies have collected data in older adults using an isokinetic dynamometer with the same contraction velocities as in the present study. The magnitudes of the highest peak torque and average power values from this study are comparable with what has been previously published $[57,59,62,70]$. Due to the small number of subjects included in our study, it is uncertain whether the subjects in the present study are truly representative of the older adult population as a whole. However, we strived to obtain a sample that is as representative as possible by formulating as few exclusion criteria as possible. The activity level of the elderly participants in our study varied from sedentary to regular exerciser behaviour that represented a heterogeneous group and had a wide range of isokinetic strength values. The relative reliability is the degree to which individuals maintain their test results in a sample with repeated measurements and is affected by sample heterogeneity, which means: the more heterogeneous a sample is, the higher the relative reliability becomes. Therefore, a high correlation may still mean unacceptable measurement error for some analytical goals [65] and data about absolute reliabilities of a test are important for clinical use.

The ICCs $(0.81$ to 0.99$)$, that we found were similar to values $(0.84$ to 0.92$)$ found by Symons et al. $[58,61]$ for concentric knee extension in older, healthy subjects (mean age: $72 \pm 5$ years). Capranica et al. [60] found clearly lower ICC (0.23 to 0.85) for knee extension and flexion in older, independent women (mean age: $68 \pm 5$ years). Furthermore, the present values were similar to those $(0.93$ to 0.95$)$ for knee extension and flexion for a young adult population (mean age: $20 \pm 1$ years) found by Sole et al. [71]. There were no data concerning SEMs of isokinetic tests in a comparable population. Sole et al. [71] found only slightly lower SEMs (6\% to $10 \%)$ in the young adult population, and Flansbjer et al. [64] found similar SEMs ( $9 \%$ to $12 \%$ ) for concentric knee extension in a group of stroke subjects (mean age: $58 \pm 6$ years). The other studies involving reliability of isokinetic dynamometers in older adults calculated CVs, and therefore they are not directly comparable to the SEMs. 
The CVs ranged from $7 \%$ to $20 \%$ [58] and $8 \%$ to $13 \%$ [61] found by Symons et al.. In the present study, the RLOAs ranged from $18 \%$ to $35 \%$, except for the ankle plantar flexion (39\% to $48 \%$ ). Ordway et al. [57] found similar systematic biases (1 to $4 \mathrm{Nm}$ ), random errors (7 to $13 \mathrm{Nm}$ ) and RLOAs ( $21 \%$ to $43 \%$ ) for average peak torque for knee extension and flexion and for ankle plantar and dorsiflexion in 33 older adults (mean age: $72 \pm 6$ years). Symons et al. $[58,61]$ found similar RLOAs for highest and average peak torque (21\% to $33 \%)$ in two studies for concentric knee flexion, but higher results for average power ( $42 \%$ to $52 \%$ ). Because these RLOAs were larger than expected in these two studies, the authors do not recommend the use of a single-session test protocol in elderly individuals. Because SDDs and LOAs are equivalent [65], it is possible to compare our results with the results of Sole et al. [71] and Flansbjer et al. [64]. The results of our study are higher compared to younger adult populations $(12 \%$ to $23 \%$ ) reported by Sole et al. [71] and slightly lower to the group of stroke subjects ( $26 \%$ to $55 \%)$ found by Flansbjer et al. [64].

In this study, the SEMs were moderate for ankle plantar flexion and low for the other contractions. Compared with the other studies, it can be concluded that our isokinetic strength-testing protocol can be used to detect real changes in an older adult group after, e.g., a training intervention. However, training studies with elderly where this protocol is used should substantiate this assumption. Furthermore, the testing protocol used showed moderate to high RLOAs, and therefore it can be expected that it is not sufficiently sensitive to detect real changes in older, single subjects. However, there are only limited amounts of training studies with elderly where power has been used as an outcome measure, therefore, we do not know how big a change might be expected based on muscle training interventions for the elderly.

It has been speculated that normalizing the highest peak torque with body weight may decrease the absolute reliability. However, the results showed negligible decreased values of SEMs and RLOAs (data not shown; available upon request).

The ICCs of the two average variables (ICCs range from 0.88 to 0.99 ) were slightly higher than the ICCs for the maximal variable (ICCs range from 0.81 to 0.98 ). This pattern was not reflected for the absolute reliability. Because of the small differences in reliability, we recommend to rather use an average value from a set of 3 repetitions instead of the highest score. 
With few exceptions, paired $t$-tests revealed small systematic biases between the two tests (tables 2 and 4). Subjects often found the movement toward the gravity more difficult to perform than against the gravity. These significantly increased means may indicate a learning effect that still takes place in spite of the familiarization session. Ploutz-Snyder and Giamis [72] compared the number of testing sessions required to achieve consistent 1 repetition maximum strength measurements in untrained older and younger women. The older subjects required significantly more familiarization testing sessions (8 to 9 sessions) compared with the younger subjects (3 to 4 sessions) to achieve the same absolute consistency of measurements [72]. However, multiple sessions may not be practical for older adults. It may be speculated that the period of warm-up in our protocol should be modified to minimize the systematic bias, while including more submaximal contractions and one or two maximal contractions.

The LOAs that include the systematic biases and the random errors together were moderate to high and therefore not always satisfactory. Because the systematic biases were small in the majority of cases, we conclude that the random errors were large. The random error can be affected by instrument, data processing, rater and subject-linked variability, test procedure, and protocol errors [73]. The mechanical reliability of the Biodex System 3 isokinetic dynamometer has been shown to be excellent, with ICCs of 0.99 for torque, position and velocity [66]. To minimize test procedure and protocol-linked errors, the test procedure was standardized, the subject positioning was recorded and the two raters gave standardized instructions and verbal encouragement. The subject-linked variability is affected by different factors, such as an effect of learning or fatigue, fluctuations in daily condition and/or motivation. We tried to reduce the learning effects by including a familiarization session. Because the interrater reliability showed slightly better results compared to the intrarater reliability, we conclude that subject-linked variability is higher than rater-linked variability. Particularly the fluctuations in daily condition and/or motivation may strongly affect the results of strength measurements in older adults. An average of multiple test sessions may minimize these factors, whereas in clinical practice the number of test session is normally restricted.

A limitation of this study is the questionable relation between test specificity of strength and power measurements together with the transferability on everyday functional requirements. Although we know from a cross-sectional study design applied on very old people [26] that there is a close correlation between leg extensor power and chair-rising, stair climbing and walking speeds, and stair-climbing power, we cannot state that this is also a causal relation. Until some prospective studies are performed that indicate such a causality between 
isokinetic measures of power with functional everyday activities, we will be mainly restricted to assessing the effects of resistance training on isokinetic strength testing. In these cases, the form of resistance training should resemble the isokinetic test procedure.

\section{Conclusions}

The results of this study demonstrate that the Biodex System 3 is a reliable device when used on independent living elderly. The ability of the device to determine a real change in isokinetic ankle and knee contractions is better on a group level than on the individual level. The Biodex System 3 may be employed in studies to determine the effect of exercise intervention programs on physical activity.

\section{Acknowledgements}

The authors wish to thank all the subjects who participated in the study and the student apprentices who collected the data. They also wish to thank the Stiftung Diakoniewerk Neumunster - Schweizerischen Pflegerinnenschule for their financial support and we gratefully acknowledge the support of PROXOMED ${ }^{\circledR}$ for providing the test material for this study. Thanks also to Leanne Pobjoy for help in preparing the manuscript. 



\section{Chapter 3}

Concurrent validity of a tri-axial accelerometer system for gait analysis in older adults

Antonia Hartmann, Susanna Luzi, Kurt Murer, Rob A. de Bie, Eling D. de Bruin.

Gait \& Posture 2009;29:444-448 


\section{Abstract}

Objective: The aim of this study was 1) to determine the concurrent validity of a trunk tri-axial accelerometer system (DynaPort ${ }^{\circledR M i n i M o d}$ ) with the GAITRite ${ }^{\circledR}$ system for spatio-temporal gait parameters at preferred, slow and fast self-selected walking speed that were recorded for averaged and individual step data in an older adult population and 2) to compare the levels of agreement for averaged step data from different walking distances and individual step data.

Results: The levels of agreement between the two systems for averaged step data was excellent for walking speed, cadence, step duration and step length (intraclass correlation coefficients (ICCs) between 0.99 and 1.00 , ratios limits of agreement (RLOA) between $0.7 \%$ and $3.3 \%$ ), moderate for variability of step duration (ICCs between 0.88 and 0.98 and RLOAs between $19 \%$ and $34 \%$ ) and low for variability of step length (ICCs between 0.24 and 0.33 and RLOAs between $73 \%$ and $87 \%$ ). The levels of agreement for individual step duration and step length were moderate with ICCs between 0.81 and 0.89 and with RLOAs between $9 \%$ and $13 \%$. Comparing RLOAs from averaged step data across the different walking distances and individual step data, the RLOAs decreased with increased number of steps.

Conclusions: The results of this study demonstrate that the DynaPort ${ }^{\text {बMiniMod }}$ system, which allows measurements in real life conditions, is a highly valid tool for assessment of spatiotemporal gait parameters for averaged step data across a walkway length of approximately $20 \mathrm{~m}$ in independent living elderly. Gait variability measures and individual step data need to be viewed with caution because of the moderate to low levels of agreement between the two systems. 


\section{Introduction}

For clinical and research settings, objective measurements of spatio-temporal gait parameters are needed to identify possible gait impairments or to evaluate the effects of therapeutic interventions. Different valid and reliable methods exist for the assessment of gait parameters, e.g. force plates, three-dimensional motion analyses systems and pressureactivated sensors [74-76]. However, most methods are time-consuming, costly, limited to a single gait cycle and labour-intensive. As an example, the GAITRite ${ }^{\circledR}$ system is a reliable and valid portable electronic walkway for measuring both averaged and individual step parameters in older populations $[74,77]$ and was designed for gait analysis in clinical settings $[74,76]$. However, the relative short length of the active area of the GAITRite ${ }^{\circledR}$ system can be a limitation in measurements of averaged step data [78]. Furthermore, it is questionable whether data collected in a laboratory environment from individual steps adequately mimic natural walking performance in daily life [79]. Therefore, user-friendly portable gait analysis systems which are able to capture data from many gait cycles and allow measurements in a more challenging context are potentially important for clinical and research settings.

In the last few years, accelerometer-based gait analysis systems fixed at different body locations have been proposed for ambulatory gait assessment and have been found valid and reliable for the analysis of gait parameters [80-88]. However, most body-fixed accelerometer-based systems are still in need of further development in older adult populations [89].

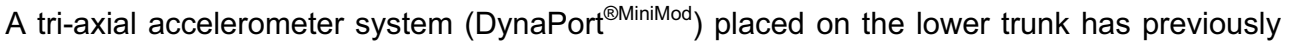
been identified as a valid measure to detect differences in spatio-temporal gait parameters in children [86] and healthy, young adults [84,85] for averaged step data. Based on a more conservative gait pattern characterised by a reduced trunk acceleration, walking speed and step length, that is often observed in older adults $[18,19,88,90,91]$, it is not clear however, whether the application of this system in the elderly is valid.

The aim of this study was 1 ) to determine the concurrent validity of the DynaPort ${ }^{\circledR M i n i M o d}$ system with the GAITRite ${ }^{\circledR}$ system for spatio-temporal gait parameters that were recorded for averaged and individual step data in an older adult population and 2) to compare the levels of agreement for averaged step data from different walking distances and individual step data. 


\section{Methods}

\section{Subjects}

Twenty-three independent living, older subjects ( 7 males, 16 females) aged $77.2 \pm 4.7$ years, height $1.65 \pm 0.09 \mathrm{~m}$, weight $66.5 \pm 10.9 \mathrm{~kg}$, and Body Mass Index $24.2 \pm 2.6 \mathrm{~kg} / \mathrm{m}^{2}$ were recruited from the local community at Zollikerberg, Zurich, Switzerland. The inclusion criteria were a minimum age of 65 years and the ability to walk without an aid. The local ethical committee approved the study and all subjects participating in the study provided informed consent.

\section{Data acquisition}

The DynaPort ${ }^{\circledR \text { MiniMod }}$ tri-axial accelerometer, size $6.4 \mathrm{~cm} \times 6.2 \mathrm{~cm} \times 1.4 \mathrm{~cm}$, and mass $75 \mathrm{~g}$ (McRoberts BV, The Hague, The Netherlands), was placed at the lower back of the subject with the centre of the device at the level of the second sacral vertebrae with sport tape [92]. It was operated with a remote control, and data were stored locally on a secure digital memory card. Measurements were made with a sample rate of $100 \mathrm{~Hz}$. Recorded signals were read out using AccRead Acquisition Software (McRoberts BV, The Hague, The Netherlands), formatted in text-files and analyzed by software developed in the MATLAB environment.

The GAITRite ${ }^{\circledR}$ system (CIR Systems Inc., Havertown, USA) used for this study was $13 \mathrm{~m}$ long and $0.89 \mathrm{~m}$ wide, with an active sensor area of $7.32 \mathrm{~m}$ long and $0.61 \mathrm{~m}$ wide. The sampling rate of the system is $80 \mathrm{~Hz}$. Spatial-temporal gait parameters were processed and stored using the application software. The system has been shown to be accurate at measuring individual footstep parameters such that individual step values were within $1.5 \mathrm{~cm}$ and 0.02 s on the majority ( $80 \%$ to $94 \%$ ) of occasions [74].

\section{Test procedure}

During the measurements, the subjects walked on the walkway while wearing their own comfortable clothing and low-heeled habitual shoes. Gait was evaluated at preferred, slow and fast self-selected walking speed over the $13 \mathrm{~m}$ long walkway. To measure steady state walking, the central $7.32 \mathrm{~m}$ active sensor area of the GAITRite ${ }^{\circledR}$ system was used as the test distance. GAITRite ${ }^{\circledR}$ and DynaPort ${ }^{\circledR M i n i M o d}$ data collection were started simultaneously by triggering a remote control of the DynaPort ${ }^{\circledR \text { MiniMod }}$ by the researcher, when the subjects passed the test distance lines. Subjects performed four trials each at slow, preferred and fast speed and always started with the preferred speed. The order of the other two walking speeds was randomized. The subjects were instructed to 'walk towards the end of the carpet 
at a pace that is comfortable for you/at a pace that is slower/faster than you would normally walk'.

\section{Data analysis}

Gait parameters of the GAITRite ${ }^{\circledR}$ system were generated by GAITRite ${ }^{\circledR}$ software. Full descriptions of the data analyses of the DynaPort ${ }^{\circledR M i n i M o d}$ have been reported elsewhere $[84,85,92]$.

Per trial, all measured data between the two trigger signals were used for analysis. Walking speed (test distance/walking time), cadence (number of steps/walking time), mean values ( $\bar{X}$ ) of step duration and step length, corresponding standard deviations (SD) and gait variabilities of step duration and length, expressed as coefficient of variation $(100 \times \mathrm{SD} / \overline{\mathrm{X}})$, were calculated for both systems. A total of 800 to 1000 steps ( 7 to 13 per subject and walking trial) were thus recorded for the different speed conditions. For concurrent validity, all gait parameters were consecutively averaged for all four, the first three, the first two and the first walking trials combined at each speed. The aim of this procedure was to determine the amount of trials needed for clinical protocols by continuously decreasing the number of steps. Finally, all individual steps for each walking speed condition were used for the determination of the concurrent validity for individual footsteps.

\section{Statistical analysis}

One-way ANOVAs were performed to determine whether significant differences in gait parameters existed between the four walking trials at each speed condition. Means and SDs for both systems were calculated for averaged and individual step data at each speed condition. The normal distribution of the data was tested with a Kolmogorov-Smirnov Test. Bland-Altman plots were generated to provide a visual representation of heteroscedasticity by plotting the individual subject difference between the two systems against the individual mean of the two systems $[65,68]$. The levels of agreement between DynaPort ${ }^{\circledR M i n i M o d}$ and GAITRite $^{\circledR}$ were expressed as intraclass correlation coefficients (ICCs) of the type $(2, k)$, associated $95 \%$ confidence intervals $(\mathrm{Cl})$, limits of agreement $(\mathrm{LOA})$ and ratio limits of agreement (RLOA). LOA and RLOA were calculated according to Bland and Altman [68] as 1.96 times the SD of the differences between both systems. The difference between the two measurement systems is expected to be less than this LOA with a probability of $95 \%$. In addition, paired $t$-tests were used to determine systematic differences between the two systems. Statistical significance was set at $p<0.05$. 


\section{Results}

No significant differences between the four walking trials were found for either speed condition. All data were normally distributed and showed no heteroscedasticity. All averaged gait parameters across four walking trials at preferred walking speed are illustrated in figure 1 by Bland-Altman plots.

Table 1 presents comparative data for the two systems for both averaged values across four walking trials and for individual step data. There were significant differences between the two systems in the majority of the parameters for both averaged and individual step data. The levels of agreement between the two systems for averaged step data was excellent for walking speed, cadence, step duration and step length (ICCs between 0.99 and 1.00, RLOAs between $0.7 \%$ and $3.3 \%$ ), moderate for variability of step duration (ICCs between 0.88 and 0.98 and RLOAs between $19 \%$ and $34 \%$ ) and low for variability of step length (ICCs between 0.24 and 0.33 and RLOAs between $73 \%$ and $87 \%$ ). The levels of agreement for individual step duration and step length were moderate with ICCs between 0.81 and 0.89 and with RLOAs between $9 \%$ and $13 \%$. Comparing RLOAs from averaged step data across the different walking distance and individual step data (table 2), the RLOAs decreased with increased number of steps.

\section{Discussion}

The aim of this study was 1 ) to determine the concurrent validity of the DynaPort ${ }^{\text {बMiniMod }}$ system with the GAITRite ${ }^{\circledR}$ system for spatio-temporal gait parameters that were recorded for averaged and individual step data in an older adult population and 2) to compare the levels of agreement for averaged step data from different walking distances and individual step data. The concurrent validity for averaged step data was excellent for walking speed, cadence, step duration and step length, moderate for variability of step duration and low for variability of step length between DynaPort ${ }^{\circledR \text { MiniMod }}$ and GAITRite ${ }^{\circledR}$ system in a convenience sample of independent living, older adults. There was moderate concurrent validity for individual footstep data. Spatial gait parameters (step length and variability of step length) showed lower levels of agreement compared to temporal gait parameters (step duration and variability of step duration). Furthermore, the levels of agreement between the two systems decreased with decreased number of steps, whereas the highest level was shown for averaged step data across four walking trials. The results of four and three walking trials were similar. The three different speed conditions showed similar levels of agreement. 

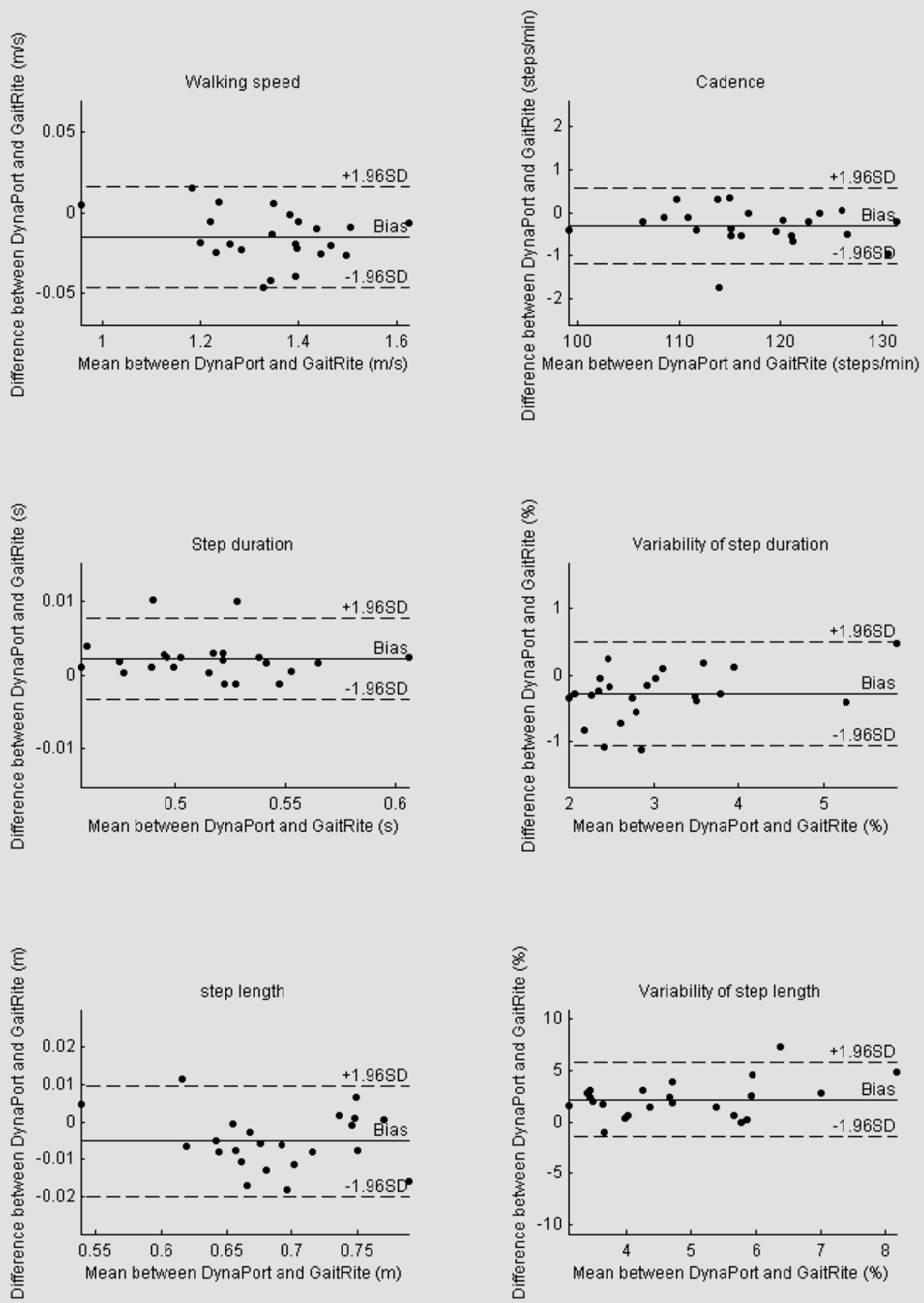

\section{Figure 1}

Bland-Altman plots of all averaged gait parameters across four walking trials at preferred walking speed. Solid line systematic bias; dashed lines limits of agreements. 


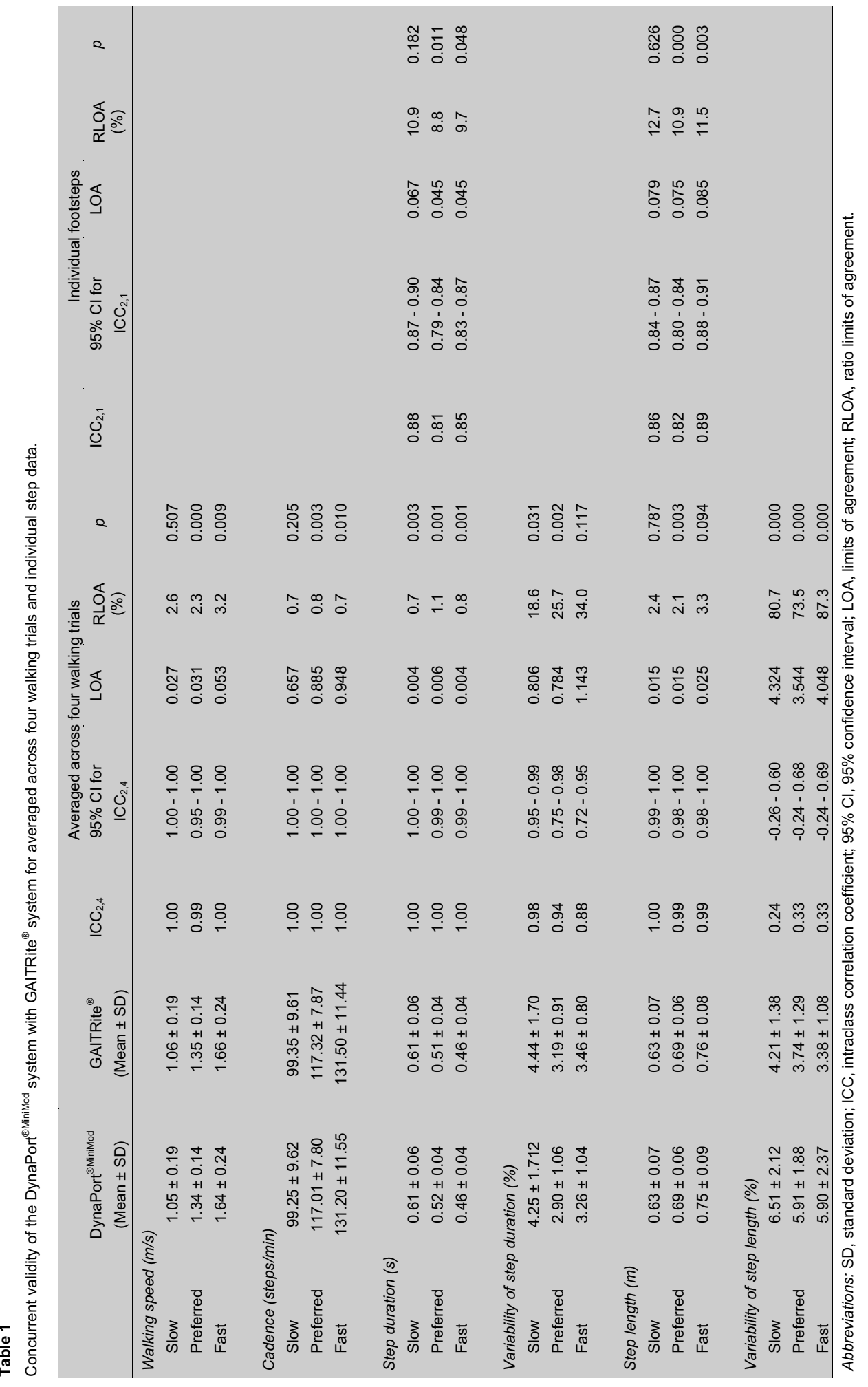




\section{Table 2}

Ratio limits of agreement (\%) from averaged across four to one walking trials and individual step data.

\begin{tabular}{|c|c|c|c|c|c|}
\hline & \multicolumn{4}{|c|}{ Averaged across } & \multirow{2}{*}{$\begin{array}{l}\text { Individual } \\
\text { footsteps }\end{array}$} \\
\hline & Four trials & Three trials & Two trials & One trial & \\
\hline \multicolumn{6}{|c|}{ Walking speed $(\mathrm{m} / \mathrm{s})$} \\
\hline Slow & 2.6 & 2.6 & 3.0 & 3.2 & \\
\hline Preferred & 2.3 & 2.5 & 2.8 & 3.5 & \\
\hline Fast & 3.2 & 3.1 & 3.4 & 4.0 & \\
\hline \multicolumn{6}{|c|}{ Cadence (steps/min) } \\
\hline Slow & 0.7 & 0.8 & 0.9 & 1.1 & \\
\hline Preferred & 0.8 & 0.8 & 0.9 & 1.1 & \\
\hline Fast & 0.7 & 0.6 & 0.8 & 1.0 & \\
\hline \multicolumn{6}{|c|}{ Step duration (s) } \\
\hline Slow & 0.7 & 0.8 & 0.9 & 1.3 & 10.9 \\
\hline Preferred & 1.1 & 1.1 & 1.3 & 1.3 & 8.8 \\
\hline Fast & 0.8 & 0.8 & 0.8 & 1.1 & 9.7 \\
\hline \multicolumn{6}{|c|}{ Variability of step duration (\%) } \\
\hline Slow & 18.6 & 18.3 & 24.0 & 38.5 & \\
\hline Preferred & 25.7 & 29.6 & 34.3 & 56.1 & \\
\hline Fast & 34.0 & 45.3 & 44.1 & 93.5 & \\
\hline \multicolumn{6}{|c|}{ Step length ( $m$ ) } \\
\hline Slow & 2.4 & 2.4 & 2.8 & 2.9 & 12.7 \\
\hline Preferred & 2.1 & 2.3 & 2.7 & 3.7 & 10.9 \\
\hline Fast & 3.3 & 3.1 & 3.3 & 3.8 & 11.5 \\
\hline \multicolumn{6}{|c|}{ Variability of step length (\%) } \\
\hline Slow & 80.7 & 93.4 & 99.1 & 130.6 & \\
\hline Preferred & 73.5 & 74.2 & 73.5 & 100.9 & \\
\hline Fast & 87.3 & 88.8 & 93.0 & 139.9 & \\
\hline
\end{tabular}

Except for gait variability, the levels of agreement that we observed for averaged step data were similar to other studies that determined concurrent validity of accelerometer gait analysis and footswitches systems with the GAITRite ${ }^{\circledR}$ system, respectively (ICCs between 0.93 and 0.99 and RLOAs between 1.1 and $7.3 \%$ ) [75,87].

There were significant and systematic differences between the two systems in the majority of the parameters for both individual and averaged step data. However, the systematic differences for gait speed, cadence, step duration and step length were small (between 0.1 and $1.1 \%$ ) and have mostly no clinical relevance. Several factors may have contributed to this. First, there was a minor difference of sampling rates between the two systems. However, consistent with other studies [74,75], compensatory calculations to synchronize the data sets were not undertaken, since the absolute difference in sampling rates was small and represented a tolerable margin of error. Second, an accelerometer will measure gravity and 
skin motion artefacts as well as dynamic acceleration caused by changes in speed during walking. An accelerometer positioned over the trunk may be tilted due to lumbar lordosis, postural alignment of the walking subject, and inaccuracy in positioning of the instrument. Therefore, corrections of data must be made in order to assess the true dynamic trunk accelerations during gait in a horizontal-vertical coordinate system. It is unclear if the offset of axes misalignment determined from acceleration data collected during quiet stance is sufficient to minimise the variability of the gravity component and skin motion artefact during walking. And third, it seems that the simple inverted pendulum model [92] and any drift occurring during double integration of the acceleration signal for spatial gait parameters may be a limitation.

Individual step data seem to be more affected by these aforementioned factors than averaged step data based on the higher systematic differences. Consequently, these factors can be seen as limitations for estimations of gait variability calculated from individual SDs of step data. The variability of step length is more affected than variability of step duration, possibly due to the simple inverted pendulum model and to the drift occurring during double integration. Nevertheless, it is interesting to note that gait speed, cadence, step duration and length for averaged step data were found to be valid and extremely similar to GAITRite ${ }^{\circledR}$ measurements with high ICCs and small RLOAs. Therefore, we recommend using averaged step data across a walkway length of approximately $20 \mathrm{~m}$ or at least include 25 steps in total, which is equivalent to the walking distance across three walking trials, since the amount of steps influences the level of agreement. To quantify the gait variability, which is related to the fall risk in older adults $[18,19,90,91]$, we recommend to use the variability of step duration rather then the variability of step length.

\section{Conclusion}

The results of this study demonstrate that the DynaPort ${ }^{\circledR M i n i M o d}$ system, which allows measurements in real life conditions, is a highly valid tool for spatio-temporal gait parameters for averaged step data across a walkway length of approximately $20 \mathrm{~m}$ in independent living elderly. Gait variability measures and individual step data need to be viewed with caution because of the moderate to low levels of agreement between the two systems. 


\section{Acknowledgements}

We thank all the subjects who participated in the study. Thanks are also due to Dr. Peter Wolf who wrote the data analyses Matlab program. We also thank the Stiftung Diakoniewerk Neumunster - Schweizerische Pflegerinnenschule for their financial support. 



\section{Chapter 4}

Reproducibility of spatio-temporal gait parameters under different conditions in older adults using a trunk tri-axial accelerometer system

Antonia Hartmann, Kurt Murer, Rob A. de Bie, Eling D. de Bruin.

Gait \& Posture 2009;30:351-355 


\section{Abstract}

Objective: The aim of this study was to determine intra- and interrater reliability of spatiotemporal gait parameters on different walking surfaces and under dual-task conditions in an older adult population using a trunk tri-axial accelerometer (DynaPort ${ }^{\circledR \text { MiniMod }}$ ) system.

Methods: Twenty-three independent living, older subjects (8 males, 15 females) aged $73.4 \pm$ 4.3 years walked three times at their preferred walking speed in two test sessions under four different conditions over $24 \mathrm{~m}$ (gymnasium floor versus soft foam rubber walkway, with both normal and dual-task walking conditions). Inter- and intrarater reliability was assessed. Subsequently intraclass correlation coefficients (ICC), coefficients of variation (CV) and ratios limits of agreement (RLOA) were calculated.

Results: The reliability of walking speed, cadence, step duration and step length was excellent with high ICCs and small CVs and RLOAs. ICCs of gait variability ranged from 0.12 to 0.88 . The corresponding CVs ranged from $12 \%$ to $34 \%$ and RLOAs from $35 \%$ to $93 \%$ and appeared relatively large.

Conclusions: The results of this study demonstrate that walking speed, cadence, step duration and step length under more challenging conditions can be reliably measured in independent living, older adults using the DynaPort ${ }^{\circledR \text { MiniMod }}$ system. Gait variability measures need to be viewed with caution and further research in older populations is needed to determine the value of these parameters derived from this measurement system. 


\section{Introduction}

Most falls in older adults occur at home during whole-body movements like transferring and walking $[8,93]$. Compared to younger adults, older adults often exhibit a more conservative gait pattern that is characterised by reduced speed, step length and trunk acceleration as well as increased cadence, variabilities of step duration and length $[17-19,85,88,94]$. These gait changes are more pronounced when walking on an irregular surface than on level ground [19] and under dual-task conditions [20,21,95-97]. Further, gait variability has also been identified as fall risk factor in prospective studies [17,18]. MacLellan and Patla [98] showed that walking patterns are adapted when walking on a foam surface in order to regulate dynamic stability. The vertical centre of mass can be expected to decrease on compliant surfaces to provide a more stable posture when walking on the surface. This will lead to an increase of step length and time and their corresponding variabilities when walking on foam is compared to ground walking [98].

However, there is at present only limited information available pertaining to the reliability of spatio-temporal gait parameters in older adults. The reliability needs to be determined in order to differentiate between real changes in walking and biological variability. Bilney et al. [76] reported high intraclass correlation coefficients (ICC) for walking speed, cadence and stride length in normal and fast-walking (ICCs between 0.92 to 0.97 ) and moderate ICCs in slow-walking (ICCs between 0.78 to 0.91 ) obtained from three repeat trials recorded on the same day in healthy subjects aged 21 to 71 years. Menz et al. [77] reported high test-retest reliability of walking speed, cadence and step length with ICCs between 0.82 to 0.91 and coefficients of variation (CV) between $3.1 \%$ to $3.5 \%$ in older adults aged 76 to 87 years recorded on two separate occasions, approximately 2 weeks apart. Similar findings were reported by van lersel et al. [99] with ICCs between 0.84 to 0.93 for walking speed, variabilities of stride duration and length in older adults with a mean age of 73.8 years. However, all studies measured only on a regular surface using the GAITRite ${ }^{\circledR}$ system. The limited relative short length of the GAITRite ${ }^{\circledR}$ system can be a limitation in measuring variability of gait [78]. Further, to our knowledge, there is no study about the reliability of walking under challenging conditions, like on irregular or compliant surfaces or under dualtask conditions in this population. 
The findings that gait changes are more pronounced when walking over a more challenging surface, underpin the necessity of objective measurements of spatio-temporal gait parameters in older adults in settings that closely resemble 'real life' circumstances. In the last few years, accelerometer-based gait analysis systems fixed over different parts of the body have been proposed for ambulatory gait assessment and have been found to be valid and reliable for the analysis of gait parameters [80,82-87]. A tri-axial accelerometer system (DynaPort ${ }^{\circledR \text { MiniMod }}$ ) placed on the lower trunk has previously been identified as a valid measure to detect differences in spatio-temporal gait parameters in children [86], healthy, young [84,85] and independent living, older adults [100]. Compared to other motion measurement devices, accelerometry has several advantages. Accelerometers are non-time consuming, easy to use, cost effective, are able to capture data from many gait cycles, are lightweight and portable and are not confined to data collection in a gait laboratory environment. However, most body-fixed accelerometer based systems are still in need of further development in older adult populations [89].

Therefore, the aim of this study was to determine intra- and interrater reliability of spatiotemporal gait parameters on different walking surfaces and under dual-task conditions in an older adult population using the DynaPort ${ }^{\circledR \text { MiniMod }}$ system.

\section{Methods}

\section{Subjects}

Twenty-three independent living, older subjects ( 8 males, 15 females) aged $73.4 \pm 4.3$ years, height $1.67 \pm 0.09 \mathrm{~m}$, weight $70.8 \pm 13.1 \mathrm{~kg}$, and Body Mass Index $25.4 \pm 4.2 \mathrm{~kg} / \mathrm{m}^{2}$ were recruited. The inclusion criteria were a minimum age of 65 years and the ability to walk without an aid. The local ethical committee approved the study and all subjects participating in the study provided informed consent.

\section{Data acquisition}

The DynaPort ${ }^{\text {¿MiniMod }}$ tri-axial accelerometer, size $6.4 \mathrm{~cm} \times 6.2 \mathrm{~cm} \times 1.4 \mathrm{~cm}$, and mass $75 \mathrm{~g}$ (McRoberts BV, The Hague, The Netherlands), was placed at the lower back of the subject with the centre of the device at the level of the second sacral vertebrae with sport tape [92]. It was operated with a remote control, and data were stored locally on a secure digital memory card. Measurements were made with a sample rate of $100 \mathrm{~Hz}$. Recorded signals were read out using AccRead Acquisition Software (McRoberts BV, The Hague, The 
Netherlands), formatted in text-files and analyzed by software developed in the MATLAB environment.

\section{Test procedure}

Each subject was assessed three times (t1, t2, t3) in two test sessions; once in the first (t1) and twice in the second session ( $\mathrm{t} 2, \mathrm{t} 3)$. The two test sessions were scheduled at approximately the same time of day, and were separated by 5 to 10 days, under the assumption that the gait pattern of the volunteers would not change over this time. The intrarater reliability was calculated from $\mathrm{t} 1$ in the first and from $\mathrm{t} 2$ in the second session where assessment was performed by one rater only. The interrater reliability was established in the second session ( $\mathrm{t} 2, \mathrm{t} 3$ ) with 20 minutes rest between the assessments by two different raters, whereas, however, the accelerometer was not reattached by the second rater.

During the measurements, the subjects walked on the walkway while wearing their own comfortable clothing and low-heeled habitual shoes. Gait was evaluated during usual walking at preferred speed under four different conditions over $24 \mathrm{~m}$ in a gym: 1) on the gymnasium floor, 2) on the gymnasium floor under a dual-task condition, 3) on a soft foam rubber walkway (1.25 m wide, $16 \mathrm{~mm}$ thick), and 4) on a soft foam rubber walkway under a dual-task condition. The dual-task in both conditions was subtracting repeatedly the number three starting from 200 down and was practiced before gait testing while sitting on a chair. To measure steady state walking, the central $18 \mathrm{~m}$ of the walking course was used as the test distance. A small receiver was mounted on the accelerometer and the researcher placed a signal in the data through triggering by use of a remote control when the subjects passed the $18 \mathrm{~m}$ distance lines. The researcher walked alongside the subjects to ensure their safety. After a test walk on the gymnasium floor to get accustomed to the experimental procedure, the subjects were instructed not to talk whilst walking at their preferred walking speed. Walking on the foam was not practiced.

\section{Data analysis}

Whenever a sensing axis deviates from the horizontal plane, an accelerometer will measure gravity as well as dynamic acceleration caused by changes in speed during walking. An accelerometer positioned over the lower part of the back may be tilted due to the lumbar lordosis, postural alignment of the walking subject, and inaccuracy in positioning of the instrument. Corrections of data must be made in order to assess the true dynamic trunk accelerations during gait in a horizontal-vertical coordinate system. The offset of axes misalignment was determined from acceleration data collected during quiet stance and the whole signal was shifted according to this offset. All acceleration data were low-pass filtered 
before further analyses ( $4^{\text {th }}$ order zero-lag Butterworth filter at $20 \mathrm{~Hz}$ ). Full descriptions of the data analyses have been reported elsewhere [84,85,92].

Per trial, all measured data between the two trigger signals were used for analysis. Walking speed (test distance/walking time), cadence (number of steps/walking time), mean values ( $\bar{X}$ ) of step duration and step length, corresponding standard deviations (SD) and gait variabilities of step duration and length $(100 \times \mathrm{SD} / \overline{\mathrm{X}})$ were calculated for each subject and each trial.

\section{Statistical analysis}

Means and SDs were calculated for each test (t1, t2, t3). The normal distribution of the data was tested with a Kolmogorov-Smirnov-Test. A two-way analysis of variance, followed by the Bonferroni post-hoc test in case of significant differences for the multiple comparisons, was used to determine whether gait parameters differed between the four conditions (using the average of the three test sessions), or between the three test sessions (for intra- and interrater reliabilities) with an $\alpha$ of 0.05 . Bland-Altman plots were generated to provide a visual representation of heteroscedasticity by plotting the individual subject difference between the two tests against the individual mean of the two tests [65]. The relative reliabilities were expressed as ICC of the type $(2,1)$ and $(3,1)$ for inter- and intrarater reliabilities, respectively, and associated 95\% confidence intervals (CI) [69]. The absolute reliabilities were expressed as the $C V$, limits of agreement (LOA) and ratio limits of agreement (RLOA) [65,69]. The CV indicates the changes in score required to be confident that a real change has occurred in a group of subjects, whereas the LOA and RLOA indicate change for a single individual [65]. All statistical analyses were performed using Matlab 7.1. 


\section{Results}

Differences between the four conditions and the three tests

Table 1 presents means and SDs of all three tests. Significant differences between the four conditions were identified for all gait parameters (walking speed: $F(3,19)=19.11, p<0.001$, cadence: $F(3,19)=24.53, p<0.001$, step duration: $F(3,19)=24.22, p<0.001$, variability of step duration: $F(3,19)=16.31, p<0.001$, step length: $F(3,19)=8.63, p<0.001$ and variability of step length $(F(3,19)=6.37, p=0.001)$. Walking speed and cadence were significantly decreased and step duration and variability of step duration were significantly increased in dual-task walking compared to normal walking on both surfaces $(p<0.05)$. Step length and variability of step length in dual-task walking differed significantly only on the gymnasium floor. No significant differences were detected between the two surfaces and between the three tests.

\section{Reliability}

All data were normally distributed and showed no heteroscedasticity. All gait parameters on the soft foam rubber with dual-task walking with regard to intrarater reliability are illustrated in figure 1 by Bland-Altman plots.

The results of intra- and interrater reliabilities are shown in table 2 and in table 3 , respectively. The reliability of walking speed, cadence, step duration and step length was excellent (ICCs between 0.86 to 0.99 , CVs between $1 \%$ to $4 \%$ and RLOAs between $3 \%$ to $10 \%$ ) and were comparable for the four different conditions. ICCs of gait variability for intraand interrater reliability ranged respectively from 0.12 to 0.78 and 0.59 to 0.88 . The corresponding CVs ranged from $14 \%$ to $34 \%$ and $12 \%$ to $23 \%$ and RLOAs from $39 \%$ to $93 \%$ and $35 \%$ to $64 \%$. 


\section{Table 1}

Mean values of the gait parameters for all three tests and significant differences between the four conditions at $p<0.05$.

\begin{tabular}{|c|c|c|c|}
\hline & $\begin{array}{c}\text { Test } 1 \\
(\text { Mean } \pm \text { SD) }\end{array}$ & $\begin{array}{c}\text { Test } 2 \\
(\text { Mean } \pm \text { SD) }\end{array}$ & $\begin{array}{c}\text { Test } 3 \\
(\text { Mean } \pm \text { SD) }\end{array}$ \\
\hline \multicolumn{4}{|l|}{ Walking speed $(\mathrm{m} / \mathrm{s})$} \\
\hline Gym floor & $1.37 \pm 0.17$ & $1.38 \pm 0.15$ & $1.37 \pm 0.20$ \\
\hline Gym floor with dual-task* & $1.27 \pm 0.17$ & $1.28 \pm 0.18$ & $1.28 \pm 0.24$ \\
\hline Soft foam rubber & $1.37 \pm 0.18$ & $1.39 \pm 0.17$ & $1.36 \pm 0.22$ \\
\hline Soft foam rubber with dual-task ${ }^{*}$ & $1.31 \pm 0.17$ & $1.30 \pm 0.19$ & $1.27 \pm 0.26$ \\
\hline \multicolumn{4}{|l|}{ Cadence (steps/min) } \\
\hline Gym floor & $114.3 \pm 8.4$ & $115.8 \pm 7.1$ & $115.0 \pm 7.7$ \\
\hline Gym floor with dual-task* & $110.1 \pm 9.1$ & $110.1 \pm 9.0$ & $109.7 \pm 10.9$ \\
\hline Soft foam rubber & $113.5 \pm 8.2$ & $114.8 \pm 7.1$ & $113.2 \pm 8.0$ \\
\hline Soft foam rubber with dual-task ${ }^{*}$ & $109.5 \pm 9.5$ & $109.5 \pm 9.1$ & $107.5 \pm 11.1$ \\
\hline \multicolumn{4}{|l|}{ Step duration (s) } \\
\hline Gym floor & $0.53 \pm 0.04$ & $0.52 \pm 0.03$ & $0.53 \pm 0.04$ \\
\hline Gym floor with dual-task* & $0.55 \pm 0.05$ & $0.55 \pm 0.05$ & $0.55 \pm 0.06$ \\
\hline Soft foam rubber & $0.53 \pm 0.04$ & $0.53 \pm 0.03$ & $0.53 \pm 0.04$ \\
\hline Soft foam rubber with dual-task ${ }^{*}$ & $0.55 \pm 0.05$ & $0.55 \pm 0.05$ & $0.57 \pm 0.06$ \\
\hline \multicolumn{4}{|l|}{ Variability of step duration (\%) } \\
\hline Gym floor & $2.36 \pm 0.74$ & $2.20 \pm 0.61$ & $2.68 \pm 1.22$ \\
\hline Gym floor with dual-task* & $3.09 \pm 1.17$ & $3.40 \pm 1.27$ & $3.26 \pm 1.58$ \\
\hline Soft foam rubber & $2.63 \pm 0.93$ & $2.78 \pm 0.92$ & $3.25 \pm 1.79$ \\
\hline Soft foam rubber with dual-task ${ }^{*}$ & $3.40 \pm 1.27$ & $3.24 \pm 1.19$ & $3.34 \pm 1.53$ \\
\hline \multicolumn{4}{|l|}{ Step length $(m)$} \\
\hline Gym floor & $0.72 \pm 0.07$ & $0.72 \pm 0.06$ & $0.72 \pm 0.09$ \\
\hline Gym floor with dual-task* & $0.69 \pm 0.06$ & $0.70 \pm 0.06$ & $0.70 \pm 0.09$ \\
\hline Soft foam rubber & $0.73 \pm 0.07$ & $0.72 \pm 0.06$ & $0.72 \pm 0.10$ \\
\hline Soft foam rubber with dual-task & $0.72 \pm 0.06$ & $0.71 \pm 0.07$ & $0.70 \pm 0.10$ \\
\hline \multicolumn{4}{|l|}{ Variability of step length (\%) } \\
\hline Gym floor & $4.91 \pm 1.73$ & $4.75 \pm 1.87$ & $4.81 \pm 1.71$ \\
\hline Gym floor with dual-task* & $5.71 \pm 2.19$ & $5.53 \pm 2.60$ & $5.46 \pm 1.98$ \\
\hline Soft foam rubber & $5.29 \pm 1.77$ & $5.11 \pm 1.95$ & $5.36 \pm 2.13$ \\
\hline Soft foam rubber with dual-task* & $5.69 \pm 1.81$ & $5.27 \pm 2.16$ & $5.28 \pm 1.88$ \\
\hline
\end{tabular}

* Significant differences between normal walking and dual-task walking $(p<0.05)$. 

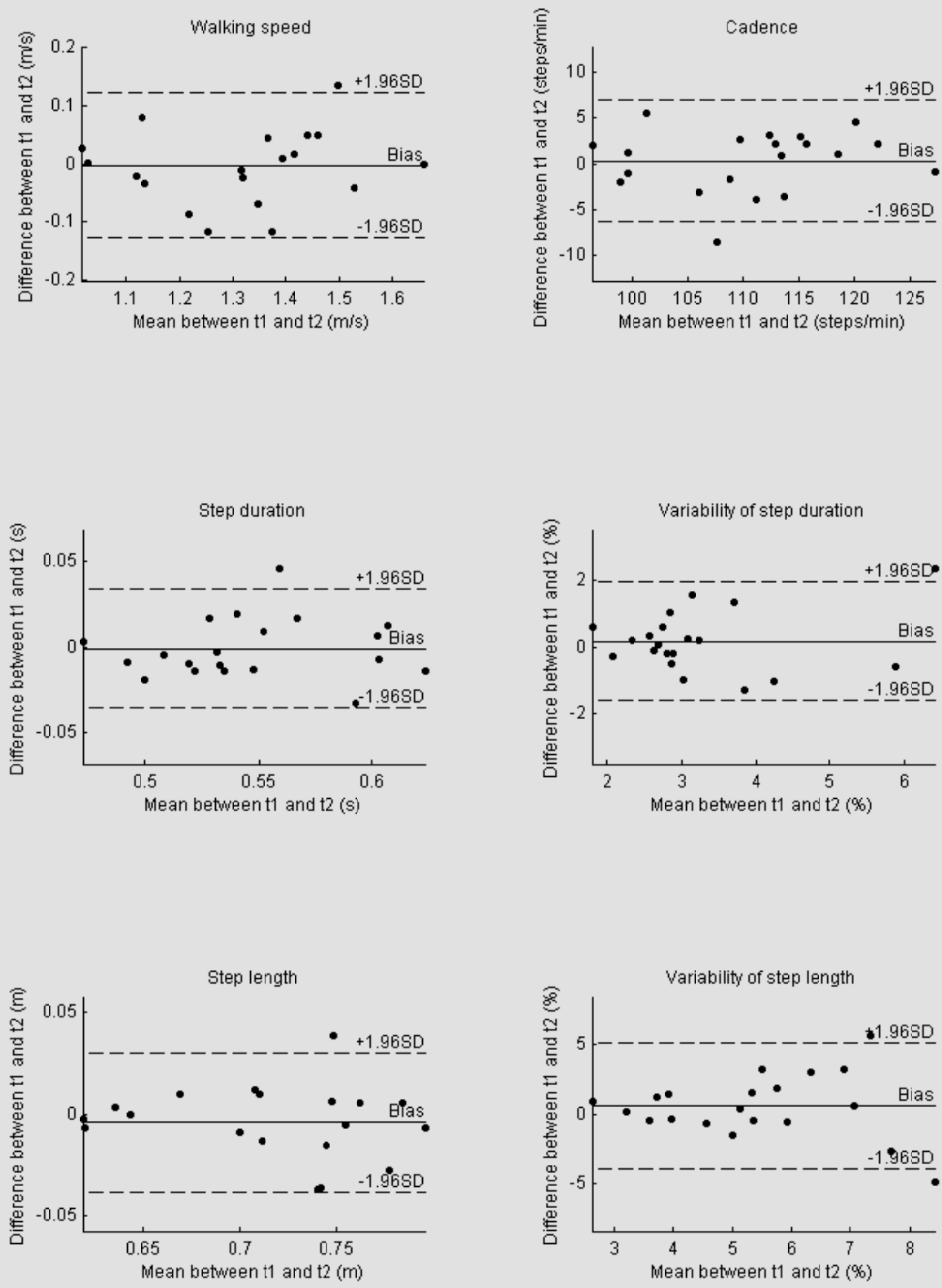

Figure 1

Bland-Altman plots of all gait parameters on the soft foam rubber with dual-task walking with regard to intrarater reliability. Solid line systematic bias; dashed lines limits of agreements. 


\section{Table 2}

Intrarater reliability.

\begin{tabular}{|c|c|c|c|c|c|}
\hline & $\mathrm{ICC}_{3,1}$ & $\begin{array}{c}95 \% \mathrm{Cl} \text { for } \\
\mathrm{ICC}_{3,1}\end{array}$ & $\begin{array}{l}\text { CV } \\
(\%)\end{array}$ & LOA & $\begin{array}{c}\text { RLOA } \\
(\%)\end{array}$ \\
\hline \multicolumn{6}{|l|}{ Walking speed $(\mathrm{m} / \mathrm{s})$} \\
\hline Gym floor & 0.93 & $0.84-0.97$ & 3.1 & \pm 0.12 & 8.7 \\
\hline Gym floor with dual-task & 0.92 & $0.80-0.97$ & 3.7 & \pm 0.13 & 10.3 \\
\hline Soft foam rubber & 0.98 & $0.93-0.99$ & 1.9 & \pm 0.07 & 5.3 \\
\hline Soft foam rubber with dual-task & 0.93 & $0.84-0.97$ & 3.4 & \pm 0.13 & 9.4 \\
\hline \multicolumn{6}{|l|}{ Cadence (steps/min) } \\
\hline Gym floor & 0.91 & $0.79-0.96$ & 2.0 & \pm 6.26 & 5.4 \\
\hline Gym floor with dual-task & 0.86 & $0.69-0.94$ & 2.8 & \pm 8.50 & 7.6 \\
\hline Soft foam rubber & 0.95 & $0.86-0.98$ & 1.6 & \pm 4.96 & 4.3 \\
\hline Soft foam rubber with dual-task & 0.92 & $0.82-0.97$ & 2.2 & \pm 6.65 & 6.0 \\
\hline \multicolumn{6}{|l|}{ Step duration (s) } \\
\hline Gym floor & 0.91 & $0.78-0.96$ & 2.0 & \pm 0.03 & 5.6 \\
\hline Gym floor with dual-task & 0.86 & $0.68-0.94$ & 2.8 & \pm 0.04 & 7.8 \\
\hline Soft foam rubber & 0.95 & $0.86-0.98$ & 1.6 & \pm 0.02 & 4.4 \\
\hline Soft foam rubber with dual-task & 0.92 & $0.81-0.97$ & 2.3 & \pm 0.03 & 6.3 \\
\hline \multicolumn{6}{|l|}{ Variability of step duration (\%) } \\
\hline Gym floor & 0.78 & $0.50-0.89$ & 13.9 & \pm 0.89 & 38.6 \\
\hline Gym floor with dual-task & 0.46 & $0.04-0.75$ & 28.4 & \pm 2.57 & 78.6 \\
\hline Soft foam rubber & 0.12 & $-0.31-0.54$ & 31.8 & \pm 2.43 & 88.1 \\
\hline Soft foam rubber with dual-task & 0.73 & $0.44-0.89$ & 19.8 & \pm 1.77 & 54.8 \\
\hline \multicolumn{6}{|l|}{ Step length $(m)$} \\
\hline Gym floor & 0.95 & $0.88-0.98$ & 1.9 & \pm 0.04 & 5.3 \\
\hline Gym floor with dual-task & 0.92 & $0.78-0.96$ & 2.3 & \pm 0.04 & 6.3 \\
\hline Soft foam rubber & 0.99 & $0.96-0.99$ & 0.9 & \pm 0.02 & 2.6 \\
\hline Soft foam rubber with dual-task & 0.95 & $0.88-0.98$ & 1.7 & \pm 0.03 & 4.8 \\
\hline \multicolumn{6}{|l|}{ Variability of step length (\%) } \\
\hline Gym floor & 0.31 & $-0.10-0.65$ & 30.3 & \pm 4.10 & 84.1 \\
\hline Gym floor with dual-task & 0.37 & $-0.06-0.70$ & 33.7 & \pm 5.27 & 93.3 \\
\hline Soft foam rubber & 0.21 & $-0.23-0.60$ & 32.3 & \pm 4.71 & 89.6 \\
\hline Soft foam rubber with dual-task & 0.30 & $-0.15-0.65$ & 30.6 & \pm 4.55 & 84.9 \\
\hline
\end{tabular}

Abbreviations: ICC, intraclass correlation coefficient; $95 \% \mathrm{Cl}, 95 \%$ confidence interval; CV, coefficients of variation; LOA, limits of agreement; RLOA, ratio limits of agreement. 


\section{Table 3}

Interrater reliability.

\begin{tabular}{|c|c|c|c|c|c|}
\hline & $\mathrm{ICC}_{2,1}$ & $\begin{array}{c}95 \% \mathrm{Cl} \text { for } \\
\mathrm{ICC}_{2,1} \\
\end{array}$ & $\begin{array}{l}\mathrm{CV} \\
(\%) \\
\end{array}$ & LOA & $\begin{array}{c}\text { RLOA } \\
(\%)\end{array}$ \\
\hline \multicolumn{6}{|l|}{ Walking speed $(\mathrm{m} / \mathrm{s})$} \\
\hline Gym floor & 0.94 & $0.87-0.98$ & 2.7 & \pm 0.10 & 7.5 \\
\hline Gym floor with dual-task & 0.97 & $0.91-0.99$ & 2.4 & \pm 0.09 & 6.7 \\
\hline Soft foam rubber & 0.96 & $0.90-0.99$ & 2.0 & \pm 0.08 & 5.6 \\
\hline Soft foam rubber with dual-task & 0.95 & $0.87-0.98$ & 3.7 & \pm 0.13 & 10.4 \\
\hline \multicolumn{6}{|l|}{ Cadence (steps/min) } \\
\hline Gym floor & 0.92 & $0.81-0.96$ & 1.8 & \pm 5.72 & 4.9 \\
\hline Gym floor with dual-task & 0.92 & $0.82-0.97$ & 2.3 & \pm 6.91 & 6.2 \\
\hline Soft foam rubber & 0.94 & $0.86-0.98$ & 1.4 & \pm 4.58 & 4.0 \\
\hline Soft foam rubber with dual-task & 0.92 & $0.80-0.96$ & 2.6 & \pm 7.73 & 7.1 \\
\hline \multicolumn{6}{|l|}{ Step duration (s) } \\
\hline Gym floor & 0.91 & $0.81-0.96$ & 1.9 & \pm 0.03 & 5.2 \\
\hline Gym floor with dual-task & 0.91 & $0.80-0.96$ & 2.4 & \pm 0.04 & 6.7 \\
\hline Soft foam rubber & 0.95 & $0.87-0.98$ & 1.4 & \pm 0.02 & 4.0 \\
\hline Soft foam rubber with dual-task & 0.90 & $0.77-0.96$ & 2.9 & \pm 0.04 & 8.0 \\
\hline \multicolumn{6}{|l|}{ Variability of step duration (\%) } \\
\hline Gym floor & 0.59 & $0.23-0.81$ & 17.9 & \pm 1.16 & 49.6 \\
\hline Gym floor with dual-task & 0.72 & $0.44-0.87$ & 21.4 & \pm 1.93 & 59.4 \\
\hline Soft foam rubber & 0.80 & $0.54-0.92$ & 16.9 & \pm 1.35 & 46.9 \\
\hline Soft foam rubber with dual-task & 0.80 & $0.56-0.91$ & 17.9 & \pm 1.60 & 49.5 \\
\hline \multicolumn{6}{|l|}{ Step length $(m)$} \\
\hline Gym floor & 0.96 & $0.90-0.98$ & 1.7 & \pm 0.03 & 4.8 \\
\hline Gym floor with dual-task & 0.97 & $0.94-0.99$ & 1.6 & \pm 0.03 & 4.3 \\
\hline Soft foam rubber & 0.98 & $0.94-0.99$ & 1.1 & \pm 0.02 & 3.0 \\
\hline Soft foam rubber with dual-task & 0.95 & $0.89-0.98$ & 2.1 & \pm 0.04 & 5.8 \\
\hline \multicolumn{6}{|l|}{ Variability of step length (\%) } \\
\hline Gym floor & 0.69 & $0.39-0.86$ & 21.4 & \pm 2.80 & 59.3 \\
\hline Gym floor with dual-task & 0.71 & $0.41-0.87$ & 23.2 & \pm 3.48 & 64.2 \\
\hline Soft foam rubber & 0.68 & $0.34-0.86$ & 22.6 & \pm 3.20 & 62.6 \\
\hline Soft foam rubber with dual-task & 0.88 & $0.73-0.95$ & 12.4 & \pm 1.75 & 34.5 \\
\hline
\end{tabular}

Abbreviations: ICC, intraclass correlation coefficient; $95 \% \mathrm{Cl}, 95 \%$ confidence interval; CV, coefficients of variation; LOA, limits of agreement; RLOA, ratio limits of agreement. 


\section{Discussion}

This study has shown that the reliability of walking speed, cadence, step duration and step length on different surfaces and under dual-task conditions was high with high ICCs and

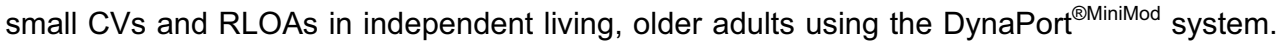
The reliability of gait variabilities of step duration and length was moderate with deficient ICCs and large CVs and RLOAs.

The activity level of the elderly participants in our study varied from sedentary to regular exercise behaviour. $39 \%$ of the participants reported at least 1 fall during the last half year. We thus expected our subjects to represent a heterogeneous group with regard to walking abilities.

Except for step length and variability of step length on the soft foam rubber walkway, the gait changes that we observed in dual-task walking are consistent with other studies that demonstrate that cognitive tasks have a destabilizing effect on gait shown as increased gait variability [19-21,95-97]. Our findings might be due to the cognitive task that we used. This task was always used in the same way and we can not exclude that a learning effect of the task took place. Since the gait changes on the soft foam rubber were smaller than the observed changes on the gym floor there might have been an order effect within the test procedure as well. For further research we recommend to change the cognitive task for different conditions, for instance random starting numbers for the start of subtracting and the application of a random test order.

The results of our study are at variance with an earlier report on the effects of walking on compliant foam. Where MacLellan \& Patla [98] reported higher values for step length, step time and the corresponding variability values for these parameters in young adults, there were no such differences observable in older subjects. It can be speculated that elderly either have a different ability to regulate dynamic stability when walking over compliant surfaces or they changed their walking behaviour such that a stable posture walking strategy is also taken for walking on the gymnastic floor [98]. Future research in larger (sub)samples of elderly should substantiate the value of this finding.

There is scarce information available about the reliability of gait parameters in older, healthy adults. The ICCs and CVs for walking speed, cadence, step duration and length (0.86 to 0.99 and $1 \%$ to $4 \%$, respectively), that we found were, however, similar to values (0.82 to 0.97 and $3 \%$ to $4 \%$ ) found by Bilney et al. [76], Menz et al. [77] and van lersel et al. [99] who 
were using the GAITRite ${ }^{\circledR}$ in older, healthy subjects. However, van lersel et al. [99] found higher ICCs for variabilities of stride duration and length (0.84 and 0.88).

The relative reliability is the degree to which individuals maintain their test results in a sample with repeated measurements and is affected by sample heterogeneity, that means the more heterogeneous a sample is, the higher the relative reliability becomes. Therefore, a high correlation may still mean unacceptable measurement error for some analytical goals [65] and data about absolute reliabilities of a test are important for clinical use. The determination of what constitutes an acceptable CV or RLOA depends on what size difference the researcher or clinician wants to detect when comparing groups or when assessing the effect of interventions [69].

To our knowledge, no study has examined the RLOAs of the spatio-temporal gait parameters and the absolute reliability of gait variability in older adults, even though the gait variability has been reported with increasing frequency in the gait literature and this parameter has been shown to be a fall risk factor in prospective studies $[18,19,90]$. The absolute reliability reported here for gait variability may not be sufficiently high to identify gait impairments or small effects of an intervention program to improve walking in aged populations. In particular, the CVs and RLOAs for variability of step duration and length indicate that these parameters can be expected to vary between $12 \%$ to $34 \%$ for a group of subjects and between $35 \%$ to $93 \%$ for a single individual between testing sessions, meaning that only large changes in the parameters could be detected with the measurement system. To our knowledge, no study has reported changes in gait variability after an intervention program with a comparable testing protocol; therefore, we can only speculate about the change that might be expected in such a population. A study that investigated gait recovery after total hip arthroplasty in a sample with a mean age of 62 years and that used the same gait analysis system showed that changes in gait variability of around $30 \%$ are observable after six months of post-operative rehabilitation [101].

There are some possible explanations for the comparatively low reliability of gait variability. First, we suppose that the subject's fluctuations in daily condition may strongly affect the results of gait variability in this population, because the interrater reliability of gait variability showed slightly better results compared to the intrarater reliability. Secondly, the walkway length of $18 \mathrm{~m}$ may be a limitation in obtaining reliable measures of gait variability. Owings and Grabiner [78] suggested, that accurate estimation of gait variability on a treadmill in young adults required at least 400 steps. However, the translation of the results of the treadmill study to over-ground walking is questionable. And thirdly, the low reliability may be 
affected by the instrument and data analysis. Hartmann et al. [100] showed that the concurrent validity of the DynaPort ${ }^{\circledR \text { MiniMod }}$ system with the GAITRite ${ }^{\circledR}$ system was moderate for variability of step duration with an ICC of 0.94 and a repeatability coefficient of $26 \%$ and low for variability of step length with an ICC of 0.33 and a repeatability coefficient of $74 \%$ at preferred walking speed over $28 \mathrm{~m}$. On the other hand, the concurrent validity between the two systems was excellent for walking speed, cadence, step duration and step length with ICCs between 0.99 to 1.00 and repeatability coefficients between $1 \%$ to $2 \%$.

Additionally, it is generally believed that the gait of elderly fallers is different from that of nonfallers. Analysing our data by dividing the subjects into two groups; non-fallers $(n=14)$ and fallers $(n=9)$, revealed that the reliability of gait variability in non-fallers (RLOAs between $17 \%$ to $96 \%$ ) were slightly better compared to fallers (RLOAs between $34 \%$ to $114 \%$ ) (results not shown). The limitations of this post-hoc classification, however, are the retrospective fall status determination and the small number of the subjects. Therefore, future work should investigate the reliability of gait parameters in non-fallers and fallers where the determination of fall status is collected in a prospective way.

\section{Conclusion}

The results of this study demonstrate that walking speed, cadence, step duration and step length under more challenging conditions can be reliably measured in independent living, older adults using the DynaPort ${ }^{\circledR M i n i M o d}$ system. Gait variability measures need to be viewed with caution and further research in older populations is needed to determine the value of these parameters that are derived from this measurement system.

\section{Acknowledgements}

We thank all the subjects who participated in the study and the student apprentices (Susanna Luzi, Flurina Meier, Isaline Schwarz) who helped in collecting the data. Thanks are also due to Dr. Peter Wolf who wrote the data analyses Matlab programme. We also thank the Stiftung Diakoniewerk Neumunster - Schweizerische Pflegerinnenschule for their financial support. 



\section{Chapter 5}

The effect of a training program combined with augmented afferent feedback from the feet using shoes insoles on gait performance and muscle power in older adults: a randomised controlled trial 


\section{Abstract}

Background: Aged-related loss of afferent feedback of the feet plays an important role in gait performance. Although strength, balance and gait training can significantly improve the muscle power and functional abilities of older individuals, it remains unclear whether training effects can be enhanced by augmenting afferent feedback from the feet adding shoe insoles as a complement to conventional training.

Objective: The current study investigated the effect of physical exercise combined with wearing MedReflex ${ }^{\circledR}$ shoe insoles on the gait performance and muscle power in older adults. Methods: Twenty-eight independent living, older adults aged 65 to 91 years were randomly assigned to either an insole group (IG; $n=14$ ) or a training group (TG; $n=14$ ). Further 14 subjects matched to the IG and TG were recruited as a control group (CG; $n=14$ ) (no exercise). The IG and TG completed the same training program consisting of aerobic exercises, progressive resistance strength training and stretching exercises twice per week for 12 weeks, whereas, the IG wore the insoles during everyday life and during training sessions. Assessments included the Falls Efficacy Scale - International (FES-I), gait analysis and muscle power measurements of the knee and ankle joint at pre- and post-training.

Results: There were significant time $\mathrm{x}$ group interactions in walking speed, step length and in several muscle power measurements. The positive effects of gait parameters ranged between $1 \%$ to $12 \%$ and between $1 \%$ to $8 \%$ and the trend to improvements of muscle power ranged between $15 \%$ to $79 \%$ and $20 \%$ to $79 \%$ for the IG and TG, respectively. The IG and TG did not differ significantly in their improvements. The CG showed a trend to deteriorations between $0 \%$ and $-5 \%$ for gait parameters and between $-4 \%$ and $-14 \%$ for muscle power. No significant change in FES-I score occurred in neither groups.

Conclusions: The results of this study provide evidence of significant improvements in gait performance and muscle power after a conventional training program in independent living, older adults. However, there is no additional effect of long-term adaptation of gait caused by wearing insoles concurrent to physical training. 


\section{Introduction}

Maintaining balance, performing functional tasks and locomotion depend on the interaction of neural, sensory and musculoskeletal systems [11]. Functioning of each of these systems declines with age, independent from geriatric pathologies [12], and such changes have been associated with diminished motor performance [13]. In particular, structures and functions of the foot and ankle change with age. Several studies demonstrated that older people have more pronated feet [31,32], reduced ankle [31,33] and 1st metatarsophalangeal joint [31] flexibility, toe plantarflexor weakness $[31,34,35]$ and reduced plantar tactile sensation $[31,36]$. Because the foot is the point of direct contact between the body and the surface during standing and walking, sensory feedback originating from tactile and proprioceptive receptors in the foot $[49,102-104]$ and toe plantarflexor muscles $[35,105]$ play an important role in the control of balance, in the stabilization of the foot and in the regulation of normal gait patterns.

Age-related loss of plantar tactile sensation and toe plantarflexor strength appears to correlate with impaired control of postural sway [11], as well as risk of falling [11,14]. Further, the muscle activation patterns [103] during walking were altered when afferent feedback from plantar surface of the foot had been inhibited by exposing the subject's feet to hypothermia. Additionally, stimulation of proprioceptive and tactile receptors that innervate the foot can affect $\alpha$-motoneuron activities in the muscles of the legs and change lower extremity kinematics during walking and running [106]. These results further indicate that afferent feedback from proprioceptive and tactile receptors is important in regulating the timing and intensity of human gait patterns. This leads to the possibility that by targeted manipulation of afferent feedback from the feet, one could change muscle, and consequently gait, patterns [103].

Both tactile and proprioceptive mechanisms can be influenced by therapeutic shoes or insoles [49]. Shoe insoles and orthotics are successfully used for physical activity and sport [107] for different reasons: to reduce the frequency of movement-related injuries, to align the skeleton properly, to provide improved cushioning, to improve afferent feedback, and to improve comfort. There is on the one hand emerging evidence that insoles with raised projections [50], vibrating [51] or magnetic [52] pads lead to improved plantar tactile and proprioceptive feedback from the foot and ankle, increased $\alpha$-motoneuron activities in the muscles and, therefore, may improve strength of toe plantarflexor muscles, balance and functional ability. However, on the other hand soft soles can distribute pressure under the soles, which may result in a deterioration of the detection of pressure changes at the soles and therefore, have a negative effect on balance [108]. 
Further, older adults often exhibit a loss of muscle power around the ankle and knee joint $[26,27]$ and a more conservative gait pattern that is characterized by reduced speed, step length and cadence and increased variabilities of step duration and length $[17,18]$. These gait changes are more pronounced when walking on an irregular surface than on level ground [19] and under dual-task conditions [20,21]. Further, reduced leg power and gait function may be directly related to impaired physical performance [26,27], and have been identified as risk factors for falls $[17,18]$. Conventional training programs that include strength and power training, balance and flexibility exercises can significantly improve the muscle strength, power and functional abilities of older individuals [3]. Unclear is, however, whether training effects can be enhanced by adding shoe insoles with older adults as a complement to training.

Therefore, the aim of this study was to investigate the effect of strength, balance and gait training combined with augmented afferent feedback from the feet using MedReflex ${ }^{\circledR}$ shoe insoles with raised projections on the gait performance and muscle power in older adults. We hypothesized that wearing MedReflex ${ }^{\circledR}$ shoe insoles during daily living activities and during training sessions would result in additional training effects.

\section{Methods}

\section{Subjects}

Independent living subjects over 65 years old were recruited from the local community at Zollikerberg, Zurich, Switzerland. Exclusion criteria were acute or terminal illness, cognitive impairment, unstable or ongoing cardiovascular/respiratory disorders, and resistance strength training experience within the past 12 months. The requirement of walking aids was also an exclusion criterion. Prior to participation, subjects completed medical and exercise histories that assessed the exclusion criteria. A flowchart of recruitment and follow-up of participants is shown in figure 1 . In a first section, 28 subjects were randomly allocated, using a computer generated random numbers table, into the insole group (IG; $n=14$ ) or the training group (TG; $n=14$ ). In a second section, 14 subjects matched to the IG and TG were recruited as a control group (CG; $n=14$ ). During the course of the study, the subjects were encouraged to maintain their customary activity. The local ethical committee approved the study and all subjects participating in the study signed an informed consent form. 


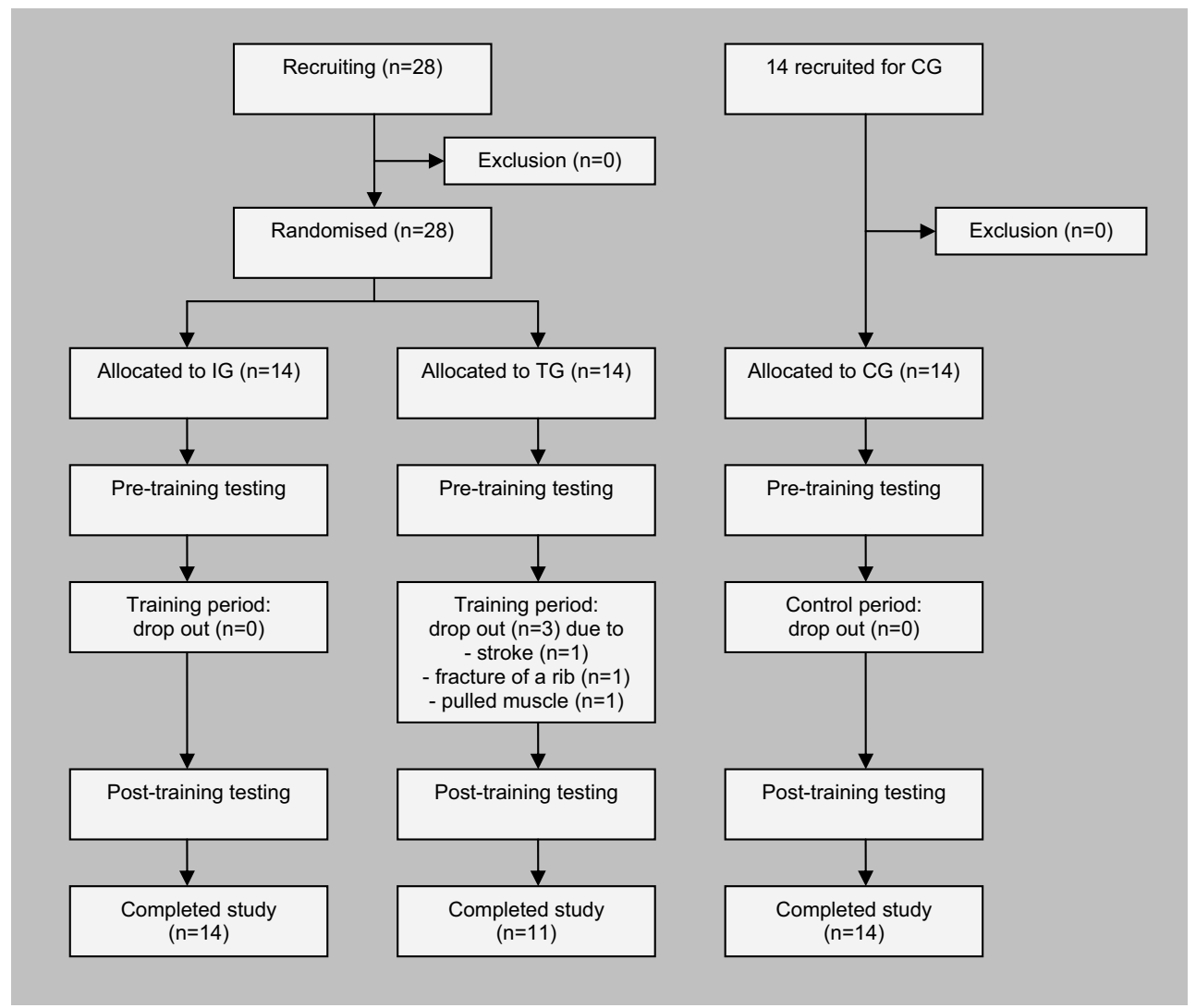

Figure 1

Flowchart of subjects through the study period.

\section{Shoe insoles application}

MedReflex ${ }^{\circledR}$ shoe insoles with raised projections (MedReflex ${ }^{\circledR}$ Therapiekonzept $\mathrm{GmbH}$, Munich, Germany) were developed to improve afferent feedback from the foot. The theory behind the concept is that the MedReflex ${ }^{\circledR}$ shoe insoles stimulate the proprioceptive and tactile receptors under the toe plantarflexor muscles and this leads to increased $\alpha$ motoneuron activities in the muscles of the feet and legs through reflex activity. This manipulation of the $\alpha$-motoneuron activities may strengthen postural and motor muscles and consequently, may change postural control and gait patterns.

Prior to training and pre-training testing, the subjects of the IG underwent a physical examination by an official MedReflex ${ }^{\circledR}$-physician to measure $\alpha$-motoneuron activities in the muscles of the feet and consequently, to customize the insoles (figure 2). The subjects were asked to wear the insoles as much as possible and use them during everyday life and during 
training sessions. The pre-training testing for these individuals occurred 3 to 5 days after the customization of the insoles in order to allow subjects to get accustomed to the insoles. The subjects wore the insoles during the testing procedure.

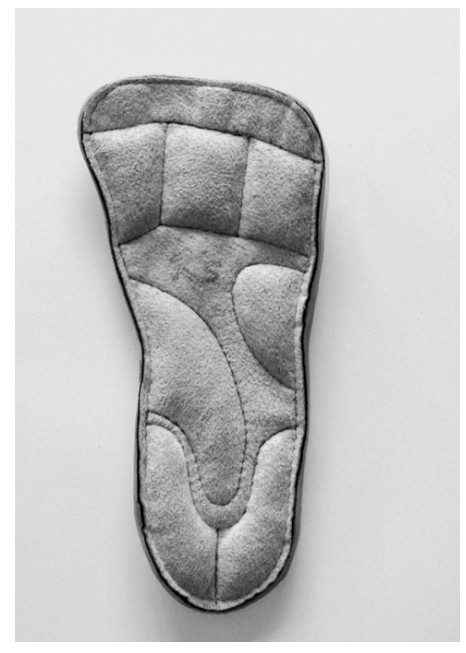

Figure 2

MedReflex® shoe insoles.

\section{Conventional training program}

The subjects from the IG and TG completed the same training program twice per week for 12 weeks. The subjects were divided into 4 training groups with 7 subjects per group, whereas in each training group subjects from the IG and TG were included. The rationale behind this procedure is the assumption that a steady training group allows for better social interaction and enjoyment. The training sessions consisted of four parts: 1) a 10 minutes warm-up activity, mainly in sitting and standing positions, 2) a 15 minutes aerobic exercise including walking, dancing and balance exercises, 3) progressive, resistance strength training exercises including leg press, leg extension/flexion, hip abduction/adduction and rowing, as well as 5 minutes treadmill, spinning and balance exercises on the Biodex Balance System (Biodex Medical Systems, Shirley, N.Y., USA), 4) a 10 minutes stretching and relaxation exercises. During the resistance training, the subjects performed 2 to 3 sets of 12 repetitions at an intensity between 'hard' to 'very hard' at the Borg scale, which is a valid tool to quantify the intensity of resistance exercise [109]. All strength exercises were performed on Compass equipment (Compass Strength Equipment, Proxomed, Switzerland). Exercises were conducted by a physical education instructor with specialization in adult training and under the supervision of a movement and sport scientist and student apprentices. When a subject was unable to attend the training session, complementary sessions were conducted immediately following the 12-week period, so that all of the required 24 training sessions 
were completed. No active intervention was prescribed for the CG and they were asked to perform no more or less activity than before the study.

\section{Outcome measures}

All subjects underwent the same evaluation procedure at pre- and post-training after 24 training sessions or after 12 weeks of control period. Assessments included the Falls Efficacy Scale - International (FES-I; German Version), gait analysis and muscle power measurements of the knee and ankle joint. Pre- and post-training testing was done at the same time of day and by the same observers.

\section{Gait parameters}

Spatio-temporal gait parameters were determined using the DynaPort ${ }^{\text {@MiniMod }}$, a trunk tri-axial accelerometer system (McRoberts BV, The Hague, The Netherlands). During testing, the subjects walked on the walkway while wearing their own comfortable clothing and low-heeled habitual shoes. Gait was evaluated during usual walking at preferred speed under four different conditions over 24 meters in a gym: 1) on the gymnasium floor, 2) on the gymnasium floor under a dual-task condition, 3) on a soft foam rubber walkway (1.25 m wide, $16 \mathrm{~mm}$ thick), and 4) on a soft foam rubber walkway under a dual-task condition. The dualtask in both conditions was subtracting repeatedly the number three starting from 200 down and was practiced before gait testing while sitting on a chair. To measure steady state walking, the central $18 \mathrm{~m}$ of the walking course was used as the test distance. A small receiver was mounted on the accelerometer and the researcher placed a signal in the data through triggering by use of a remote control when the subjects passed the $18 \mathrm{~m}$ distance lines. The researcher walked alongside the subjects to ensure their safety. After a test walk on the gymnasium floor to get accustomed to the experimental procedure, the subjects were instructed not to talk whilst walking at their preferred walking speed. Full descriptions of the data analyses have been reported elsewhere $[84,85]$. The measurement device and testing protocol have previously been identified as being valid [100] and reliable [110] measure for the common gait parameters, except for gait variability in independent living, older adults.

\section{Muscle power measurements}

To minimize the learning effect, the muscle power testing started with a familiarization session, followed by the test session. Muscle power tests of the knee and ankle joints were determined using a Biodex System 3 dynamometer (Biodex Medical Systems, Shirley, N.Y., USA) at angular velocities of $60 \%$ and $120 \%$ for the knee joint and of $60 \%$ for the ankle joint. Power measures were made bilateral, whereas the data for the right and left side were averaged for analysis. The tests started with the knee joint and the subjects were seated in 
an upright position. They completed a standardised 5 minutes period of warm-up. All subjects performed 6 to 8 passive repetitions followed by 3 submaximal contractions at each speed condition. During the test, they performed 4 continuous maximal voluntary flexionextension contractions at each speed with 1 minute of rest between the 2 speeds. The first knee flexion and the last knee extension were not recorded. This procedure was chosen to ensure that the test conditions of all recorded contractions would be equal. For ankle testing, the subjects were positioned semi-reclined with the knee in $30^{\circ}$ of flexion and with the back of the seat tilted at an angle of $40^{\circ}$. The test procedure of the ankle was identical to the procedure of the knee. The subjects performed 4 maximal voluntary contractions after the warm-up procedure starting with dorsiflexion, whereas the first dorsiflexion and the last plantarflexion were not recorded. The subjects were instructed to push and pull 'as fast and hard as possible' through the full available ROM at every trial. Full descriptions of the used testing protocol have previously been reported and identified as a reliable measure in independent living, older adults [111].

\section{Statistical analysis}

All statistical analyses were performed according to the intention-to-treat principle using the group mean method [112]. Means and standard deviations (SD) were calculated for each group and test. The normal distribution of the data was tested with a Kolmogorov-Smirnov test. One-way ANOVAs were used to analyze differences between groups at pre-training testing. Two-way (time $x$ group) repeated-measures ANOVAs were used to test for differences between the three groups over time. In case of a time $x$ group interaction, Student's paired-sample $t$-tests were used to detect the significance between pre- and posttraining testing and one-way ANOVAs for percent changes, followed by Bonferroni post hoc tests for multiple comparisons. The percentage change was calculated on individual data as (post - pre-training)/pre-training $\times 100$. Further, one-way ANOVAs, followed by the Bonferroni post hoc tests for multiple comparisons, were used to determine whether gait parameters differed between the four walking conditions at pre-training testing for all subjects summarized, or whether percent changes within each group differed between the four walking conditions. Statistical significance was set at $p<0.05$. All data were analyzed using Matlab 7.1. 


\section{Results}

Three subjects from the TG dropped out during the training period due to illness and injury (not related to the exercise program; figure 1). A summary description of the demographic variables of the groups is presented in table 1. The CG showed a significantly higher FES-I score compared to the IG at pre- and post-training testing. No significant change in FES-I score occurred in neither groups. There were no significant differences between the three groups for the anthropometric measures, spatio-temporal gait parameters and muscle power measurements at pre-training.

Table 1

A summary description of the demographic variables of the groups.

\begin{tabular}{|c|c|c|c|c|c|}
\hline & & $\begin{array}{l}\text { Insole group } \\
\text { (Mean } \pm \mathrm{SD} \text { ) }\end{array}$ & $\begin{array}{c}\text { Training group } \\
(\text { Mean } \pm \text { SD) }\end{array}$ & $\begin{array}{l}\text { Control group } \\
\text { (Mean } \pm \text { SD) }\end{array}$ & $p$ \\
\hline \multirow[t]{3}{*}{$\mathrm{N}$} & Total & 14 & 14 & 14 & \\
\hline & Women & 10 & 9 & 10 & \\
\hline & Men & 4 & 5 & 4 & \\
\hline \multicolumn{2}{|c|}{ Age (years) } & $76.4 \pm 5.9$ & $79.4 \pm 5.2$ & $76.0 \pm 6.0$ & 0.236 \\
\hline \multicolumn{2}{|c|}{ Weight $(\mathrm{kg})$} & $67.1 \pm 8.0$ & $62.3 \pm 13.3$ & $69.1 \pm 11.7$ & 0.266 \\
\hline \multicolumn{2}{|c|}{ Height (m) } & $1.7 \pm 0.1$ & $1.6 \pm 0.1$ & $1.7 \pm 0.1$ & 0.921 \\
\hline \multicolumn{2}{|c|}{ BMI $\left(\mathrm{kg} / \mathrm{m}^{2}\right)$} & $24.3 \pm 1.7$ & $22.9 \pm 3.8$ & $25.1 \pm 3.3$ & 0.164 \\
\hline \multicolumn{2}{|c|}{ FES-I (pre-training) } & $17.8 \pm 1.6^{*}$ & $18.5 \pm 1.9$ & $21.5 \pm 5.6^{*}$ & 0.019 \\
\hline \multicolumn{2}{|c|}{ FES-I (post-training) } & $17.4 \pm 1.4^{*}$ & $17.6 \pm 1.5$ & $21.4 \pm 5.8^{*}$ & 0.007 \\
\hline
\end{tabular}

\section{Compliance}

All subjects from the IG and TG completed 24 training sessions within 15 training weeks. Four subjects from the IG wore the insoles all day, four half a day, four $2 \mathrm{~h} /$ day and two less than $1 \mathrm{~h} /$ day.

\section{Gait parameters}

At pre-training and for all subjects summarized, significant differences between the four walking conditions were identified for all gait parameters, except for step length (walking speed: $F(3,156)=6.59, p<0.001$, cadence: $F(3,156)=12.71, p<0.001$, step duration: $F(3,156)=12.42, p<0.001$, step length: $F(3,156)=0.71, p=0.55)$. Walking speed and cadence were significantly decreased and step duration was significantly increased in dualtask walking compared to normal walking on both surfaces $(p<0.05)$. No significant differences were detected between the two surfaces. 
Table 2 presents means, SDs and $p$-values from paired $t$-tests within each group and from the two-way repeated-measures ANOVAs for time $x$ group interactions. There were significant time $x$ group interactions in walking speed and step length. The IG and TG did not differ significantly in their improvements. When the paired $t$-tests were used on pre- and posttraining data in each group separately, the IG and TG showed some significant improvements, whereas the CG showed rather a trend to deterioration. But the changes were not statistically significant for this group. The percent changes between pre- and posttraining are illustrated in figure 3 and the positive effects ranged between $1 \%$ to $12 \%$ and between $1 \%$ to $8 \%$ for the IG and TG, respectively. The CG showed a trend to deteriorations between $0 \%$ and $-5 \%$. There were no significant differences for percent changes between the four walking conditions within each group; implying that all walking conditions showed similar percent changes.

\section{Muscle power measurements}

Similar to the results of gait analysis, there were associations of muscle power improvements with training in itself (table 3). The IG and TG, however, did not differ significantly in their improvements. When the paired $t$-tests were used on pre- and post-training data within each group separately, the IG and TG showed some significant improvements, whereas the CG showed rather a trend to deterioration. But, the changes were not statistically significant for this group. The percent changes of power measurements ranged between $15 \%$ to $79 \%$ and $20 \%$ to $79 \%$ for the IG and TG, respectively and to deteriorations between $-4 \%$ and $-14 \%$, except for dorsiflexion with an improvement of $15 \%$ for the CG (figure 4). 


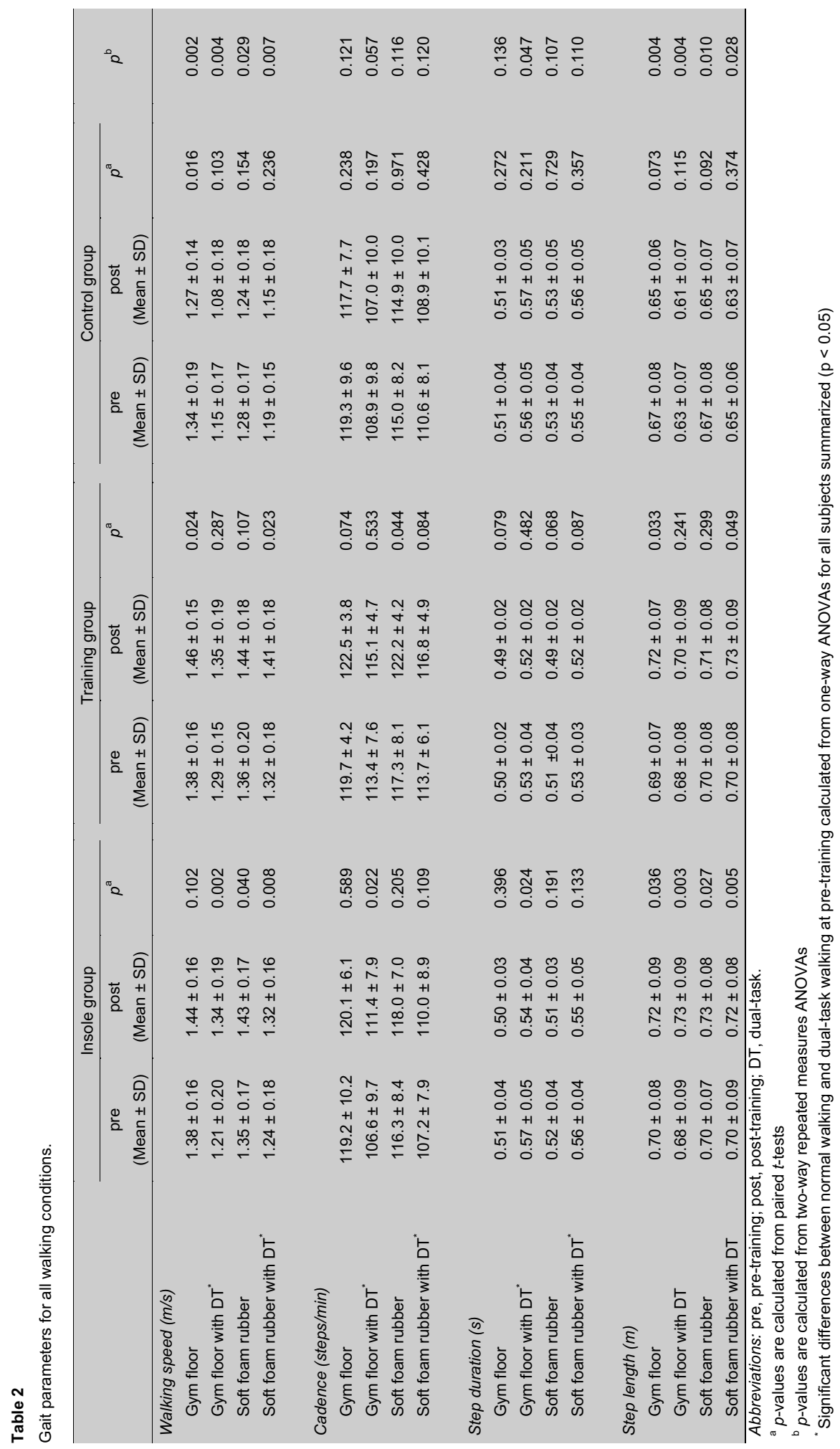




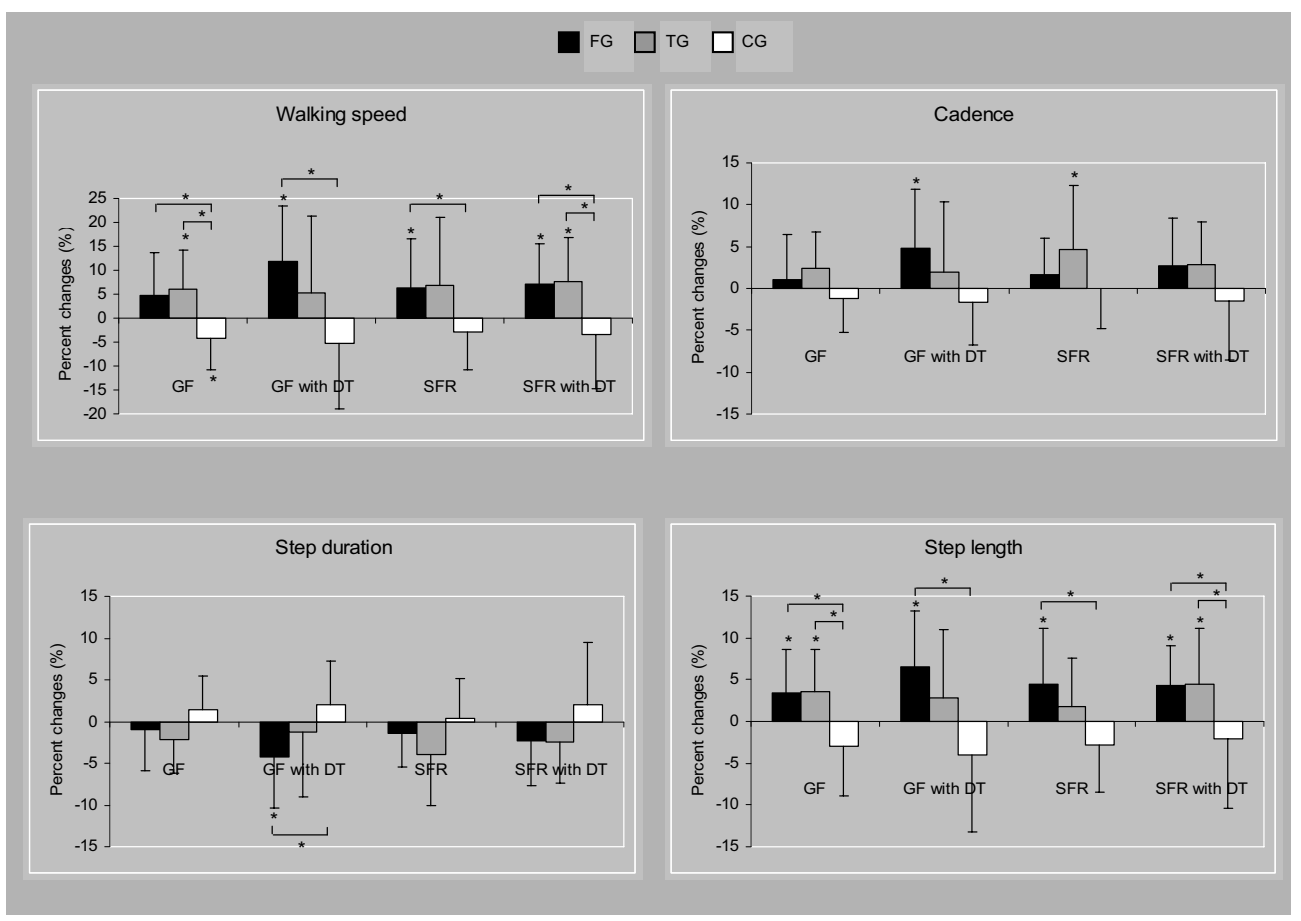

Figure 3

Percent changes of gait parameters.

Abbreviations: IG, insole group; TG, training group; CG, control group; GF, gym floor; DT, dual-task; SFR, soft foam rubber.

* Significant change $(p<0.05)$ as compared with pre-training testing and between groups, respectively. 


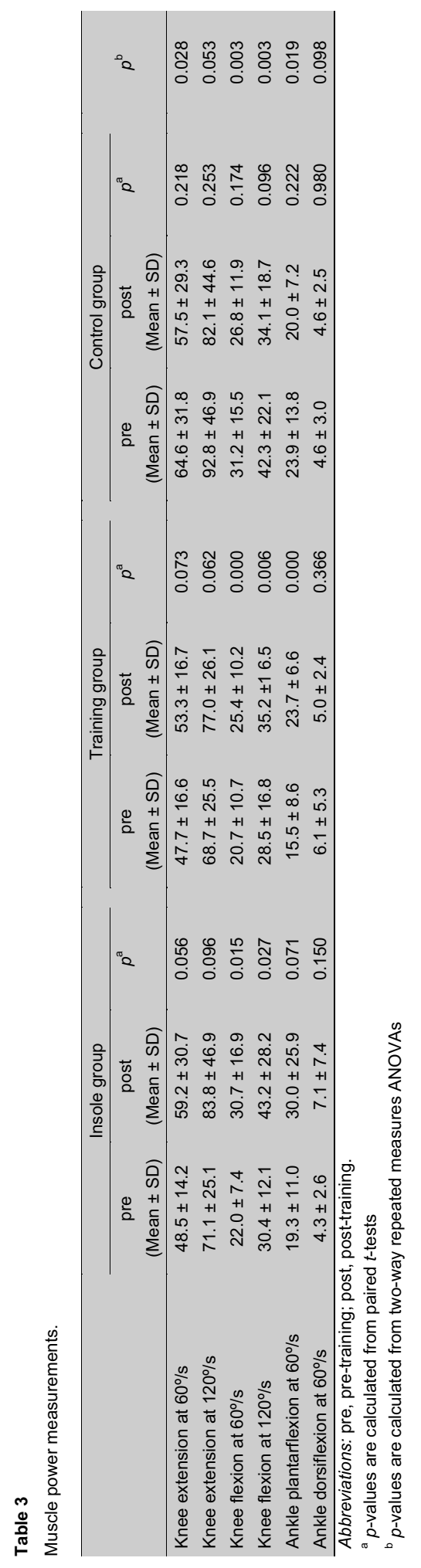




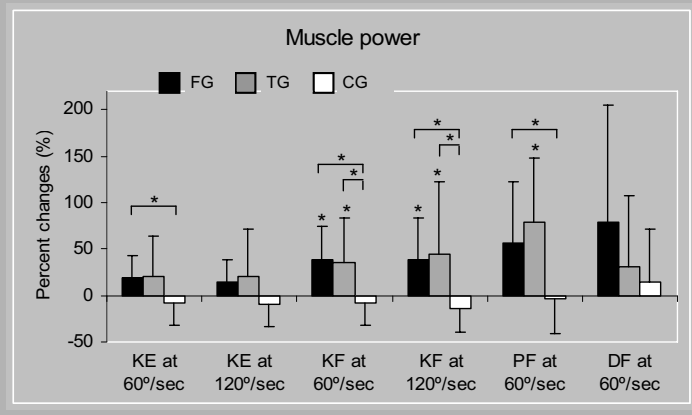

Figure 4

Percent changes of muscle power.

Abbreviations: IG, insole group; TG, training group; CG, control group; KE, knee extension; KF, knee flexion; PF, ankle plantarflexion; DF, ankle dorsiflexion.

* Significant change $(p<0.05)$ as compared with pre-training testing and between groups, respectively.

\section{Discussion}

The primary findings of this study was that the conventional training program in itself resulted in improvements in muscle power and in gait parameters compared to the CG in independent living, older adults. Wearing insoles with raised projections during everyday life and during training sessions had no additional effects.

\section{The effect of wearing insoles}

IG and TG did not differ significantly in their improvements, indicating that wearing insoles with raised projections during everyday life and during training sessions had no additional effects on gait performance and leg muscle power in this population. However, it is not clear whether the insoles had any stimulating effects to the proprioceptive and tactile receptors and $\alpha$-motoneuron activities of the lower extremity muscles or whether increased afferent feedback and $\alpha$-motoneuron activities were not sufficient to improve the gait performance and muscle power. A possible explanation for this finding might be that the subjects did not comply with wearing the insoles continuously. The insoles had to change from one shoe to the other and some subjects wore the insoles only in their indoor shoes or slippers and not in their outdoor shoes. It can be assumed that indoor activities are performed mostly while sitting and not while standing or walking. Further, the relative short duration of the study period may not be sufficient to show an effect of long-term adaption of gait caused by wearing insoles. 


\section{The effect of training on FES-I}

The training program had no effect on fear of falling, possibly because of the low pre-training FES-I score of the subjects, which caused floor effects for this assessment. These results are consistent with other studies which showed only beneficial effects of fear of falling after a training program in fearful person $[113,114]$.

\section{The effect of training on gait parameters}

Previous exercise interventions to improve gait performance in older adults have been shown to be effective, within the limitation that most investigations have focused mainly on level ground walking under a single task condition [115,116]. It has been shown that cognitive tasks have a destabilizing effect on gait in older adults [19-21]. Consistent with these studies, a comparison between the four different walking conditions showed that the subjects significantly changed the gait pattern in dual-task walking at pre-training testing, except for step length. Further, the results showed associations of improvements in some gait parameters with training in itself compared to the $C G$, but the time $x$ group interactions were not statistically significant in either case. Our results might be due to the relative short training period of 12 weeks and to the relative healthy status of our subjects.

Even though the gait variability has been reported with increasing frequency in the gait literature, and this parameter has been shown to be an important fall risk factor $[18,19]$, we consciously abandoned to report this parameter because of the moderate to low reliability [110] and validity [100] of this variable in contrast to the reported parameters. However, we assume that the IG and TG gained real improvements in the reported gait parameters, because the percent changes of the values are higher than the measurement error of our measurement protocol [100].

\section{The effect of training on muscle power}

Research has consistently demonstrated that muscle strength and power increases after progressive resistance strength training in older adults $[3,55,117]$. However, there are only few intervention studies with similar muscle power outputs. Muscle power gains for knee extension at $60 \%$ s and $120 \%$ s (15\% to $21 \%$ versus $24 \%$ ) in the present study were similar, and those for ankle plantarflexion at $60 \%$ higher (56\% to $79 \%$ versus $33 \%$ ), than those reported in older men after 16 weeks progressive resistance training [55]. Symons et al. [117] reported muscle power gains for knee extension at $90 \%$ of $21 \%$ to $52 \%$ following resistance training of various intensities over 12 weeks. Differences in the mode, intensity and frequency of the exercise or in the contents of the test protocols used in different studies may also explain these inconsistencies. The training program gained also real improvement in 
muscle power, since the percent changes were higher than the measurement error for the used measurement protocol [111].

\section{Limitations of the study}

Our study has several limitations. First, our subjects were a group of relatively healthy independent living, older adults, and consequently, these results can not be generalized to frail persons or persons with foot symptoms. Second, the subjects did not comply with wearing the insoles continuously. Third, we did not include a 'wearing insoles only' control group to compare the effect of the insoles without physical training. Fourth, we did not measure the effect of the insoles to the proprioceptive and tactile receptors and $\alpha$ motoneuron activities and therefore we can not conclude if the insoles increase afferent feedback. And lastly, testers were not blinded to the group status of the subjects. Further study should involve lager sample sizes, less healthy populations of older adults with foot symptoms and measurements of muscle activities to investigate the effect of the insoles on a-motoneuron activities.

\section{Conclusions}

The findings from the present study provide evidence of significant improvements in physical performance related to muscle power and walking abilities after a conventional strength and coordination training program in independent living, older adults. There is no additional effect of long-term adaptation of gait that is caused by wearing insoles concurrent to physical training.

\section{Acknowledgments}

The authors wish to thank all the subjects who participated in the study and the student apprentices who supervised the training sessions. Thanks are also due to Marlies Dorfschmid who conducted the training program and Dr. Michael Wawroschek who customized the insoles. We also wish to thank MedReflex ${ }^{\circledR}$ Therapiekonzept $\mathrm{GmbH}$ for providing the insoles, and the Stiftung Diakoniewerk Neumunster - Schweizerischen Pflegerinnenschule and Hatt-Bucher-Stiftung for their financial support. We gratefully acknowledge the support of $P R O X O M E D$ for providing the training and test materials for this study. 



\section{Chapter 6}

The effect of a foot gymnastic exercise program on gait performance in older adults: a randomised controlled trial

Antonia Hartmann, Kurt Murer, Rob A. de Bie, Eling D. de Bruin.

Disability and Rehabilitation 2009;21:1-10 


\section{Abstract}

Background: Aged-related loss of ankle dorsiflexion range of motion (ROM) and toe plantarflexor strength play an important role in gait performance. Further, conventional strength, balance and gait training can significantly improve the lower extremity muscle power and functional abilities of older individuals. It remains unclear, however, whether training effects can be enhanced by augmenting ankle ROM and toe plantarflexor strength as a complement to training.

Objective: The current study investigated the effect of physical exercise combined with foot gymnastics on the gait performance in older adults.

Methods: Fifty-six independent living, older adults aged 66 to 91 years were randomly assigned to either foot gymnastics group (FG; $n=28$ ) or training group (TG; $n=28$ ). Further 14 subjects were integrated as a control group (CG; $n=14$ ) (no exercise). The FG and TG completed the same training program consisting of aerobic exercises, progressive resistance strength training and stretching exercises twice per week for 12 weeks, whereas, the FG performed additional foot gymnastic exercises at the end of the training session and a 10minute foot gymnastics home-program daily. Assessments included the Falls Efficacy Scale - International (FES-I), Expanded Timed Get-up-and-Go test (ETGUG), gait analysis and muscle power measurements of the knee and ankle joint at pre- and post-training.

Results: No significant change in FES-I score occurred in either group. The FG showed a significant improvement of ankle ROM. There were significant time $x$ group interactions in walking speed, step length, in several muscle power measurements and in ETGUG. The positive effects of gait parameters ranged between $1 \%$ and $11 \%$ and between $2 \%$ and $12 \%$, of muscle power between $14 \%$ and $34 \%$ and $14 \%$ and $46 \%$ and of ETGUG were $10 \%$ and $8 \%$ for the FG and TG, respectively. The FG and TG did not differ significantly in their improvements. The CG showed a trend to deteriorations between $0 \%$ and $-6 \%$ for gait parameters, between $-4 \%$ and $-14 \%$ for muscle power and $0 \%$ for ETGUG.

Conclusions: The results of this study provide evidence of significant improvements in gait performance, muscle power and ETGUG after a conventional training program in independent living, older adults. However, there is no additional effect on physical performance after foot gymnastic exercises. 


\section{Introduction}

Because the foot is the point of direct contact between the body and the surface during standing and walking, the structures and functions of the foot and ankle play an important role in functional activities such as walking. Several studies demonstrated that aging is associated with significant changes to the musculoskeletal and sensory characteristics of the foot. Older people have more pronated feet [31,32], reduced ankle joint flexibility $[31,33,37,38]$, toe plantarflexor weakness $[31,34,35]$ and reduced plantar tactile sensation $[31,36]$. In particular, the ankle dorsiflexion range of motion (ROM) $[11,39,46]$ and the toe plantarflexor muscles $[34,35,105]$ are said to have importance in controlling balance and gait performance.

The toes stabilize the foot during standing and walking [34,35,105], and an adequate ROM at the ankle and toes is necessary for normal gait. At least 10 degrees of ankle dorsiflexion are needed in the stance phase of gait [118]. Rising from a chair or descending stairs requires a maximum of between 21 and 36 degrees of dorsiflexion [119]. However, it has been shown that there is a general decrease in ankle joint ROM of $20 \%$ to $30 \%[31,33,37,38]$ and a loss of toe plantarflexor strength of $27 \%$ to $32 \%$ [34,35] with age. This age-related loss of ankle ROM and toe plantarflexor strength correlates with impaired balance $[11,34,39]$, functional abilities [11,34] and risk of falling [14].

Differences in physical activity levels have been suggested as one possible factor interacting with the observed age-related differences in ankle joint ROM [33] and in toe plantarflexion strength [53,54]. Variations in movement patterns may potentiate ROM of the ankle joint in children [37]. Elderly subjects, who exhibit less movement pattern variation, might be expected to limit ankle joint movements to those required for normal walking [37]. Furthermore, it is well established that stretching can effectively increase ankle ROM [45-47] in older people, however the results of several studies are inconsistent whether stretching has a beneficial effect on gait performance [46-48]. Only few studies have evaluated the factors that contribute to the strength of the toes. There is emerging evidence, that physical activity involving toe muscles like dancing [53] or grasping [54] may improve toe muscles function. Kobayashi et al. [54] showed that grasping exercises to strengthen toe muscles result in improved standing balance in older people. In this context, however, it is not known whether a lower extremity strength training that is complemented with specific training of ankle ROM and toe plantarflexor strength has an additional effect for the improvement of gait performance in older adults. 
Older adults often exhibit loss of muscle power around the ankle and knee joint $[26,27]$ and show a more conservative gait pattern that is characterized by reduced speed, step length and cadence and increased variabilities of step duration and length $[17,18]$. These gait changes are more pronounced when walking on an irregular surface than on level ground [19] and under dual-task conditions [20,21]. Further, reduced leg power and gait function may be directly related to impaired physical performance [26,27], and have been identified as risk factors for falls $[17,18]$. Conventional training programs that include strength and power training, balance and flexibility exercises can significantly improve muscle strength, power and functional abilities of older individuals [3].

Therefore, the aim of this study was to investigate the effect of strength, balance and gait training combined with specific foot gymnastic exercises on the gait performance in older adults. We hypothesised that increased ankle ROM and strengthened toe plantarflexor strength, attained by extra grasping and stretching exercises of the feet, would result in additional training effects.

\section{Methods}

\section{Subjects}

Independent living subjects over 65 years of age were recruited from the local community at Zollikerberg, Zurich, Switzerland. Exclusion criteria were acute or terminal illness, cognitive impairment, unstable or ongoing cardiovascular/respiratory disorders and resistance strength training experience within the past 12 months. The requirement of walking aids was also an exclusion criterion. Prior to participation, subjects completed medical and exercise histories that assessed the exclusion criteria. A flowchart of recruitment and follow-up of participants is shown in figure 1.56 subjects were randomly allocated, using a computer generated random numbers table, into the foot gymnastic group (FG; $n=28$ ) or the training group (TG; $n=28$ ). Further, 14 subjects were integrated as a control group (CG) from a previous study, which included the same exclusion criteria. During the course of the study, the subjects were encouraged to maintain their customary level of activity. The local ethical committee approved the study and all subjects participating in the study signed an informed consent form. 


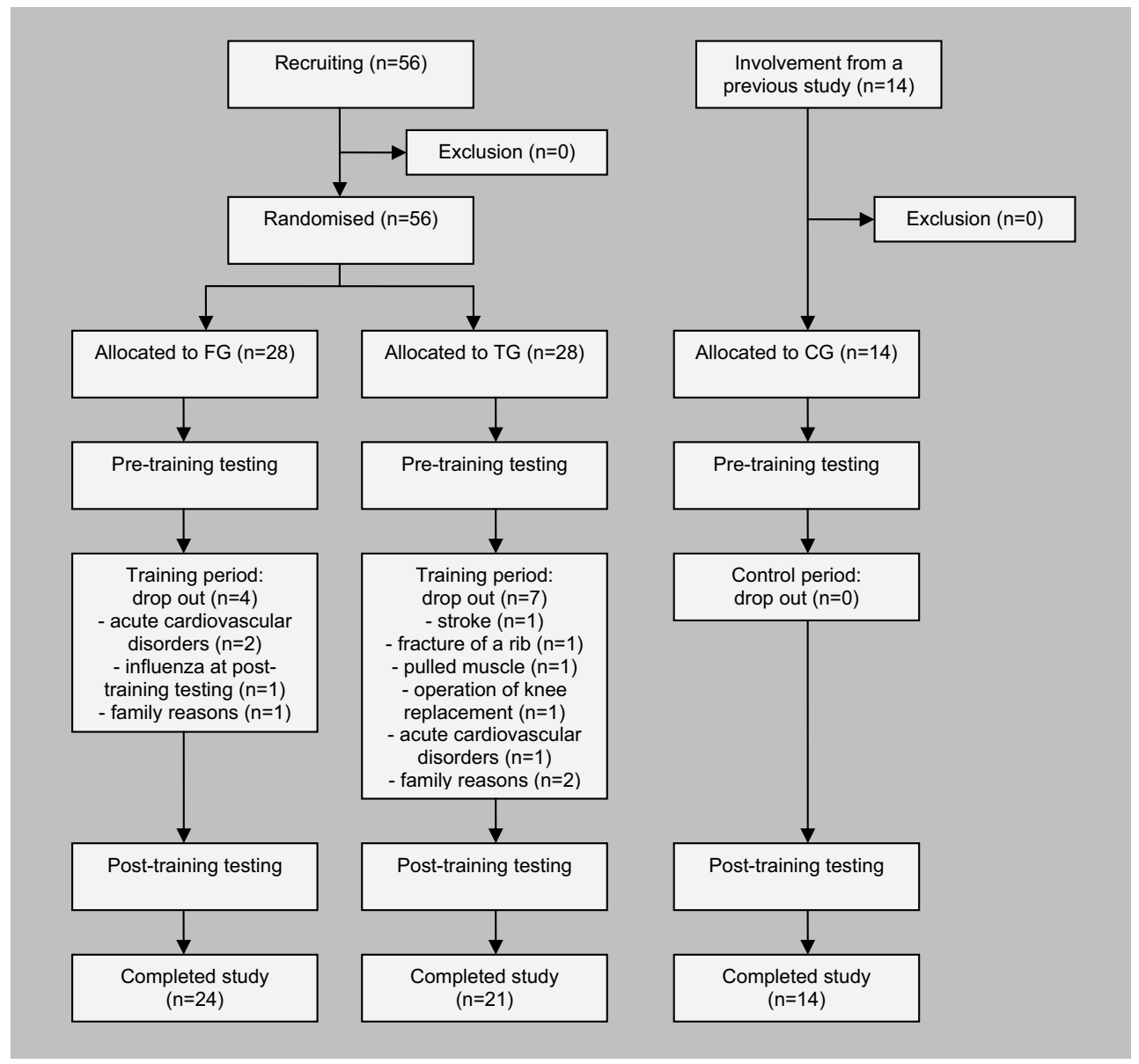

Figure 1

Flowchart of subjects through the study period.

\section{Conventional training program}

The subjects from the $F G$ and $T G$ completed the same training program twice per week for 12 weeks, whereas, the FG performed additional foot gymnastic exercises at the end of the training sessions. The subjects were divided into 8 training groups with 7 subjects per group between August 2006 and June 2008. The rationale behind this procedure is the assumption that a steady training group allows for better social interaction and enjoyment. The training sessions consisted of five parts for the FG and of four parts for the TG: 1) a 10 minutes warm-up activity, mainly in sitting and standing positions, 2) a 15 minutes aerobic exercise including walking, dancing and balance exercises, 3) progressive, resistance strength training exercises including leg press, leg extension/flexion, hip abduction/adduction and rowing, as well as 5 minutes treadmill, spinning and balance exercises on the Biodex 
Balance System (Biodex Medical Systems, Shirley, N.Y., USA), 4) only the FG: a 5 minutes foot gymnastics included exercises intended to strengthen the muscles of the feet and increase the ankle joint ROM, 5) a 10 minutes stretching and relaxation exercises. During the resistance training, the subjects performed 2 to 3 sets of 12 repetitions at an intensity between 'hard' to 'very hard' at the Borg scale, which is a valid tool to quantify the intensity of resistance exercise [109]. All strength exercises were performed on Compass equipment (Compass Strength Equipment, Proxomed, Switzerland). Exercises were conducted by a physical education instructor with specialization in adult training and under the supervision of a movement and sport scientist and student apprentices. When a subject was unable to attend the training session, complementary sessions were conducted immediately following the 12 -week period, so that all of the required 24 training sessions were completed.

No active intervention was prescribed for the CG and participants were asked to perform no more or less activity than before the study.

\section{Foot gymnastic exercises}

The subjects of the FG were asked to perform a 10-minute home-program daily (excluded the training days) during the training period. In the first training session, they received instructions and a copy with illustrations and descriptions on how to perform the homeprogram by the physical education instructor. Foot gymnastics included exercises intended to strengthen the muscles of the feet and increase the ankle joint ROM. The home-program consisted of three parts: 1) 2 minutes warm-up activity, including lifting heels and toes while sitting and standing, and walking on tiptoe and heels, 2) 4 minutes foot gymnastics including moving and spreading toes, grabbing small objects and playing various skill games with the feet, 3) 4 minutes stretching of the ankle joint. The subjects were instructed to perform two static stretches on both sides while standing. Subjects placed one foot in front of the other, at a comfortable and stable stepping stance, with hands resting on the wall for stability. First, subjects were instructed to lean their pelvis forward toward the wall until a stretch was felt, keeping the trunk upright, the knee extended and without lifting the heel from the ground. Second, in this position, the subjects bended their knees to squat down as low as possible. Each stretch was held for 30 seconds and repeated 2 times on each lower limb with a rest of 15 seconds between. 


\section{Outcome measures}

All participants underwent the same evaluation procedure at pre- and post-training after 24 training sessions or after 12 weeks of control period. Assessments included the Falls Efficacy Scale - International (FES-I; German Version), ankle ROM, Expanded Timed Get-up-and-Go test (ETGUG), gait analysis and muscle power measurements of the knee and ankle joint. However, the ankle ROM of the CG was not determined, because these subjects were integrated from a previous study without ankle ROM measurements. Pre- and post-training testing was done at the same time of day and by the same observers.

\section{Ankle ROM}

Ankle dorsiflexion ROMs were taken from the right lower extremity in a weight-bearing position with the knee flexed. The weight-bearing position was chosen because this position is more relevant to the performance of functional activities such as walking [119]. ROM was measured in degrees using a goniometer according to Norkin and White [119]. Subjects placed the left foot in front of the right, at a comfortable and stable stepping stance, with hands resting on the wall for stability. In this position, the subjects bended the right knees to squat down as low as possible while keeping the trunk upright and without lifting the right heel from the ground.

\section{Gait parameters}

Spatio-temporal gait parameters were determined using the DynaPort ${ }^{\text {@MiniMod }}$, a trunk tri-axial accelerometer system (McRoberts BV, The Hague, The Netherlands). During testing, the subjects walked on the walkway while wearing their own comfortable clothing and low-heeled habitual shoes. Gait was evaluated during usual walking at preferred speed under four different conditions over 24 meters in a gym: 1) on the gymnasium floor, 2) on the gymnasium floor under a dual-task condition, 3 ) on a soft foam rubber walkway (1.25 m wide, $16 \mathrm{~mm}$ thick), and 4) on a soft foam rubber walkway under a dual-task condition. The dualtask in both conditions was subtracting repeatedly the number three starting from 200 down and was practised before gait testing while sitting on a chair. To measure steady state walking, the central $18 \mathrm{~m}$ of the walking course was used as the test distance. A small receiver was mounted on the accelerometer and the researcher placed a signal in the data through triggering by use of a remote control when the subjects passed the $18 \mathrm{~m}$ distance lines. The researcher walked alongside the subjects to ensure their safety. After a test walk on the gymnasium floor to get accustomed to the experimental procedure, the subjects were instructed not to talk whilst walking at their preferred walking speed. Full descriptions of the data analyses have been reported elsewhere $[84,85]$. The measurement device and testing 
protocol have previously been identified as being a valid [100] and reliable [110] measure gait parameters, except for gait variability in independent living, older adults.

\section{Muscle power measurements}

To minimize the learning effect of isokinetic testing, the muscle power testing started with a familiarization session, followed by the test session. Muscle power tests of the knee and ankle joints were determined using a Biodex System 3 dynamometer (Biodex Medical Systems, Shirley, N.Y., USA) at angular velocities of $60 \%$ s and $120 \%$ for the knee joint and of $60 \%$ for the ankle joint. Power measures were made bilateral, whereas the data for the right and left side were averaged for analysis. The tests started with the knee joint and the subjects were seated in an upright position. They completed a standardized 5 minutes period of warm-up. All subjects performed 6 to 8 passive repetitions followed by 3 submaximal contractions at each speed condition. During the test, they performed 4 continuous maximal voluntary flexion-extension contractions at each speed with 1 minute of rest between the 2 speeds. The first knee flexion and the last knee extension were not recorded. This procedure was chosen to ensure that the test conditions of all recorded contractions would be equal. For ankle testing, the subjects were positioned semi-reclined with the knee in $30^{\circ}$ of flexion and with the back of the seat tilted at an angle of $40^{\circ}$. The test procedure of the ankle was identical to the procedure of the knee. The subjects performed 4 maximal voluntary contractions after the warm-up procedure starting with dorsiflexion, whereas the first dorsiflexion and the last plantarflexion were not recorded. The subjects were instructed to push and pull 'as fast and hard as possible' through the full available ROM at every trial. Full descriptions of the used testing protocol and its reliability with older adults have previously been reported [111].

\section{ETGUG}

The functional test for physical performance includes the ETGUG performance measure. In the ETGUG test, times for the component tasks are measured using a multimemory stopwatch. The ETGUG test is a sensitive and objective assessment of function [120].

\section{Statistical analysis}

All statistical analyses were performed according to the intention-to-treat principle using the group mean method [112]. Means and standard deviations (SD) were calculated for each group and test. The normal distribution of the data was tested with a Kolmogorov-Smirnov test. One-way ANOVAs were used to analyze differences between groups at pre-training testing. Two-way (time $x$ group) repeated-measures ANOVAs were used to test for differences between the three groups over time. In case of a time $x$ group interaction, 
Student's paired-sample $t$-tests were used to detect the significance between pre- and posttraining testing and one-way ANOVAs for percent changes, followed by Bonferroni post hoc tests for multiple comparisons. The percentage change was calculated on individual data as (post - pre-training)/pre-training $\times 100$. Further, one-way ANOVAs, followed by the Bonferroni post hoc tests for the multiple comparisons, were used to determine whether gait parameters differed between the four walking conditions at pre-training testing for all subjects summarized, or whether percent changes within each group differed between the four walking conditions. Statistical significance was set at $p<0.05$. All data were analyzed using Matlab 7.1.

\section{Results}

Four subjects from the FG and seven from the TG dropped out during the training period due to illness, injury and family reasons (not related to the exercise program; figure 1). A summary description of the demographic variables of the groups is presented in table 1 . The CG showed a significantly higher FES-I score compared to the TG at pre- and post-training testing. No significant change in FES-I score occurred in either group. There were no significant differences between the three groups for anthropometric measures, ankle ROM, spatio-temporal gait parameters, muscle power and ETGUG at pre-training.

Table 1

A summary description of the demographic variables of the groups.

\begin{tabular}{|c|c|c|c|c|c|}
\hline & & $\begin{array}{l}\text { Foot gymnastic group } \\
\quad(\text { Mean } \pm \text { SD) }\end{array}$ & $\begin{array}{l}\text { Training group } \\
\text { (Mean } \pm S D)\end{array}$ & $\begin{array}{c}\text { Control group } \\
\text { (Mean } \pm \mathrm{SD} \text { ) }\end{array}$ & $p$ \\
\hline \multirow[t]{3}{*}{$\mathrm{N}$} & Total & 28 & 28 & 14 & \\
\hline & Women & 18 & 17 & 10 & \\
\hline & Men & 10 & 11 & 4 & \\
\hline \multicolumn{2}{|c|}{ Age (years) } & $75.9 \pm 5.5$ & $75.9 \pm 5.4$ & $76.0 \pm 6.0$ & 0.996 \\
\hline \multicolumn{2}{|c|}{ Weight (kg) } & $68.8 \pm 13.3$ & $69.3 \pm 15.6$ & $69.1 \pm 11.7$ & 0.992 \\
\hline \multicolumn{2}{|c|}{ Height (m) } & $1.7 \pm 0.1$ & $1.7 \pm 0.1$ & $1.7 \pm 0.1$ & 0.922 \\
\hline \multicolumn{2}{|c|}{ BMI $\left(\mathrm{kg} / \mathrm{m}^{2}\right)$} & $24.6 \pm 4.3$ & $24.8 \pm 3.6$ & $25.1 \pm 3.3$ & 0.897 \\
\hline \multicolumn{2}{|c|}{ FES-I (pre-training) } & $18.8 \pm 3.3$ & $17.7 \pm 1.8^{*}$ & $21.5 \pm 5.6^{*}$ & 0.004 \\
\hline \multicolumn{2}{|c|}{ FES-I (post-training) } & $18.5 \pm 2.8$ & $17.3 \pm 1.4^{*}$ & $21.4 \pm 5.8^{*}$ & 0.001 \\
\hline
\end{tabular}

Abbreviations: BMI, Body Mass Index; FES-I, Falls Efficacy Scale - International Version; pre, pre-training; post, posttraining.

* Significant differences between training group and control group calculated from one-way ANOVAs $(p<0.05)$ 


\section{Compliance}

All subjects from the FG and TG completed 24 training sessions within 16 training weeks. Three subjects from the FG performed the foot gymnastics home-program daily, eleven between 2 and 3 times per week and ten never.

\section{Ankle ROM}

Table 2 presents means, SDs and $p$-values from paired $t$-tests within each group and from the two-way repeated-measures ANOVAs for time $x$ group interactions for ankle ROM, ETGUG and muscle power measurements. There was no significant time $x$ group interaction for ankle ROM between the FG and TG. However, when the paired $t$-tests were used on preand post-training data within each group separately, the FG showed a significant improvement.

\section{Gait parameters}

At pre-training and for all subjects summarized, significant differences between the four walking conditions were identified for all gait parameters, except for step length (walking speed: $F(3,256)=8.47, p=0.000$, cadence: $F(3,256)=10.01, p=0.000$, step duration: $F(3,256)=10.30, p=0.000$, step length: $F(3,256)=2.68, p=0.051)$. Walking speed and cadence were significantly decreased and step duration was significantly increased in dualtask walking compared to normal walking on both surfaces $(p<0.05)$. No significant differences were detected between the two surfaces.

There were significant time $x$ group interactions mainly in walking speed and step length (table 3). The FG and TG did not differ significantly in their improvements. When the paired $t-$ tests were used on pre- and post-training data in each group separately, the FG and TG showed some significant improvements, whereas the CG showed rather a trend to deterioration. But the changes were not statistically significant in this group. The percent changes between pre- and post-training are illustrated in figure 2. The positive effects ranged between $1 \%$ and $11 \%$ and between $2 \%$ and $12 \%$ for the $F G$ and TG, respectively. The CG showed a trend to deteriorations between $0 \%$ and $-6 \%$. There were no significant differences for percent changes between the four walking conditions within each group; implying that all walking conditions showed similar percent changes. 


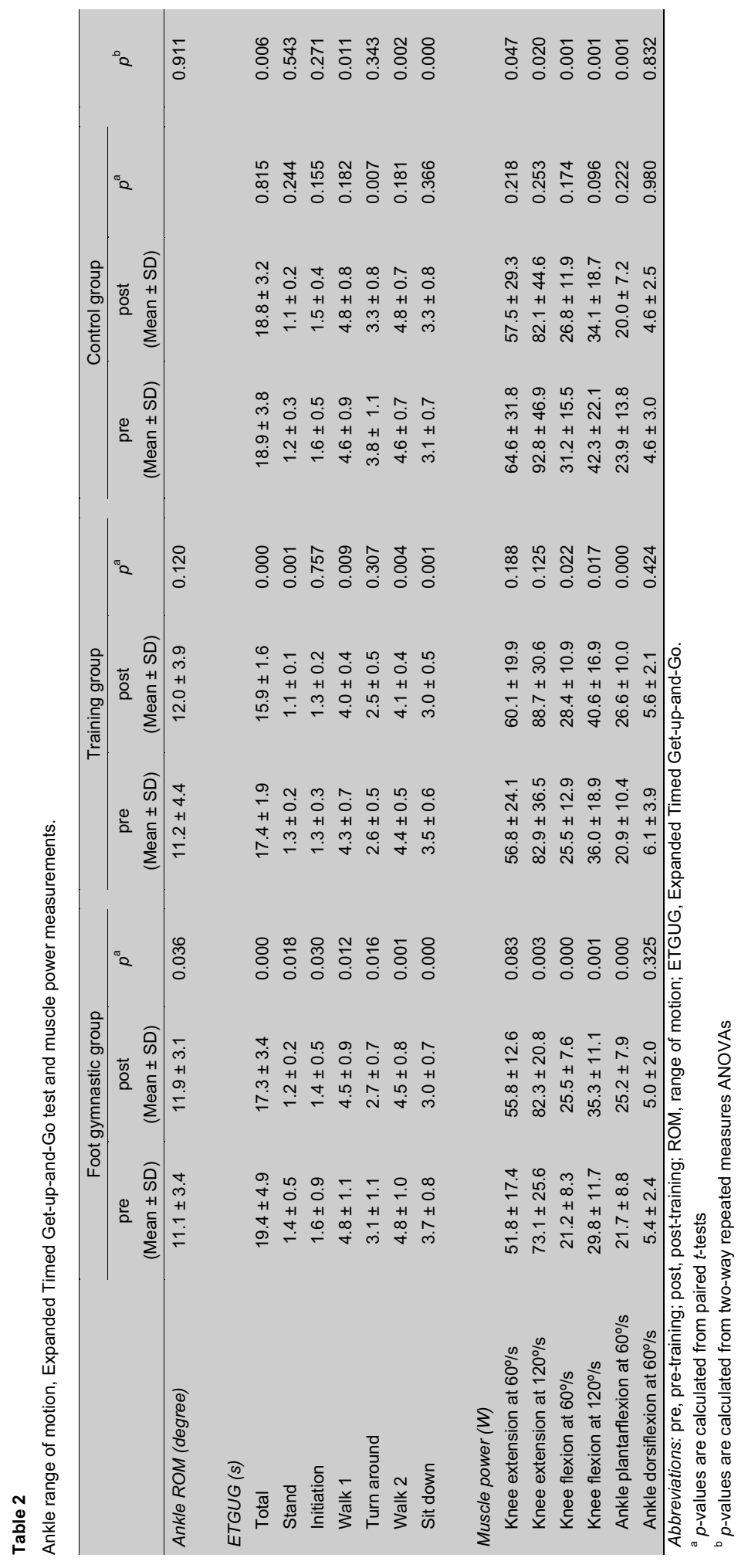




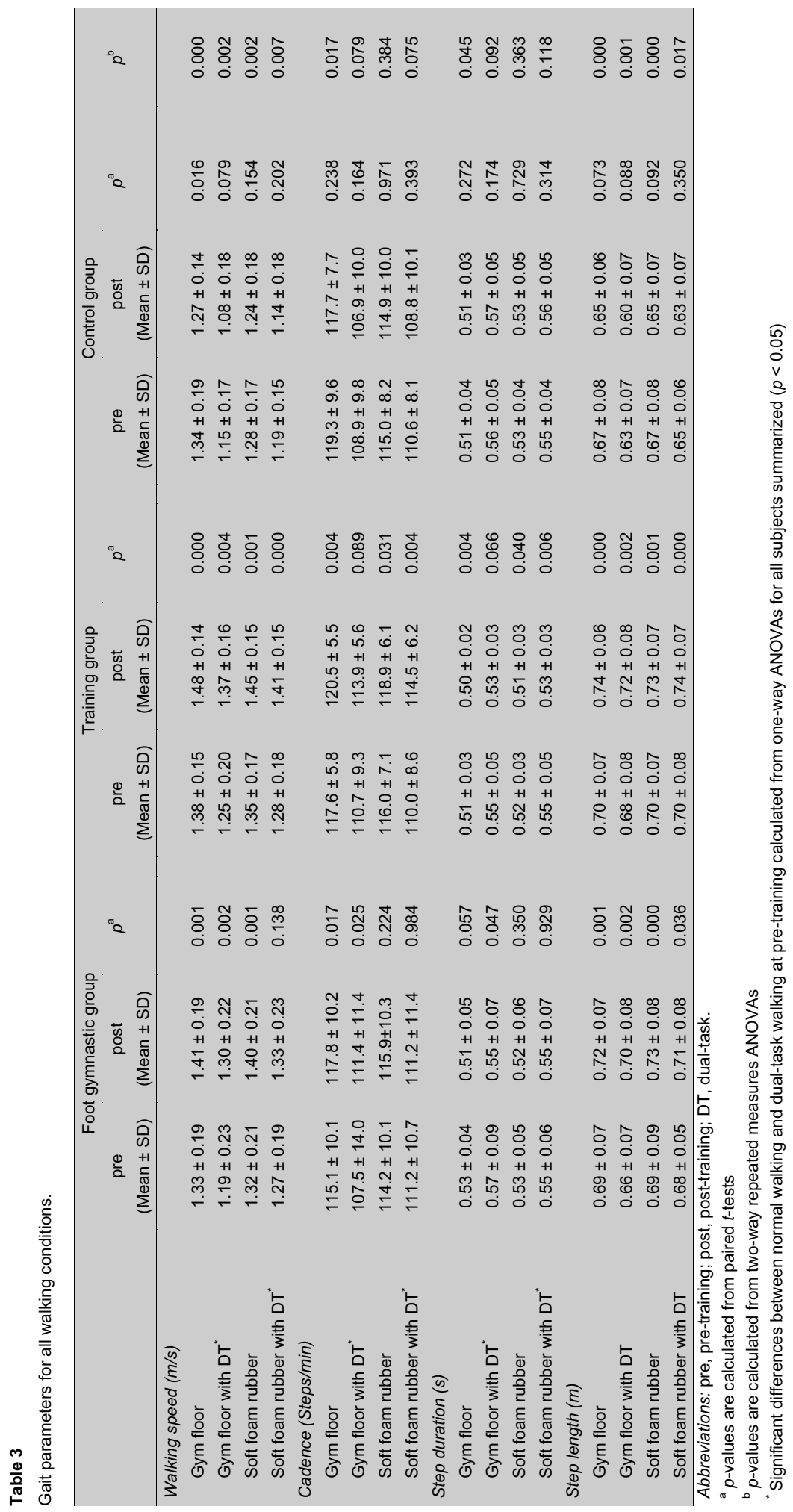




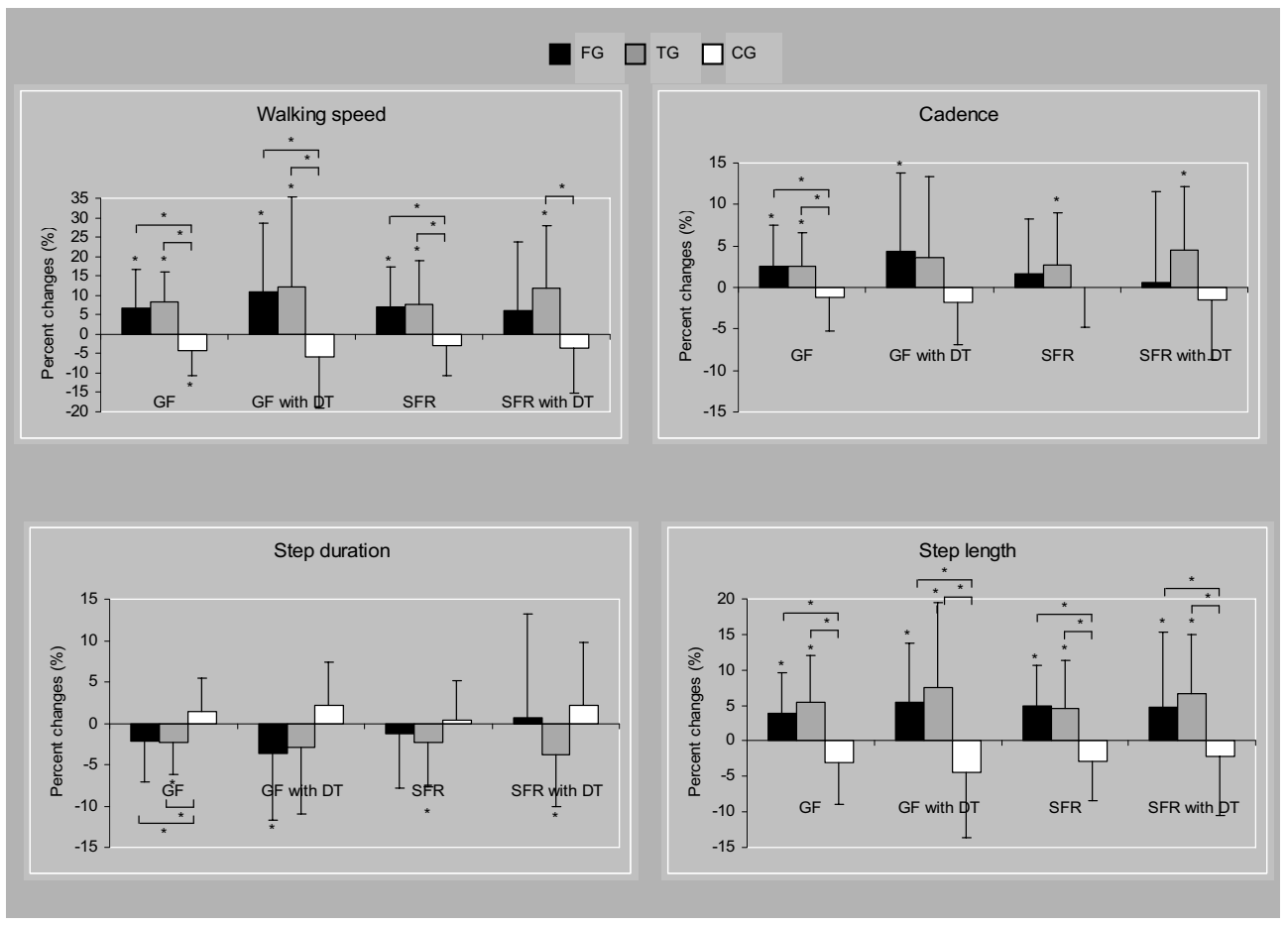

Figure 2

Percent changes of gait parameters.

Abbreviations: FG, foot gymnastic group; TG, training group; CG, control group; GF, gym floor; DT, dual-task; SFR, soft foam rubber.

* Significant change $(p<0.05)$ as compared with pre-training testing and between groups, respectively.

\section{Muscle power measurements}

Similar to the results of gait analysis, there were significant time $x$ group interactions in muscle power except for ankle dorsiflexion (table 2). The FG and TG did not differ significantly in their improvements. When the paired $t$-test was used on pre- and post-training data within each group separately, the FG and TG showed significant improvements, whereas the CG showed rather a trend to deterioration, however, the change was not big enough to reach the level of significance. Except for ankle dorsiflexion, the improvements of power measurements ranged between $14 \%$ and $34 \%$ and $14 \%$ and $46 \%$ for the FG and TG, respectively and the trend to deteriorations between $-4 \%$ and $-14 \%$ for the $C G$, however, again not significant (figure 3 ). 


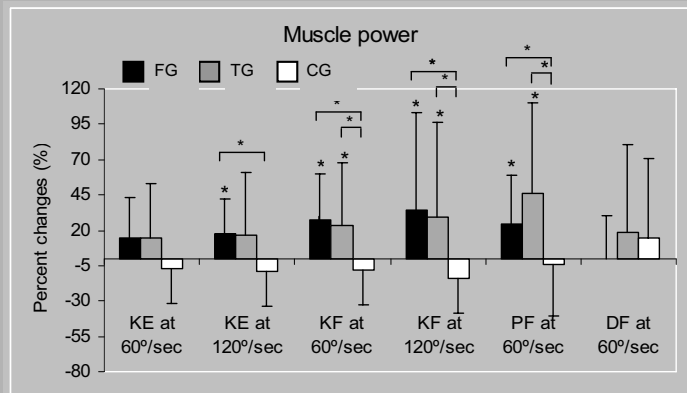

Figure 3

Percent changes of muscle power.

Abbreviations: FG, foot gymnastic group; TG, training group; CG, control group; KE, knee extension; KF, knee flexion; PF, ankle plantarflexion; DF, ankle dorsiflexion.

* Significant change $(p<0.05)$ as compared with pre-training testing and between groups, respectively.

\section{ETGUG}

There were significant time $\times$ group interactions in the ETGUG (total) and in the components 'Walk 1', 'Walk 2' and 'Sit'. FG and TG did not differ significantly in their improvements. The FG significantly improved in all components of the ETGUG, whereas the TG showed no changes in the components 'Gait Initiation' and 'Turn around' when the paired $t$-test was used. The percent decreases in time needed to perform the test were $10 \%$ and $8 \%$ for the FG and TG, and $0 \%$ for $C G$.

\section{Discussion}

This study set out to determine the additional effects of specific foot gymnastic exercises that are combined with more traditional forms of lower extremity strength training on the gait performance in older adults. The primary finding of this study was that the strength, balance and gait training in itself resulted in improvements in gait parameters, muscle power and ETGUG compared to the CG in independent living, older adults. Complementary foot gymnastics that intended to strengthen the muscles of the feet and increase the ankle joint ROM had no additional effects on these parameters. 


\section{The effect of foot gymnastics}

Even though the FG increased ankle ROM significantly, there was no significant time $x$ group interaction between FG and TG. Further, the FG and TG did not differ significantly in their improvements on gait performance, muscle power and ETGUG, indicating that foot gymnastic exercises had no additional effects in this population. A possible explanation for this finding might be that the subjects did not comply with the foot gymnastics homeprogram. The results remained similar, however, when the data were analysed according to a per-protocol analysis. From this study it is not clear whether foot gymnastic exercises had any training effects to the toe muscle strength and how the conventional training program affected the ankle ROM compared to the CG.

\section{The effect of training on FES-I}

The training program had no effect on fear of falling, possibly because of the low pre-training FES-I scores of the subjects, which caused floor effects for this assessment. These results are consistent with other studies that showed only beneficial effects on fear of falling after a training program in fearful persons $[113,114]$.

\section{The effect of training on gait parameters}

Previous exercise interventions to improve gait performance in older adults have shown to be effective, with the limitation that most investigations focused mainly on level ground walking under a single task condition $[47,115,116]$. It has been shown that cognitive tasks have a destabilizing effect on gait in older adults [19-21]. Consistent with these studies, a comparison between the four different walking conditions showed that the subjects significantly changed the gait pattern in dual-task walking on both surfaces at pre-training testing, except for step length. Further, the results showed associations of improvemens in all gait parameters with training in itself compared to the CG, but the time $x$ group interactions were not statistically significant in either case. Our results might be due to the relative short training period of 12 weeks and to the relative healthy status of our participants.

Even though gait variability has been reported with increasing frequency in the gait literature, and this parameter has been shown to be an important fall risk factor $[18,19]$, we intended not to report this parameter because of the moderate to low reliability [110] and validity [100] of this variable measured by DynaPort ${ }^{\circledR \text { MiniMod }}$. We are confident that the FG and TG gained real improvements in the reported gait parameters, because the percent changes of the values are higher than the measurement error of our measurement protocol $[100,110]$. 


\section{The effect of training on muscle power}

Research has consistently demonstrated that muscle strength and power increases after progressive resistance strength training in older adults $[3,55,117]$. However, there are only few intervention studies with similar muscle power outputs. Muscle power gains for knee extension at $60 \%$ and $120 \%$ s (14\% to $18 \%$ versus $24 \%$ ) in the present study were lower, and those for ankle plantarflexion at $60 \%$ similar (24\% to $46 \%$ versus $33 \%$ ), compared to those reported in older men after 16 weeks of progressive resistance training [55]. Symons et al. [117] reported muscle power gains for knee extension at $90 \%$ of $21 \%$ to $52 \%$ following resistance training at various intensities over 12 weeks. Differences in the mode, intensity and frequency of the exercise or in the contents of the test protocols used in different studies may also explain these inconsistencies. The training program gained also real improvement in muscle power, since the percent changes were higher than the measurement error for the used measurement protocol [111].

\section{The effect of training on ETGUG}

To our knowledge, no study has assessed the ETGUG after a similar training program in older adults. The significant time $x$ group interaction in the ETGUG with significant decreases in time between $10 \%$ and $8 \%$ for the $F G$ and TG, respectively is consistent with another study, which reported $15 \%$ decreases in the time taken to perform a similar test, namely the Timed Get-up-and-Go test, after a progressive strength training program over 14 weeks in older adults [121]. However, the significant time $x$ group interaction is caused mainly by the walking components, which is equivalent to the results of increased walking speed with training from the gait analysis.

\section{Limitations of the study}

Our study has several limitations. First, our subjects were a group of relatively healthy independent living, older adults, and consequently, these results can not be generalized to frail persons or persons with foot conditions. Second, a substantial number of participants did not comply with the foot gymnastics home-program. Third, we did not measure the foot gymnastics effect to the toe muscle strength and the ankle ROM of the control group. And lastly, testers were not blinded to the group status of the subjects. Further study should involve less healthy populations of older adults with foot symptoms. 


\section{Conclusion}

The findings from the present study provide evidence of significant improvements in physical performance related to muscle power and walking abilities after a conventional strength and coordination training program in independent living, older adults. There is no additional effect on physical performance after foot gymnastic exercises.

\section{Acknowledgments}

The authors wish to thank all the subjects who participated in the study and the student apprentices who supervised the training sessions. Thanks are also due to Marlies Dorfschmid who conducted the training program. We also wish to thank the Stiftung Diakoniewerk Neumunster - Schweizerischen Pflegerinnenschule and Hatt-Bucher-Stiftung for their financial support. We gratefully acknowledge the support of PROXOMED for providing the training and test materials for this study. 



\section{Chapter 7}

Effectiveness of a training program to reduce falls and fall-related injuries during a 12-month follow-up period in older adults 


\section{Abstract}

Background: A fall can endanger the independence and quality of life in older adults. Physical exercise not only enhances population health, but may also modify some of the strongest risk factors and thus bring about a decrease in falls in older adults.

Objective: The aim of this study was to determine whether there was a reduction in the rates of falls and fall-related injuries among the subjects who performed a conventional training program, compared to a control group, during a 12-month follow-up period.

Methods: Subjects were divided into two groups: subjects with training (TG; $n=50$ ) or subjects without training (CG; $n=24$ ). The training program consisted of aerobic exercises, progressive resistance strength training and stretching exercises twice per week for 12 weeks. The primary outcomes were rates of falls and fall-related injuries over a 12-month follow-up period.

Results: There were no significant differences between the two groups for rates of falls and fall-related injuries during the 12-month follow-up period. $18 \%$ of the TG and $26 \%$ of the CG fell more than once. $12 \%$ of the TG reported a serious injury resulting in a suture $(n=2)$, a fracture of the hip $(n=1)$, of a rib $(n=2)$ and of the humerus $(n=1)$. On the other hand, only one subject $(4 \%)$ of the $C G$ reported a suture.

Conclusions: This conventional training program did not prevent falls compared to the CG in independent living, older adults, although the training program significantly diminished some of the strongest risk factors for falls. 


\section{Introduction}

A fall can endanger mobility, physical performance and health in older adults and, consequently, their independence and quality of life [5]. Falls become one of the major problems of older adults and care services for the aged. Between $30 \%$ to more than $50 \%$ of the population aged 65 years and over fall each year. Of those who fall, $50 \%$ do so repeatedly [6-9]. Common fall-related consequences include injuries, decreased mobility or physical performance, loss of independence, increased health care utilization and mortality [5-8]. Up to $10 \%$ of falls result in serious injuries such as hip fractures, subdural hematoma, serious soft tissue injuries and head injuries, with hip fractures being associated with the highest morbidity and mortality [6-10]. $90 \%$ of hip fractures result from a fall [8]. In addition to injury, falls can also have psychological and social consequences. Fear of falling and avoidance of activities due to fear of falling are well-recognized negative consequences of falls [6]. Therefore, a priority area for promotion of health in aging is the prevention of falls and fall-related injuries.

Several studies have shown that the risk of falling increases dramatically as the number of risk factors increases, such as postural hypotension, the use of multiple medications, impairments in balance, gait, strength, range of motion, foot problems, cognition and vision. The percentage of older people falling increased from $10 \%$ to $30 \%$ for those with no or one risk factor to $70 \%$ to $80 \%$ for those with four or more risk factors $[6,40]$. Physical exercise not only enhances population health, but may also modify some of the strongest risk factors and bring about a decrease in falls in older adults [3,5,41,42].

This study was designed to determine whether there was a reduction in the rates of falls and fall-related injuries among subjects who performed a conventional training program, compared to a control group with no training, during a 12-month follow-up period. The designs and short-term results have been published elsewhere [122,123].

\section{Methods}

\section{Subjects}

Subjects who completed the 12-month follow-up up to October 2008 described in Hartmann et al. [122,123] were summarized and divided into two groups: subjects with 12 weeks training (TG; $n=50$ ) or subjects without training (CG; $n=24)$. 


\section{Methods}

Falls and fall-related injuries were recorded over a 12-month follow-up period following the training program. A fall was defined as 'an unexpected event in which the participants come to rest on the ground, floor, or lower level' [4]. Subjects recorded their falls prospectively using fall protocols, and posted monthly fall calendars to the research team. The fall protocol recorded the circumstances and consequences of the fall, including injury and doctor attendance or hospital admission. Injuries as a result of a fall were classified as serious (a fracture, suture, hospital admission) or moderate (bruising, sprains, cuts, abrasions, seeking medical attention, or a decrease in physical performance for a period of 3 days or more) [124]. Subjects not returning the fall protocols were contacted by telephone within a month to ask about falls.

Secondary outcome measures were assessed at baseline and included anthropometric measurements and fear of falling (Falls Efficacy Scale - International (FES-I) German Version).

\section{Training program}

The training program consisted of aerobic exercises, progressive resistance strength training and stretching exercises twice per week for 12 weeks, as described in Hartmann et al. $[122,123]$. These subjects started using the fall protocols after the post-training measurements during the 12-month follow-up period. $75 \%$ of these subjects continued the training program at least once per week. A further $5 \%$ attended another strength training program during the 12-month follow-up period.

No active intervention was prescribed for the CG during the 12-month follow-up period.

\section{Statistical analysis}

All statistical analyses were performed according to the intention-to-treat principle using the group mean method. Baseline characteristics of the TG and CG were analyzed using descriptive statistics. Student's unpaired-sample $t$-tests and Pearson's chi-square test were used to analyze differences between the two groups. All statistical analyses were performed using Matlab 7.1. 


\section{Results}

Five subjects from the TG dropped out during the 12-month follow-up period due to moving to another geographic area and death. A summary description of the demographic variables of the groups is presented in table 1. The CG showed a significantly lower age, a significantly higher FES-I score and a significantly higher number of subjects reporting at least one fall in the previous 6 months compared to the TG at baseline.

Table 1

A summary description of the demographic variables of the groups.

\begin{tabular}{|c|c|c|c|}
\hline & $\begin{array}{l}\text { Training group } \\
\qquad(\mathrm{n}=50)\end{array}$ & $\begin{array}{l}\text { Control group } \\
\qquad(n=23)\end{array}$ & $p$ \\
\hline Women, $\mathrm{n}(\%)^{\mathrm{a}}$ & $34(68 \%)$ & $18(78 \%)$ & 0.368 \\
\hline Age, mean $\pm S D^{b}$ & $76.5 \pm 5.4$ & $72.2 \pm 6.3$ & 0.004 \\
\hline Weight $(\mathrm{kg})$, mean $\pm \mathrm{SD}^{\mathrm{b}}$ & $67.3 \pm 12.2$ & $66.6 \pm 12.9$ & 0.815 \\
\hline Height $(m)$, mean $\pm S D^{b}$ & $1.66 \pm 0.10$ & $1.64 \pm 0.08$ & 0.297 \\
\hline BMI $\left(\mathrm{kg} / \mathrm{m}^{2}\right)$, mean $\pm \mathrm{SD}^{\mathrm{b}}$ & $24.4 \pm 3.5$ & $24.8 \pm 4.2$ & 0.624 \\
\hline FES-I, mean $\pm S^{b}$ & $18.0 \pm 2.2$ & $19.3 \pm 2.8$ & 0.041 \\
\hline \multicolumn{4}{|c|}{ Fall history in the previous 6 months ${ }^{\text {a }}$} \\
\hline$\geq 1, \mathrm{n}(\%)$ & $12(24 \%)$ & $12(52 \%)$ & 0.017 \\
\hline$\geq 2, \mathrm{n}(\%)$ & $4(8 \%)$ & $4(17 \%)$ & 0.234 \\
\hline
\end{tabular}

Abbreviations: BMI, Body Mass Index; FES-I, Falls Efficacy Scale - International Version

a $p$-values are calculated from Pearson's chi-square test

${ }^{\mathrm{b}} p$-values are calculated from paired $t$-tests

Table 2 presents the incidence of falls during the 12-month follow-up period. Using Pearson's chi-square test, there were no significant differences between the two groups for rates of falls and fall-related injuries during the 12-month follow-up period. $18 \%$ of the TG and $26 \%$ of the CG fell more than once. $12 \%$ of the TG reported a serious injury resulting in a suture $(n=2)$, a fracture of the hip $(n=1)$, of a rib $(n=2)$ and of the humerus $(n=1)$. On the other hand, only one subject $(4 \%)$ of the CG reported a suture. 
Table 2

Incidence of falls during the 12-month follow-up period.

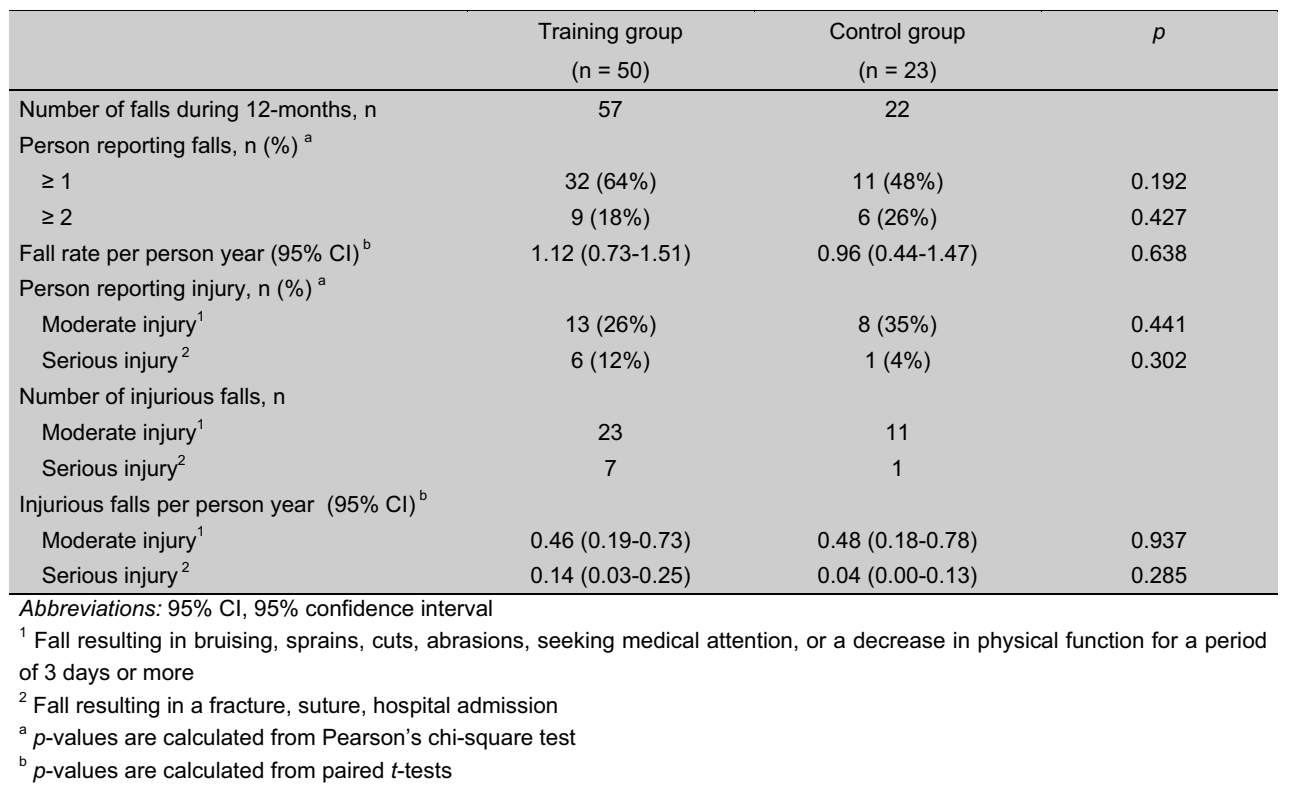

\section{Discussion}

The conventional training program was not effective in reducing falls and fall-related injuries during the 12-month follow-up period in independent living, older adults, although the training program resulted in significant improvements in gait performance, muscle power and Expanded Timed Get-up-and-Go test, compared to subjects without training as shown in Chapters 5 and 6. Also, a significantly higher number of subjects with a history of falls in the previous 6 months and a significantly higher FES-I score at baseline for the CG did not result in higher rates of falls and fall-related injuries.

For all summarized subjects, the number of fallers at $59 \%$, with recurrent fallers at $21 \%$ and the number of serious injuries at $11 \%$ were similar to other studies which reported $47 \%$ to $52 \%, 19 \%$ to $23 \%$ and $10 \%$ in their study of falls in subjects over 65 years, respectively [6-9].

Close et al. [5] concluded in their systematic review that both single and multifactorial interventions have been shown to be effective to reduce falls and fall-related injuries in community-dwelling elderly, whilst a multifactorial intervention seems to be required for inpatients and care-home residents. Exercise in the form of strength and balance training is effective in a variety of populations and settings, whereas high-risk subjects are most likely to 
benefit from these interventions [5]. The included single intervention studies recruited community-dwelling elderly with a mean age between 75 and 84 years and sample sizes ranged from 163 to more than 500 subjects. Using a power analysis for the chi-square test calculating rates of falls and fall-related injuries, the power in the current study ranged between $12 \%$ and $26 \%$, meaning that the probability of a Type II error was high and that not enough subjects were included. Therefore, differences in the sample size and in the subject characteristics in contrast to the current study, which included relatively healthy independent living, older adults with a mean age of 75 years, may explain these inconsistencies. Further, the subjects of the CG in the current study were significantly younger than the subjects of the TG. Possibly, the significantly lower mean age of the CG may have resulted in a lower fall risk and may have strongly affected the rate of falls and fall-related injuries during the 12month follow-up period. On the other hand, the time spent in physical activities may generally increase as the level of physical performance increases. Since the TG significantly improved their physical performance after the training period, it can be hypothesized that these subjects exposed themselves for a longer period of time to physical activities. This in turn may result in a higher risk of falling during everyday activities, which may explain the observed similar rate of falls.

Our study has several limitations. First, the subjects were not randomized and bias can, therefore, not be excluded. Second, we did not measure the physical performance of the CG at baseline and therefore we cannot assess whether both groups were comparable in this context. Further studies should involve larger sample sizes resulting in higher testing power, measurements of physical performance at baseline and reports of time spent in physical activities during the 12-month follow-up period. This would enable the detection of potential connections between a higher level of physical performance, increased time spent in physical activities, and rate of falls.

\section{Conclusion}

The conventional training program did not significantly prevent falls compared to a nonmatched CG of independent living, older adults, although the training program significantly diminished some of the strongest risk factors for falls. 



\section{Chapter 8}

\section{General discussion}


Chapter 8 


\section{Introduction}

The primary public health goal is to increase the number of years of good health, and therefore to maintain independence and quality of life as long as possible. However, a fall can endanger mobility, physical performance and health of the elderly and is one of the major problems in older adults and care services for the aged. Since the risk of falling increases dramatically as the number of risk factors increases [6,40], the goal of fall prevention is to modify some of the strongest risk factors through, for example, physical exercise. Physical exercise is one of the most important intervention strategies that can significantly improve physical performance, contributing to the maintenance of independence and quality of life, and has the strongest evidence to minimize or eliminate some of the strongest fall risk factors, such as impairments in balance, gait, strength and range of motion $[3,16,25,43,44]$.

Several studies with a focus on fall prevention were performed in this thesis. In this last chapter an overview and discussion with respect to the main findings and limitations of these studies, as well as implications for practice and future research are provided. To complete this thesis some personal opinions and conclusions have also been included.

\section{Main findings}

\section{Assessments}

The prerequisites for an objective measurement device are validity and reliability [69]. In Chapter 2 we investigated the reliability of an isokinetic strength-testing protocol of the knee and ankle in older adults. The results showed that the Biodex System 3 is a reliable device when used for independent living, older adults. The relative reliabilities for muscle power for knee extension and flexion and ankle dorsiflexion and plantarflexion were 'very good' (ICCs between 0.81 and 0.98 ). The results of absolute reliabilities were partly satisfactory. The standard error of measurement and ratio of limits of agreement for knee extension and flexion and ankle dorsiflexion represented acceptable agreement (SEMs between 6\% and $13 \%$, RLOAs between $18 \%$ and $37 \%$ ). No acceptable agreement was found for ankle plantarflexion (SEMs between $14 \%$ and $17 \%$, RLOAs between $39 \%$ and $48 \%$ ). 
In Chapters 3 and 4 the validity and the reliability of the gait analysis using the DynaPort ${ }^{\circledR \text { MiniMod, }}$, a trunk tri-axial accelerometer system, were determined. The results demonstrated that the DynaPort ${ }^{\circledR M i n i M o d}$ system is a highly valid tool for assessment of the most important spatio-temporal gait parameters for averaged step data across a walking length of approximately $20 \mathrm{~m}$ and that walking speed, cadence, step duration and step length under different walking conditions can be reliably measured in independent living, older adults. However, gait variability needs to be viewed with caution because of the moderate to low validity and reliability.

\section{Intervention studies}

The main objectives of the two intervention studies were to evaluate the effects of stimulation of different foot structures and functions, combined with conventional training, on physical performance and fear of falling. The primary findings of Chapters 5 and 6 were that the conventional training program in itself resulted in significant improvements in gait performance, muscle power and Expanded Timed Get-up-and-Go test compared to the control group in independent living, older adults. The training program had, however, no effect on self-perceived fear of falling, possibly because of the low pre-training Falls Efficacy Scale of the subjects, which caused floor effects for this assessment. Neither wearing insoles during everyday life and during training sessions nor foot gymnastic exercises integrated in conventional training had additional effects on physical performance. Possible explanations for these findings might be that the subjects did not fully comply with wearing the insoles or with the foot gymnastic home-program. Some subjects only wore the insoles in their indoor shoes or slippers and not in their outdoor shoes. It can be assumed that indoor activities are performed mostly while sitting and not while standing or walking and therefore, the insoles had no stimulation effect. Further, the relatively short duration of the study periods may not be sufficient to show an adaption of gait.

The primary goal of fall prevention is to decrease the number of falls and to prevent fallrelated injuries. In Chapter 7 the effectiveness of the training program to reduce falls and fallrelated injuries during the 12-month follow-up period in older adults was determined. The training program was not effective in reducing falls and fall-related injuries, although the training program resulted in significant improvements in physical performance compared to subjects without training. Possible explanations of these findings may be potential bias because of the non-randomization of the subjects, the small sample size resulting in low testing power (Type II error), the significantly younger age of the control group at baseline or the significantly improved physical performance after the training period of the subjects with 
training, which may result in a longer time spent exposed to a higher risk of falling during everyday life that consequently leads to a higher rate of falls.

\section{Limitations of the studies}

\section{Subjects}

There is a potential bias in using a volunteer sample, as it may not accurately represent the older adult population at large. Robust people may have been more likely than frail ones to volunteer for participation in physical intervention studies. Our subjects were a group of relatively healthy, independent living, older adults with normal age-related changes of foot structures and functions. Consequently, these results cannot be generalized to frail older people or people with specific foot symptoms. This must be considered when comparing the results of the present studies with others. Further studies should involve less healthy populations of older adults with specific foot symptoms, who would probably benefit more from such stimulation of foot structures and functions and a training program.

\section{Main outcome measures}

A major challenge is to determine the best outcome measures. For technical reasons, we did not measure the effect of the insoles to the proprioceptive and tactile receptors and $\alpha$ motoneuron activities, or the effect of the foot gymnastics to the toe muscle strength. Therefore, it is not clear whether the insoles and the foot gymnastic exercises had any stimulating effects on the corresponding foot structures or whether the stimulating effects were not sufficient to improve physical performance. Measurements of muscle activities of the lower limbs would give more information about the effect of the stimulations on $\alpha$ motoneuron activities.

The informative value of improvements in gait performance, muscle power and Expanded Timed Get-up-and-Go test in a gym environment for mobility, physical performance or quality of life in older adults is questionable. First, such performance-based measures of physical function have the disadvantage that performance at the time of assessment may not represent the usual performance of the tested individual [125]. Second, a training program was considered to be successful when the participations became noticeably more mobile, were able to continue performing daily tasks better than previously and without the need for assistance (e.g. shopping or carrying out a recreational activity of their choice) or there was a reduction in the rates of falls and fall-related injuries [16]. Disability in mobility and in performing daily tasks are usually assessed with self-reports $[89,126]$. However, the reliability 
of these methods in older individuals seems questionable $[89,127]$. Therefore, valid outcome measures that allow long-term monitoring of activity patterns such as postural transitions or time spent in certain activities in their habitual environment might be more informative.

Currently available literature does not provide a wealth of information on long-term monitoring of movements in subjects older than 65 years. There are few feasible methods available for long-term monitoring of activity patterns and gait in older people, such as pedometers, accelerometer or estimator of energy expenditure [89]. In the last few years, accelerometer-based gait analysis systems have been proposed for ambulatory gait assessment [80-88]. The DynaPort ${ }^{\circledR \text { MiniMod }}$ used in this thesis has been identified as a valid instrument to detect differences in spatio-temporal gait parameters in different populations $[84-86,100]$ in a protected environment. However, the application area of this measurement system is not only restricted to detect spatio-temporal gait parameters. We suppose that this system has the potential to allow long-term monitoring of activity patterns such as postural transitions or time spent in certain activities in participants' habitual or outdoor environment and will become increasingly important. However, data collection methods and algorithms for data analysis are still in need of further development.

The Prevention of Falls Network Europe (ProFaNE) recommends explicitly focusing on falls as a primary outcome measure in trials that intend to reduce falls in older adults. ProFaNE is a thematic network group of health care practitioners, researchers and public health specialists dedicated to the prevention of falls in Europe and beyond (http://www.profane.eu.org). One of the network's aims is to identify major gaps in knowledge in fall injury prevention. ProFaNE has developed a common set of outcome definitions and measures for future trials. Falls should be recorded using prospective daily recording and a notification system with a minimum of monthly reporting. Fall data should be summarized as number of falls, number of fallers/nonfallers/frequent fallers, fall rate per person year, and time to first fall (as a safety measure) [4]. Future research with similar populations to those used in this thesis should consider these outcomes. This implies, however, that larger samples are needed, because the power needed to test significant differences between exercise and non-exercise groups is lower than $30 \%$

\section{Training strategies}

The subjects in the reported studies did not comply with wearing the insoles continuously and with the foot gymnastics home-program. The insoles had to be transferred from one pair of shoes to another and some subjects only wore the insoles in their indoor shoes or slippers. Several pairs of insoles for each individual would eventually solve this problem. 
To motivate the subjects to consistently perform a home-program is a big challenge. Instruction in the functional relevance of the exercises may play a significant role for complying with such a home-program. More attention to this aspect would possibly be beneficial.

\section{Implications for practice}

The acceptance of a conventional training program that was extended with additional elements was generally high in this independent living population. In the two intervention studies, $15 \%$ of the subjects dropped out due to illness, injury or for family reasons. Reasons for drop out were not related to the training program. Only $4 \%$ of the subjects dropped out for family reasons, but this was not researched in more detail and may have been related to the training program. Another indication of the high program acceptance is that $75 \%$ of the subjects who completed the study continued the training program at least once per week. A further $5 \%$ attended other kinds of strength training activities.

In my opinion it does not require much effort to arrange training opportunities for older adults and there are various possible options: e.g. the provision within a community of a training room equipped with the most essential training equipment; the organisation of training classes in a gym during off-peak hours, etc. However, social interaction and enjoyment in a regular exercise class may play a significant role for long-term exercise participation by older adults [128]. Therefore, training opportunities for older adults should be organized as a group activity among like-minded people.

\section{Future research}

First, the validity and the reproducibility of the gait analysis using the DynaPort ${ }^{\circledR M i n i M o d}$ in a more frail population should be determined.

Second, data collection methods and algorithms for data analysis for long-term monitoring of activity patterns in participants' habitual or outdoor environment to quantify mobility, physical performance or quality of life should be developed.

Third, the isokinetic strength-testing protocol for muscle power outcome was reliable, however, the testing procedure is time-consuming and, maybe, not feasible for large sample 
sizes in clinical settings. Simpler and user-friendly muscle power testing methods should be developed.

Fourth, further intervention studies should involve a larger sample size and less healthy populations of older adults with specific foot symptoms, who would probably benefit more from stimulation of different foot structures and functions. Additionally, measurements of muscle activities of the lower limb should include detecting possible effects on the corresponding foot structures.

\section{Personal opinions and conclusions}

In the last few years a huge amount of different intervention studies in this area of research have been published. The overall message is clear, that strength and power training, balance, mobility and stretching exercises can significantly improve physical performance. There is also evidence that such conventional programs contribute to the maintenance of independence and quality of life and has the strongest evidence base for preventing falls in older adults $[3,16,25,43,44]$. In my opinion the research area about the optimal training program for prevention of falls in healthy, older adults is utilized, except that the training strategy is completely new. In the future, the big challenge for public health will be to persuade the vast majority of adults, not only robust adults, to become more active. It is not useful to know the optimal exercises if the participants interrupt the training after a short term because the intensities are too high or they do not enjoy them. The physical, social and cultural ideals of older adults are quite different. Therefore, training programs that target older adults must accommodate individual needs and abilities and should not focus only on the optimal benefits. Instruction in the functional relevance of physical exercise to maintain independence and quality of life [129] and the social interaction and enjoyment in a regular exercise class [128] may play a significant role for participation by older adults in long-term exercise. Therefore, the public health message for older adults should be to incorporate moderate-intensity physical exercises into their everyday life, and that physical exercises should provide enjoyment and not be a physical torture. 

Chapter 9

References 
Chapter 9 


\section{References}

1. Bundesamt für Statistik. Demografisches Porträt der Schweiz 2007

2. Rowe JW, Kahn RL. Successful aging. Gerontologist 1997;37:433-440

3. Paterson DH, Jones GR, Rice CL. Ageing and physical activity: evidence to develop exercise recommendations for older adults. Can J Public Health 2007;98 Suppl 2:S69-108

4. Lamb SE, Jorstad-Stein EC, Hauer K, Becker C. Development of a common outcome data set for fall injury prevention trials: the Prevention of Falls Network Europe consensus. J Am Geriatr Soc 2005;53:1618-1622

5. Close JC, Lord SL, Menz HB, Sherrington C. What is the role of falls? Best Pract Res Clin Rheumatol 2005;19:913-935

6. Tinetti ME, Speechley M, Ginter SF. Risk factors for falls among elderly persons living in the community. N Engl J Med 1988;319:1701-1707

7. Berg WP, Alessio HM, Mills EM, Tong C. Circumstances and consequences of falls in independent community-dwelling older adults. Age Ageing 1997;26:261-268

8. Tinetti ME, Doucette JT, Claus EB. The contribution of predisposing and situational risk factors to serious fall injuries. J Am Geriatr Soc 1995;43:1207-1213

9. Nitz JC, Choy NL. Falling is not just for older women: support for pre-emptive prevention intervention before 60. Climacteric 2008;11:461-466

10. Tinetti ME, Speechley M. Prevention of falls among the elderly. N Engl J Med 1989;320:1055-1059

11. Menz HB, Morris ME, Lord SR. Foot and ankle characteristics associated with impaired balance and functional ability in older people. J Gerontol A Biol Sci Med Sci 2005;60:1546-1552

12. Lord SR, Ward JA. Age-associated differences in sensori-motor function and balance in community dwelling women. Age Ageing 1994;23:452-460

13. Judge JO, King MB, Whipple R, Clive J, Wolfson LI. Dynamic balance in older persons: effects of reduced visual and proprioceptive input. J Gerontol A Biol Sci Med Sci 1995;50:M263-270

14. Menz HB, Morris ME, Lord SR. Foot and ankle risk factors for falls in older people: a prospective study. J Gerontol A Biol Sci Med Sci 2006;61:866-870

15. Lord SR, Menz HB, Tiedemann A. A physiological profile approach to falls risk assessment and prevention. Phys Ther 2003;83:237-252

16. Frank JS, Patla AE. Balance and mobility challenges in older adults: implications for preserving community mobility. Am J Prev Med 2003;25:157-163 
17. Maki BE. Gait changes in older adults: predictors of falls or indicators of fear. J Am Geriatr Soc 1997;45:313-320

18. Hausdorff JM, Rios DA, Edelberg HK. Gait variability and fall risk in community-living older adults: a 1-year prospective study. Arch Phys Med Rehabil 2001;82:1050-1056

19. Menz HB, Lord SR, Fitzpatrick RC. Age-related differences in walking stability. Age Ageing 2003;32:137-142

20. Hollman JH, Kovash FM, Kubik JJ, Linbo RA. Age-related differences in spatiotemporal markers of gait stability during dual-task walking. Gait Posture 2007;26:113-119

21. van lersel MB, Ribbers H, Munneke M, Borm GF, Rikkert MG. The effect of cognitive dual-tasks on balance during walking in physically fit elderly people. Arch Phys Med Rehabil 2007;88:187-191

22. Zijlstra A, de Bruin ED, Bruins N, Zijlstra W. The step length-frequency relationship in physically active community-dwelling older women. Eur J Appl Physiol 2008

23. Lexell J. Human aging, muscle mass, and fiber type composition. J Gerontol A Biol Sci Med Sci 1995;50 Spec No:11-16

24. Doherty TJ. Invited review: Aging and sarcopenia. J Appl Physiol 2003;95:1717-1727

25. Macaluso A, De Vito G. Muscle strength, power and adaptations to resistance training in older people. Eur J Appl Physiol 2004;91:450-472

26. Bassey EJ, Fiatarone MA, O'Neill EF, et al. Leg extensor power and functional performance in very old men and women. Clin Sci (Lond) 1992;82:321-327

27. Skelton DA, Greig CA, Davies JM, Young A. Strength, power and related functional ability of healthy people aged 65-89 years. Age Ageing 1994;23:371-377

28. Metter EJ, Talbot LA, Schrager M, Conwit RA. Arm-cranking muscle power and arm isometric muscle strength are independent predictors of all-cause mortality in men. $J$ Appl Physiol 2004;96:814-821

29. Skelton DA, Young A, Greig CA, Malbut KE. Effects of resistance training on strength, power, and selected functional abilities of women aged 75 and older. J Am Geriatr Soc 1995;43:1081-1087

30. Skelton DA, Kennedy J, Rutherford OM. Explosive power and asymmetry in leg muscle function in frequent fallers and non-fallers aged over 65. Age Ageing 2002;31:119-125

31. Scott G, Menz HB, Newcombe L. Age-related differences in foot structure and function. Gait Posture 2007;26:68-75

32. Staheli LT, Chew DE, Corbett M. The longitudinal arch. A survey of eight hundred and eighty-two feet in normal children and adults. J Bone Joint Surg Am 1987;69:426428 
33. Nigg BM, Fisher V, Allinger TL, Ronsky JR, Engsberg JR. Range of motion of the foot as a function of age. Foot Ankle 1992;13:336-343

34. Endo M, Ashton-Miller JA, Alexander NB. Effects of age and gender on toe flexor muscle strength. J Gerontol A Biol Sci Med Sci 2002;57:M392-397

35. Menz HB, Zammit GV, Munteanu SE, Scott G. Plantarflexion strength of the toes: age and gender differences and evaluation of a clinical screening test. Foot Ankle Int 2006;27:1103-1108

36. Kenshalo DR, Sr. Somesthetic sensitivity in young and elderly humans. J Gerontol 1986;41:732-742

37. Grimston SK, Nigg BM, Hanley DA, Engsberg JR. Differences in ankle joint complex range of motion as a function of age. Foot Ankle 1993;14:215-222

38. James B, Parker AW. Active and passive mobility of lower limb joints in elderly men and women. Am J Phys Med Rehabil 1989;68:162-167

39. Mecagni C, Smith JP, Roberts KE, O'Sullivan SB. Balance and ankle range of motion in community-dwelling women aged 64 to 87 years: a correlational study. Phys Ther 2000;80:1004-1011

40. Tinetti ME, Williams TF, Mayewski R. Fall risk index for elderly patients based on number of chronic disabilities. Am J Med 1986;80:429-434

41. Gillespie LD, Gillespie WJ, Robertson MC, et al. Interventions for preventing falls in elderly people. Cochrane Database Syst Rev 2003:CD000340

42. Chang JT, Morton SC, Rubenstein LZ, et al. Interventions for the prevention of falls in older adults: systematic review and meta-analysis of randomised clinical trials. Bmj 2004;328:680

43. Connelly DM, Carnahan H, Vandervoort AA. Motor skill learning of concentric and eccentric isokinetic movements in older adults. Exp Aging Res 2000;26:209-228

44. Latham NK, Bennett DA, Stretton CM, Anderson CS. Systematic review of progressive resistance strength training in older adults. J Gerontol A Biol Sci Med Sci 2004;59:48-61

45. Swank AM, Funk DC, Durham MP, Roberts S. Adding weights to stretching exercise increases passive range of motion for healthy elderly. J Strength Cond Res 2003; $17: 374-378$

46. Gajdosik RL, Vander Linden DW, McNair PJ, Williams AK, Riggin TJ. Effects of an eight-week stretching program on the passive-elastic properties and function of the calf muscles of older women. Clin Biomech (Bristol, Avon) 2005;20:973-983

47. Christiansen CL. The effects of hip and ankle stretching on gait function of older people. Arch Phys Med Rehabil 2008;98:1421-1428 
48. Kerrigan DC, Xenopoulos-Oddsson A, Sullivan MJ, Lelas JJ, Riley PO. Effect of a hip flexor-stretching program on gait in the elderly. Arch Phys Med Rehabil 2003;84:1-6

49. Hijmans JM, Geertzen JH, Dijkstra PU, Postema K. A systematic review of the effects of shoes and other ankle or foot appliances on balance in older people and people with peripheral nervous system disorders. Gait Posture 2007;25:316-323

50. Maki BE, Perry SD, Norrie RG, Mcllroy WE. Effect of facilitation of sensation from plantar foot-surface boundaries on postural stabilization in young and older adults. $\mathrm{J}$ Gerontol A Biol Sci Med Sci 1999;54:M281-287

51. Priplata AA, Niemi JB, Harry JD, Lipsitz LA, Collins JJ. Vibrating insoles and balance control in elderly people. Lancet 2003;362:1123-1124

52. Suomi R, Koceja DM. Effect of magnetic insoles on postural sway measures in men and women during a static balance test. Percept Mot Skills 2001;92:469-476

53. Nihal A, Goldstein J, Haas J, et al. Toe flexor forces in dancers and non-dancers. Foot Ankle Int 2002;23:1119-1123

54. Kobayashi R, Hosoda M, Minematsu A, et al. Effects of Toe Grasp Training for the Aged on Spontaneous Postural Sway. Journal of Physical Therapy Science 1999;11:31-34

55. Ferri A, Scaglioni G, Pousson M, et al. Strength and power changes of the human plantar flexors and knee extensors in response to resistance training in old age. Acta Physiol Scand 2003;177:69-78

56. Lexell J, Taylor CC, Sjostrom M. What is the cause of the ageing atrophy? Total number, size and proportion of different fiber types studied in whole vastus lateralis muscle from 15- to 83-year-old men. J Neurol Sci 1988;84:275-294

57. Ordway NR, Hand N, Briggs G, Ploutz-Snyder LL. Reliability of knee and ankle strength measures in an older adult population. J Strength Cond Res 2006;20:82-87

58. Symons TB, Vandervoort AA, Rice CL, Overend TJ, Marsh GD. Reliability of isokinetic and isometric knee-extensor force in older women. J Aging Phys Act 2004;12:525-537

59. Frontera WR, Hughes VA, Dallal GE, Evans WJ. Reliability of isokinetic muscle strength testing in 45- to 78-year-old men and women. Arch Phys Med Rehabil 1993; $74: 1181-1185$

60. Capranica L, Battenti M, Demarie S, Figura F. Reliability of isokinetic knee extension and flexion strength testing in elderly women. J Sports Med Phys Fitness 1998;38:169-176

61. Symons TB, Vandervoort AA, Rice CL, Overend TJ, Marsh GD. Reliability of a singlesession isokinetic and isometric strength measurement protocol in older men. $J$ Gerontol A Biol Sci Med Sci 2005;60:114-119 
62. Morris-Chatta R, Buchner DM, de Lateur BJ, Cress ME, Wagner EH. Isokinetic testing of ankle strength in older adults: assessment of inter-rater reliability and stability of strength over six months. Arch Phys Med Rehabil 1994;75:1213-1216

63. Roebroeck ME, Harlaar J, Lankhorst GJ. The application of generalizability theory to reliability assessment: an illustration using isometric force measurements. Phys Ther 1993;73:386-395; discussion 396-401

64. Flansbjer UB, Holmback AM, Downham D, Lexell J. What change in isokinetic knee muscle strength can be detected in men and women with hemiparesis after stroke? Clin Rehabil 2005;19:514-522

65. Atkinson G, Nevill AM. Statistical methods for assessing measurement error (reliability) in variables relevant to sports medicine. Sports Med 1998;26:217-238

66. Drouin J, Valovich-mcLeod TC, Shultz SJ, Gansneder BM, Perrin DH. Reliability and validity of the Biodex system 3 pro isokinetic dynamometer velocity, torque and position measurements. European Journal of Applied Physiology 2004;91:22-29

67. Sadeghi H, Allard P, Prince F, Labelle H. Symmetry and limb dominance in ablebodied gait: a review. Gait Posture 2000;12:34-45

68. Bland JM, Altman DG. Measuring agreement in method comparison studies. Stat Methods Med Res 1999;8:135-160

69. Portney LG, Watkins MP. Foundations of Clinical Research: Applications to Practice. In. 2 ed. Upper Saddle River, New Jersey 07458: Prentice Hall; 2000:557-586

70. Signorile JF, Carmel MP, Czaja SJ, et al. Differential increases in average isokinetic power by specific muscle groups of older women due to variations in training and testing. J Gerontol A Biol Sci Med Sci 2002;57:M683-690

71. Sole G, Hamren J, Milosavljevic S, Nicholson H, Sullivan SJ. Test-retest reliability of isokinetic knee extension and flexion. Arch Phys Med Rehabil 2007;88:626-631

72. Ploutz-Snyder LL, Giamis EL. Orientation and familiarization to 1RM strength testing in old and young women. J Strength Cond Res 2001;15:519-523

73. Dvir Z. Isokinetics: muscle testing, interpretation and clinical applications. Edinburgh: Churchill Livingstone; 2004

74. Webster KE, Wittwer JE, Feller JA. Validity of the GAITRite walkway system for the measurement of averaged and individual step parameters of gait. Gait Posture 2005;22:317-321

75. Beauchet O, Herrmann FR, Grandjean R, Dubost V, Allali G. Concurrent validity of SMTEC $((R))$ footswitches system for the measurement of temporal gait parameters. Gait Posture 2008;27:156-159 
76. Bilney B, Morris M, Webster K. Concurrent related validity of the GAITRite walkway system for quantification of the spatial and temporal parameters of gait. Gait Posture 2003; $17: 68-74$

77. Menz HB, Latt MD, Tiedemann A, Mun San Kwan M, Lord SR. Reliability of the GAITRite walkway system for the quantification of temporo-spatial parameters of gait in young and older people. Gait Posture 2004;20:20-25

78. Owings TM, Grabiner MD. Measuring step kinematic variability on an instrumented treadmill: how many steps are enough? J Biomech 2003;36:1215-1218

79. Woollacott MH, Tang PF. Balance control during walking in the older adult: research and its implications. Phys Ther 1997;77:646-660

80. Henriksen M, Lund H, Moe-Nilssen R, Bliddal H, Danneskiod-Samsoe B. Test-retest reliability of trunk accelerometric gait analysis. Gait Posture 2004;19:288-297

81. Moe-Nilssen R. Test-retest reliability of trunk accelerometry during standing and walking. Arch Phys Med Rehabil 1998;79:1377-1385

82. Mansfield A, Lyons GM. The use of accelerometry to detect heel contact events for use as a sensor in FES assisted walking. Med Eng Phys 2003;25:879-885

83. Maffiuletti NA, Gorelick M, Kramers-de Quervain I, et al. Concurrent validity and intrasession reliability of the IDEEA accelerometry system for the quantification of spatiotemporal gait parameters. Gait Posture 2008;27:160-163

84. Zijlstra W, Hof AL. Assessment of spatio-temporal gait parameters from trunk accelerations during human walking. Gait Posture 2003;18:1-10

85. Zijlstra W. Assessment of spatio-temporal parameters during unconstrained walking. Eur J Appl Physiol 2004;92:39-44

86. Brandes M, Zijlstra W, Heikens S, van Lummel R, Rosenbaum D. Accelerometry based assessment of gait parameters in children. Gait Posture 2006;24:482-486

87. Lord S, Rochester L, Baker K, Nieuwboer A. Concurrent validity of accelerometry to measure gait in Parkinsons Disease. Gait Posture 2008;27:357-359

88. Kavanagh JJ, Menz HB. Accelerometry: A technique for quantifying movement patterns during walking. Gait Posture 2008;28:1-15

89. de Bruin ED, Hartmann A, Uebelhart D, Murer K, Zijlstra W. Wearable systems for monitoring mobility related activities in older people; a systematic review. Clinical Rehabilitation 2008;22:878-895

90. Bloem BR, Steijns JA, Smits-Engelsman BC. An update on falls. Curr Opin Neurol 2003;16:15-26

91. Hausdorff JM, Edelberg HK, Mitchell SL, Goldberger AL, Wei JY. Increased gait unsteadiness in community-dwelling elderly fallers. Arch Phys Med Rehabil 1997;78:278-283 
92. Zijlstra W, Hof AL. Displacement of the pelvis during human walking: experimental data and model predictions. Gait Posture 1997;6:249-262

93. Talbot LA, Musiol RJ, Witham EK, Metter EJ. Falls in young, middle-aged and older community dwelling adults: perceived cause, environmental factors and injury. BMC Public Health 2005;5:86-95

94. Oberg T, Karsznia A, Oberg K. Basic gait parameters: reference data for normal subjects, 10-79 years of age. J Rehabil Res Dev 1993;30:210-223

95. Grabiner PC, Biswas ST, Grabiner MD. Age-related changes in spatial and temporal gait variables. Arch Phys Med Rehabil 2001;82:31-35

96. Woollacott M, Shumway-Cook A. Attention and the control of posture and gait: a review of an emerging area of research. Gait Posture 2002;16:1-14

97. Dubost V, Kressig RW, Gonthier R, et al. Relationships between dual-task related changes in stride velocity and stride time variability in healthy older adults. Hum Mov Sci 2006;25:372-382

98. MacLellan MJ, Patla AE. Adaptations of walking pattern on a compliant surface to regulate dynamic stability. Exp Brain Res 2006;173:521-30

99. van lersel MB, Benraad CE, Rikkert MG. Validity and reliability of quantitative gait analysis in geriatric patients with and without dementia. J Am Geriatr Soc 2007;55:632-634

100. Hartmann A, Luzi S, Murer K, de Bie RA, de Bruin ED. Concurrent validity of a trunk tri-axial accelerometer system for gait analysis in older adults. Gait Posture 2009;29:444-448

101. van den Akker-Scheek I, Stevens M, Bulstra SK, et al. Recovery of gait after shortstay total hip arthroplasty. Arch Phys Med Rehabil 2007;88:361-367

102. Horak FB, Nashner LM, Diener HC. Postural strategies associated with somatosensory and vestibular loss. Exp Brain Res 1990;82:167-177

103. Nurse MA, Nigg BM. The effect of changes in foot sensation on plantar pressure and muscle activity. Clin Biomech (Bristol, Avon) 2001;16:719-727

104. Lord SR, Lloyd DG, Li SK. Sensori-motor function, gait patterns and falls in community-dwelling women. Age Ageing 1996;25:292-299

105. Hughes J, Clark $\mathrm{P}$, Klenerman L. The importance of the toes in walking. J Bone Joint Surg $\mathrm{Br}$ 1990;72:245-251

106. Zehr EP, Komiyama T, Stein RB. Cutaneous reflexes during human gait: electromyographic and kinematic responses to electrical stimulation. J Neurophysiol 1997;77:3311-3325

107. Nigg BM, Nurse MA, Stefanyshyn DJ. Shoe inserts and orthotics for sport and physical activities. Med Sci Sports Exerc 1999;31:S421-428 
108. Robbins S, Waked E, Allard P, McClaran J, Krouglicof N. Foot position awareness in younger and older men: the influence of footwear sole properties. J Am Geriatr Soc 1997;45:61-66

109. O'Sullivan SB. Perceived exertion. A review. Phys Ther 1984;64:343-346

110. Hartmann A, Murer K, de Bie RA, de Bruin ED. Reproducibility of spatio-temporal gait parameters under different conditions in older adults using a trunk tri-axial accelerometer system. Gait Posture 2009;30:351-355

111. Hartmann A, Knols R, Murer K, de Bruin ED. Reproducibility of an Isokinetic StrengthTesting Protocol of the Knee and Ankle in Older Adults. Gerontology 2009;55:259-26

112. Tabachnick BG, Fidell LS. Using multivariate statistics. New York: HarperCollins College Publishers; 1996

113. Arai $\mathrm{T}$, Obuchi $\mathrm{S}$, Inaba $\mathrm{Y}$, et al. The effects of short-term exercise intervention on falls self-efficacy and the relationship between changes in physical function and falls self-efficacy in Japanese older people: a randomized controlled trial. Am J Phys Med Rehabil 2007;86:133-141

114. Rochat S, Martin E, Piot-Ziegler C, et al. Falls self-efficacy and gait performance after gait and balance training in older people. J Am Geriatr Soc 2008;56:1154-1156

115. Schlicht J, Camaione DN, Owen SV. Effect of intense strength training on standing balance, walking speed, and sit-to-stand performance in older adults. J Gerontol A Biol Sci Med Sci 2001;56:M281-286

116. Puggaard L. Effects of training on functional performance in 65,75 and 85 year-old women: experiences deriving from community based studies in Odense, Denmark. Scand J Med Sci Sports 2003;13:70-76

117. Symons TB, Vandervoort AA, Rice CL, Overend TJ, Marsh GD. Effects of maximal isometric and isokinetic resistance training on strength and functional mobility in older adults. J Gerontol A Biol Sci Med Sci 2005;60:777-781

118. Saltzman CL, Nawoczenski DA. Complexities of foot architecture as a base of support. J Orthop Sports Phys Ther 1995;21:354-360

119. Norkin CC, White DJ. Measurements of joint motion: a guide to goniometry. Philadelphia: F.A. Davis Company 2003

120. Wall JC, Bell C, Campbell S, Davis J. The Timed Get-up-and-Go test revisited: measurement of the component tasks. J Rehabil Res Dev 2000;37:109-113

121. Sousa N, Sampaio J. Effects of progressive strength training on the performance of the Functional Reach Test and the Timed Get-Up-and-Go Test in an elderly population from the rural north of Portugal. Am J Hum Biol 2005;17:746-751

122. Hartmann A, Murer K, de Bie RA, de Bruin ED. The effect of a training program combined with augmented afferent feedback from the feet using shoes insoles on gait 
performance and muscle power in older adults: a randomised controlled trial. Disabil Rehabil 2009: accepted

123. Hartmann A, Murer K, de Bie RA, de Bruin ED. The effect of a foot gymnastic exercise program on gait performance in older adults: a randomised controlled trial. Disabil Rehabil 2009;21:1-10

124. Buchner DM, Hornbrook MC, Kutner NG, et al. Development of the common data base for the FICSIT trials. J Am Geriatr Soc 1993;41:297-308

125. Myers AM, Holliday PJ, Harvey KA, Hutchinson KS. Functional performance measures: are they superior to self-assessments? J Gerontol 1993;48:M196-206

126. Ferrucci L, Guralnik JM, Studenski S, et al. Designing randomized, controlled trials aimed at preventing or delaying functional decline and disability in frail, older persons: a consensus report. J Am Geriatr Soc 2004;52:625-634

127. Rathouz PJ, Kasper JD, Zeger SL, et al. Short-term consistency in self-reported physical functioning among elderly women: the Women's Health and Aging Study. Am J Epidemiol 1998;147:764-773

128. Estabrooks PA. Sustaining exercise participation through group cohesion. Exerc Sport Sci Rev 2000;28:63-67

129. Martin Ginis KA, Latimer AE, Brawley LR, Jung ME, Hicks AL. Weight training to activities of daily living: helping older adults make a connection. Med Sci Sports Exerc 2006;38:116-121 



\section{Chapter 10}

Summary

Samenvatting

Co-authors and affiliations

Acknowledgements

Publications

Curriculum Vitae 


\section{Summary}

The primary public health goal is to increase the number of years of good health, and therefore to maintain independence and quality of life as long as possible. However, a fall can endanger mobility, physical performance and health of the elderly and is one of the major problems of older adults and care services for the aged. Since the risk of falling increases dramatically as the number of risk factors increases, the goal of fall prevention is to modify some of the strongest risk factors through, for example, physical exercises. Physical exercise is one of the most important intervention strategies that can significantly improve physical performance and contribute to maintenance of independence and quality of life. It has the strongest evidence to minimize or eliminate some of the strongest fall risk factors, such as impairments in balance, gait, strength and range of motion. Age-related changes in musculoskeletal and sensory characteristics of the feet are important risk factors too, but have not been the focus of exercise studies to date.

As described in Chapter 1, the main objectives of this thesis were to evaluate the effects of stimulation of different foot structures and functions combined with conventional training on physical performance and fear of falling, and whether training reduces the rates of falls and fall-related injuries during a 12-month follow-up period in independent living, older adults. For such intervention studies, valid and reliable assessment procedures for muscle power and gait performance are needed. Hence, the three objectives of this thesis are:

1. to determine the validity and reliability of newly developed testing procedures for muscle power and gait in independent living, older adults (Chapters 2 to 4);

2. to evaluate the effects of stimulation of different foot structures and functions combined with conventional training on physical performance and fear of falling in independent living, older adults (Chapters 5 and 6);

3. to determine the effectiveness of the conventional training program to reduce falls and fall-related injuries during a 12 month follow-up period in independent living, older adults (Chapter 7).

The prerequisites for an objective measurement device are validity and reliability. In Chapter 2 we investigated the reliability of an isokinetic strength-testing protocol of the knee and ankle in older adults. The results showed that the Biodex System 3 is a reliable device for muscle power measurements when used for independent living, older adults. The relative reliabilities for muscle power for knee extension and flexion and ankle dorsiflexion and plantarflexion were 'very good'. The results of absolute reliabilities were partly satisfactory. The coefficients of variation and ratio of limits of agreement for knee extension and flexion 
and ankle dorsiflexion represented acceptable agreement. No acceptable agreement was found for ankle plantarflexion.

In the last few years, accelerometer-based gait analysis systems fixed at different body locations have been proposed for ambulatory gait assessment and have been found valid and reliable for the analysis of gait parameters. However, most body-fixed accelerometer based systems are still in need of further development in older adult populations. In Chapters 3 and 4 the validity and the reliability of the gait analysis using the DynaPort ${ }^{\circledR M i n i M o d}$, a trunk tri-axial accelerometer system, were determined. The results demonstrated that the DynaPort $^{\circledR \text { MiniMod }}$ system is a highly valid tool for assessment of the most important spatiotemporal gait parameters for averaged step data across a walking length of approximately 20 $\mathrm{m}$ and that walking speed, cadence, step duration and step length under different walking conditions can be reliably measured in independent living, older adults. However, gait variability needs to be viewed with caution because of the moderate to low validity and reliability.

There is evidence that a conventional training program that includes strength and power training, balance, mobility and stretching exercises contributes to the maintenance of independence and quality of life and has the strongest evidence base for preventing falls. Further, aged-related losses of afferent feedback of the feet, ankle dorsiflexion range of motion and toe plantarflexor strength play an important role in balance control and gait performance and are associated with the risk of falling. It was, however, unclear whether stimulation of different foot structures and functions by wearing insoles with raised projections during everyday life and during training sessions, or by foot gymnastics including exercises intended to strengthen the muscles of the feet and increase the ankle joint range of motion, has an additional effect of physical performance in older adults. The primary findings of Chapters 5 and 6 were that the conventional training program in itself resulted in significant improvements in gait performance, muscle power and Expanded Timed Get-upand-Go test compared to the control group in independent living, older adults. The training program had, however, no effect on self-perceived fear of falling possibly because of the low pre-training Falls Efficacy Scale of the subjects, which caused floor effects for this assessment. Neither wearing insoles during everyday life and during training sessions, nor foot gymnastic exercises integrated in conventional training, had additional effects on physical performance. Possible explanations for these findings might be that the subjects did not comply with wearing the insoles continuously or with the foot gymnastic home-program. Some subjects only wore the insoles in their indoor shoes or slippers and not in their outdoor shoes. It can be assumed that indoor activities are performed mostly while sitting and not 
while standing or walking, and therefore the insoles had no stimulation effect. Further, the relatively short duration of the study periods may not be sufficient to show an adaption of gait.

The primary goal of fall prevention is to decrease the number of falls and to prevent fallrelated injuries. In Chapter 7 the effectiveness of the training program to reduce falls and fallrelated injuries during a 12-month follow-up period in older adults was determined. The training program was not effective in reducing falls and fall-related injuries, although the training program resulted in significant improvements in physical performance compared to subjects without training. Possible explanations for these findings may be potential bias because of the non-randomization of the subjects, the small sample size resulting in low testing power (Type II error), the significantly younger age of the control group at baseline or the significantly improved physical performance after the training period of the subjects with training, which may result in a longer time spent exposed to a higher risk of falling during everyday life that consequently leads to a higher rate of falls.

In Chapter 8 the main findings and limitations of these studies, as well as implications for practice and future research, are provided. In addition some personal opinions and conclusions have been included to complete this thesis. On the whole, the conventional training program in itself resulted in significant improvements in physical performance, however, it had no effects on fear of falling and rates of falls and fall-related injuries during the 12-month follow-up period compared to the control group in independent living, older adults. In spite of these partly inconsistent results, in my opinion the research area covering the optimal training program for the prevention of falls in healthy, older adults is utilized, except that the training strategy is completely new. In the future, the big challenge for public health will be to persuade the vast majority of adults, not only robust adults, to become more active. Therefore, the public health message for older adults should be to incorporate moderate-intensity physical exercises into their everyday life, and that physical exercises should provide enjoyment and not be a physical torture. 


\section{Samenvatting}

Een van de belangrijkste doelen van de gezondheidszorg is er voor te zorgen dat bij de bevolking het aantal in goede gezondheid geleefde jaren verhoogd wordt, de ervaren levenskwaliteit zich verbetert, en de zelfstandigheid zo lang mogelijk behouden kan worden. Het onvrijwillig ten val komen kan de mobiliteit, het lichamelijke prestatievermogen en de gezondheid van ouderen negatief beinvloeden. Een verhoogde valfrequentie bij ouderen vormt één van de grootste problemen voor zowel deze bevolkingsgroep als ook voor de zorginstanties die senioren als doelgroep hebben.

Omdat de kans op onvrijwillig vallen met het aantal voorhandenzijnde risiko factoren stijgt, is het doel van veel preventieve programmas enkele van de grootste risiko factoren die tot vallen kunnen leiden te beinvloeden. Dit kan bijvoorbeeld door doelgerichte lichamelijke oefeningen gebeuren. Lichamelijke oefening is één van de belangrijkste preventieve 'val' strategiën die het lichamelijk prestatievermogen beduidend kan verbeteren. Door deze verbetering in de prestatie wordt een belangrijke bijdrage aan het in stand houden van de onafhankelijkheid en de levenskwaliteit op hogere leeftijd geleverd.

$\mathrm{Er}$ is voldoende bewijs voor het feit dat het bedrijven van doelgerichte lichamelijke oefening de grootste risikos voor vallen kan verminderen of zelfs kan uitsluiten. Risikofaktoren voor het vallen op oudere leeftijd zijn problemen met het evenwicht, een verminderde spierkracht en een verminderde beweeglijkheid in de gewrichten. Veranderingen in de eigenschappen van ons spier- en skeletstelsel en veranderingen in de sensorische eigenschappen van de voet als gevolg van veroudering, vormen eveneens belangrijke risiko faktoren. Deze fakoren waren tot op heden echter zelden het onderwerp van trainingsonderzoek.

In hoofdstuk 1 is het hoofddoel van dit proefschrift beschreven: het evalueren van de effecten van doelgerichte stimulatie van verschillende strukturen en funkties in de voet in combinatie met konventionele oefenprogrammas. De oefenprogrammas hebben daarbij tot doel het lichamelijk prestatievermogen te verbeteren en de angst voor het vallen te veminderen. Vervolgens wordt bij zelfstandig levende ouderen in een 12 maanden lange follow-up periode beschreven of lichamelijke oefening het aantal val incidenties en het aantal met vallen samenhangende blessures kan verminderen.

Voor een dergelijke interventie studie zijn valide en betrouwbare meetmethodes voor het bepalen van o.a. spierkracht en loopeigenschappen nodig. Daarom zijn de drie doelen van dit proefschrift: 
1. Het bepalen van de validiteit en betrouwbaarheid van nieuw ontwikkelde test protokollen voor het meten van spiereigenschappen en van het looppatroon bij zelfstandig wonende ouderen (Hoofdstukken 2 tot 4);

2. Het bepalen van de effekten van specifieke oefenprogrammas op verschillende strukturen en funkties van de voet, vergeleken met konventionele oefeningen, welke het lichamelijk prestatievermogen en angst voor het vallen bij zelfstandig wonende ouderen verminderen (Hoofdstuk 5 en 6);

3. Het bepalen van de effektiviteit van een konventioneel lichamelijk oefenprogramma bij zelfstandig wonende ouderen met als doel het aantal val incidenten en het aantal met het vallen samenhangende blessures, gedurende een 12 maanden lange tijdsperiode te verminderen (Hoofdstuk 7).

De validiteit en betrouwbaarheid zijn belangrijke voorwaarden waaraan een meetinstrument moet voldoen. In hoofdstuk 2 werd de betrouwbaarheid van een meetprotokol voor het bepalen van de spierkracht rond het kniegewricht en het enkelgewricht van een isokinetisch meetapparaat bij ouderen onderzocht. Deze studie toont aan dat het Biodex System 3 een betrouwbaar meetinstrument is voor het meten van spiereigenschappen (spierkracht en spiervermogen (power)) bij senioren die nog zelfstandig wonen. De relatieve betrouwbaarheid voor het bepalen van het spiervermogen tijdens strekken en buigen van de knie en de enkel waren heel goed. De resultaten voor de absolute betrouwbaarheid van het instrument waren matig tot goed te noemen. De coëfficiënt voor de variabiliteit en de 'ratio of limits of agreement' voor het strekken en buigen van de knie en het strekken van de enkel zijn acceptabel voor de verschillende metingen. De coëfficiënt voor de variabiliteit en de 'ratio of limits of agreement' voor het buigen van de enkel is niet acceptabel.

In de afgelopen jaren werd regelmatig voorgesteld om loopanalyses met versnellingsmeters (accelerometers) door te voeren. Daarbij worden deze systemen op verschillende plaatsen op de romp en aan armen en benen gefixeerd en zijn zodoende te gebruiken voor het objektiveren en aldus beoordelen van de menselijke gang. Deze systemen bleken betrouwbare en valide metingen op te leveren, indien toegepast bij jonge, gezonde proefpersonen. De meeste meetsystemen dienen echter verder ontwikkeld te worden. Vooral de mogelijkheden die dergelijke systemen bieden voor het beoordelen van het lopen bij ouderen dient nog verder geanalyseerd te worden. In hoofdstuk 3 en 4 is de validiteit en de betrouwbaarheid van de DynaPort ${ }^{\text {बMiniMod }}$ onderzocht. In dit hoofdstuk is beschreven hoe dit meetinstrument op het heiligbeen (os sacrum) bevestigd kan worden. De resultaten laten zien dat de DynaPort ${ }^{\circledR \text { MiniMod }}$ voor het beoordelen van de belangrijkste temporele en spatiele parameters van het menselijk looppatroon valide is. Voorwaarde is dat daarbij over een 
afstand van 20 meter gelopen wordt en gemiddelde waardes berekend kunnen worden van de temporele en spatiele parameters van het menselijk looppatroon. Loopsnelheid, lengte en duur van de stap kunnen onder verschillende omstandigheden betrouwbaar gemeten worden. De variabiliteit van de gemeten temporele en spatiele parameters van het menselijk looppatroon dient vanwege de lage validiteit en reproduceerbaarheid voorzichtig geïnterpreteerd te worden.

Een konventioneel oefenprogramma dat de valfrequentie bij ouderen wil beinvloeden moet zich op de verbetering van de spierkracht, het evenwicht en de beweeglijkheid van de gewrichten richten. De dorsaalflexie van de voeten en de plantairflexie van de grote teen spelen een belangrijke rol bij het evenwicht en het loopgedrag. Door het verouderingsproces neemt de afferente informatie van de voeten af. Dit proces is ook met vallen geassocieerd. Deze strukturen en funkties kunnen door het dragen van inleg zooltjes in de schoenen of door middel van speciale voetoefeningen doelgericht getraind worden.

De belangrijkste conclusies van hoofdstuk 5 en 6 zijn dat een konventioneel oefenprogramma het loopvermogen, de spierkracht, de power en de funktionaliteit van het lopen verbetert. Het oefenprogramma had geen effekt op de angst om te vallen. Dit resultaat is waarschijnlijk beïnvloed door de lage valangst binnen de trainingsgroep aan het begin van het oefenprogramma. Het dragen van inleg zooltjes en het extra oefenen van de voeten hadden geen toegevoegd effect op het lichamelijke funktioneren. Mogelijke verklaringen voor deze bevindingen zijn de acceptatie voor het dragen van de zooltjes of het niet doorvoeren van de oefeningen bij de proefpersonen thuis. Enkele proefpersonen droegen de inlegzooltjes alleen binnenshuis (in hun pantoffels) en juist niet in hun wandelschoenen buitenshuis. Het is mogelijk dat de proefpersonen binnenshuis voornamelijk hebben gezeten en dat daardoor niet van de mogelijke effekten van de zooltjes kon worden geprofiteerd. Een andere verklaring kan liggen in de relatief korte duur van de onderzoeksperiode, die het onmogelijk maakte dat veranderingen in het looppatroon konden plaatsvinden.

Valpreventie heeft primair als doel het aantal val incidenties te verminderen. Hierdoor kunnen de daarmee geassocieerde ongelukken gereduceerd worden. Hoofdstuk 7 bepaald de effektiviteit van het oefenprogramma gedurende een periode van 12 maanden. Het oefenprogramma bleek niet effektief genoeg om het aantal valincidenten te verminderen ook al was het programma wel in staat het lichamelijke prestatievermogen in vergelijking tot een kontrolegroep signifikant te verbeteren. Mogelijke verklaringen voor deze uitkomst liggen in het design van de studie, in de omvang van de groepen (lage power voor statistiek), de 
relatief lage leeftijd voor de senioren in de kontrolegroep of in de verbeterde lichamelijke prestaties van de oefengroep.

In hoofdstuk 8 worden tenslotte de resulaten en beperkingen van dit proefschrift samengevat. Implikaties voor de praktijk worden geschetst, evenals aanbevelingen voor toekomstig onderzoek. Bovendien worden persoonlijke op- en aanmerkingen toegevoegd. Over het algemeen kan gesteld worden dat een konventioneel oefenprogramma voldoende was voor het verbeteren van het lichamelijke prestatievermogen, alhoewel de angst om te vallen niet kon worden beinvloed. Ondanks deze deels tegenstrijdige bevindingen is naar mijn mening genoeg evidentie aanwezig voor het bevorderen van oefenprogrammas bij ouderen. In de toekomst bestaat de uitdaging er in ouderen te overtuigen van het voordeel om zich meer te gaan bewegen. Hoe 65-plussers gestimuleerd kunnen worden om een actieve(re) leefstijl na te leven en hoe ons gezondheidswezen dit kan bewerkstelligen zijn themas voor toekomstig onderzoek. Belangrijk in dit verband lijkt dat aan ouderen het idee mee gegeven dient te worden dat bewegen toch vooral plezierig kan zijn en dat dit niet ervaren moet worden als een lichamelijke belasting. 


\section{Co-authors and affiliations}

The co-authors of the studies described in this thesis and their current research affiliations are:

Rob A. de Bie

Maastricht University, Care and Public Health Research Institute, Department of Epidemiology, Maastricht, The Netherland

Eling D. de Bruin

Institute of Human Movement Sciences and Sport, ETH Honggerberg, Zurich, Switzerland

Ruud Knols

Department of Rheumatology and Institute of Physical Medicine, University Hospital Zurich, Zurich, Switzerland

Susanna Luzi

Institute of Human Movement Sciences and Sport, ETH Honggerberg, Zurich, Switzerland

Kurt Murer

Institute of Human Movement Sciences and Sport, ETH Honggerberg, Zurich, Switzerland 


\section{Acknowledgements}

I would like to thank everyone who was involved in this work and who contributed to its completion:

- Prof. Dr. Rob A. de Bie, my external promotor, who enabled me to obtain the degree of Doctor of Sciences at Maastricht University, The Netherlands. Many thanks for guiding me through the writing of the thesis and for his positive and motivating feedback, which showed me that I was on the right track.

- Dr. Eling D. de Bruin, my co-promoter, who gave me the opportunity to conduct this thesis within his project and who has strongly supported and promoted me during the past 3 years. The discussions, encouragement and critiques made by him were crucial to the progress of this work.

- Prof. Dr. Kurt Murer, my co-promotor at ETH Zurich, for the chance to conduct this thesis at the Institute of Human Movement Sciences and Sport and for all the revisions made to the text.

- Stiftung Diakoniewerk Neumunster - Schweizerische Pflegerinnenschule (Dr. Werner Widmer, Marianne Baer Müller) for their financial and material support, who actually made this thesis possible. Without their willingness to collaborate and their help in the organisation, it would not have been possible to conduct this thesis.

- PROXOMED for providing the training and test materials.

- Hatt-Bucher-Stiftung for their financial support.

- MedReflex Therapiekonzept $\mathrm{GmbH}$ and Dr. Michael Wawroschek for providing and customizing the insoles.

- Marlies Dorfschmid, my physical education instructor, who conducted the training program and whose open-minded personality enabled her to motivate the participants.

- Dr. Roland Mueller and Ruud Knols for all the revisions made to the text.

- All the participants, whose interest stimulated them to become involved in an unknown area of research. Many thanks for having such an open mind.

- All the students (Liisa Wepf, Elsbeth Betschon, Nadja Blatter, Christine Schweizer, Flurina Meier, Susanna Luzi, Isaline Schwarz, Manuela Brütsch, Eva van het Reve und Elmar Steiner), who made precious contributions to this thesis.

- My family, my partner and my friends, who always stood by me. 


\section{Publications}

Hartmann A, Knols R, Murer K, de Bruin ED. Reproducibility of an isokinetic strength-testing protocol of the knee and ankle in older adults. Gerontology 2009;55:259-26.

Hartmann A, Luzi S, Murer K, de Bie RA, de Bruin ED. Concurrent validity of a trunk tri-axial accelerometer system for gait analysis in older adults. Gait Posture 2009;29:444-448

Hartmann A, Murer K, de Bie RA, de Bruin ED. Reproducibility of spatio-temporal gait parameters under different conditions in older adults using a trunk tri-axial accelerometer system. Gait \& Posture 2009;30:351-355

Hartmann A, Murer K, de Bie RA, de Bruin ED. The effect of a training program combined with augmented afferent feedback from the feet using shoe insoles on gait performance and muscle power in older adults: a randomised controlled trial. Disability and Rehabilitation (accepted).

Hartmann A, Murer K, de Bie RA, de Bruin ED. The effect of a foot gymnastic exercise program on gait performance in older adults: a randomised controlled trial. Disability and Rehabilitation 2009;21:1-10.

de Bruin ED, Hartmann A, Uebelhart D, Murer K, Zijlstra W. Wearable systems for monitoring mobility related activities in older people; a systematic review. Clinical Rehabilitation 2008;22:878-895. 


\section{Curriculum Vitae}

Name: $\quad$ Antonia Hartmann

Date of birth: 7 March 1979

Place of birth: Kisii, Kenya

Citizen of: $\quad$ Luzein, Switzerland

Education:

2005-2008 PhD from Care and Public Health Research Institute, Maastricht University, The Netherlands, conducted at the Institute of Human Movement Sciences and Sport, ETH Zurich, Switzerland

2005 Diploma thesis at the Institute of Human Movement Sciences and Sport, ETH Zurich, Switzerland

2004 Internship at the School of Exercise and Sport Science, The University of Sydney, Australia (3 months)

2002-2005 Graduate degree in Human Movement and Sport Sciences, ETH Zurich, Switzerland (Dipl. Natw. ETH)

2000-2002 Undergraduate degree in Environmental Sciences, ETH Zurich, Switzerland 1992-1999 High school in Chur, Switzerland

1986-1992 Primary school in Trimmis, Switzerland 